\title{
STIMULATION OF BONE HEALING IN NEW \\ FRACTURES OF THE TIBIAL SHAFT USING \\ INTERFERENTIAL CURRENTS.
}

Prepared for:

The Department of Physiotherapy

Faculty of Medicine

University of Cape Town

Prepared by:

Jeanette Ann Fourie

Submitted:

June 1994

Supervisors:

Associate Professor P Bowerbank

Associate Professor M L Thompson

Doctor R K Marks

This treatise is submitted in fulfilment of the requirement for the Degree of Master of Science in Physiotherapy. 
The copyright of this thesis vests in the author. No quotation from it or information derived from it is to be published without full acknowledgement of the source. The thesis is to be used for private study or noncommercial research purposes only.

Published by the University of Cape Town (UCT) in terms of the non-exclusive license granted to UCT by the author. 
I, ... TEANERIE...ANN... FOURE.., hereby declare that the work on which this thesis is based is my original work (except where acknowledgements indicate otherwise) and that neither the whole work nor any part of it has been, is being, or is to be submitted for another degree in this or any other University.

I empower the University to reproduce for the purpose of research either the whole or any portion of the contents in any manner whatsoever.

Signed by candidate Signature Removed $\ldots . .27 .6 /\left.\right|_{\text {DATt }} / 94 \ldots . . .$. 


\section{DEDICATION}

To Lindy-Anne, a precious daughter of our time, a victim of the hatred in our land at the Heidelberg massacre on 31 December 1993. 


\section{ACKNOWLEDGEMENTS}

I thank my supervisors for their contributions to this thesis: Associate Professor Patricia Bowerbank for meticulous scrutiny, Associate Professor Mary Lou Thompson for essential statistical input and Doctor Richard Marks for enthusiasm and encouragement throughout.

The assistance of Dr Shirley Churms (Writing Centre UCT) in preparing this manuscript is gratefully acknowledged.

Special thanks are due to Dr Robert Seggie (Dept Radiology GSH) who interpreted the radiographs for this trial.

I thank the consultants, registrars, house-doctors, nurses, physiotherapists and orthopaedic technicians (Dept Orthopaedics GSH) for their assistance, interest and support.

The loan of electrical equipment by Medical Distributors is gratefully acknowledged.

I thank Mr Etiën Plekker (electronics technician CSIR) for testing the equipment at the conclusion of the trial, and for interesting discussions about electrical currents and their possible effects on humans.

Special thanks are due to Johann and Anthony for their encouragement, and their understanding for the many hours that I was unavailable. 


\begin{abstract}
The aims of this research were twofold, firstly to find out if interferential currents could reduce the healing time for fractures of the tibia and thereby prevent nonunion and secondly to develop a model which could predict nonunion, given the subject characteristics such as race, mechanism of injury, severity of fracture etc.
\end{abstract}

Subjects, males only between the ages of 12 and 86 , who had sustained fractures of the tibiae were entered into this double blind clinical trial on admission to the orthopaedic wards at Groote Schuur Hospital (between January 1989 and October 1991). According to strict inclusion and exclusion criteria, a final sample of 227 cases (208 subjects) were entered by block randomisation into three groups; an experimental group $(n=41)$, placebo group $(n=35)$ and control group $(n=151)$. Interferential currents were applied to the experimental group via suction electrodes for, 30 minutes per day for 10 days, using a beat frequency of $10-25 \mathrm{~Hz}$ and a swing mode of $6\ulcorner 6$. The placebo group had the suction electrodes applied which produce a rhythmical massage effect. Subjects commented on pain relief which resulted in the addition of the control group as a check on the possible effect of suction, the control group received no intervention.

The data were analysed firstly, by using the ANOVA with continuous covariates which resulted in a finding of no significant difference in the time taken to union for the three groups. The second statistical analysis using the same data set, were logistic regression models demonstrating risk factors for nonunion within 24,32 and 40 weeks. These models were then validated, showing sensitivity and specificity for a variety of possible cutoffs. The conclusions reached about the validity of these models were that they could not be used to predict, accurately enough, those cases where surgical intervention would be necessary; however, for low cost non-invasive intervention they may have value. 


\section{CONTENTS}

ACKNOWLEDGEMENTS $\ldots \ldots \ldots \ldots \ldots \ldots \ldots \ldots \ldots \ldots \ldots$

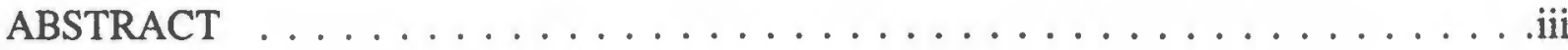

CONTENTS $\ldots \ldots \ldots \ldots \ldots \ldots \ldots \ldots \ldots \ldots \ldots \ldots \ldots$ iv

LIST OF ILLUSTRATIONS AND GRAPHS $\ldots \ldots \ldots \ldots \ldots \ldots \ldots$

LIST OF TABLES $\ldots \ldots \ldots \ldots \ldots \ldots \ldots \ldots \ldots \ldots \ldots \ldots \ldots \ldots$

Chapter 1

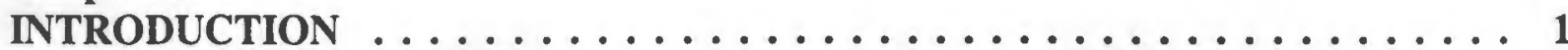

1.1 HISTORICAL BACKGROUND TO ELECTRICITY AND MEDICINE . . 1

1.2 HISTORICAL BACKGROUND TO FRACTURE MANAGEMENT . . . . 4

1.3 THE PROBLEM AND ITS SETTING . . . . . . . . . . . . . 11

1.4 ORGANISATION OF THE STUDY $\ldots \ldots \ldots \ldots \ldots \ldots \ldots$

Chapter 2

LITERATURE SURVEY . . . . . . . . . . . . . . . . . 15

2.1 INTRODUCTION . . . . . . . . . . . . . . . . . . . 15

2.2 CURRENT CONCEPTS IN BONE HEALING AND INFLUENCING FACTORS . . . . . . . . . . . . . . . . . . . . 15

2.3 BACKGROUND TO THE THERAPEUTIC USE OF ELECTRICAL STIMULATION IN FRACTURE HEALING . . . . . . . . . . . . . 23

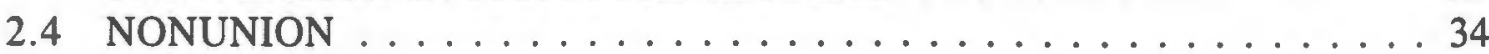

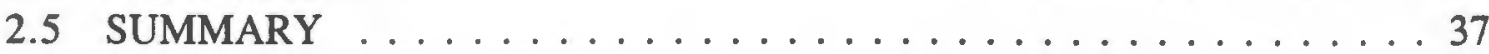

Chapter 3

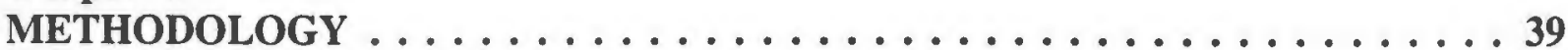

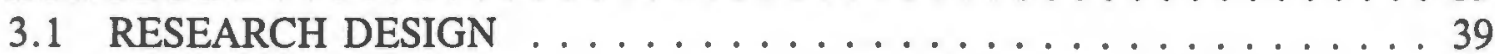

3.2 HYPOTHESES . . . . . . . . . . . . . . . . . . . 39

3.3 CHANGES MADE TO THE PROPOSAL . . . . . . . . . . . . . 40

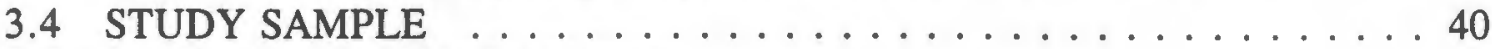

3.5 ETHICAL CONSIDERATIONS .................. 42

3.6 TRIAL PROCEDURE . . . . . . . . . . . . . . . . . 43

3.8 VARIABLES. . . . . . . . . . . . . . . . . . 47

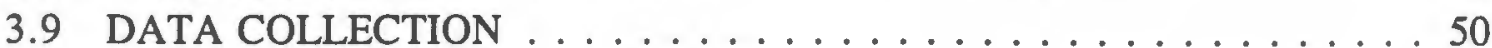

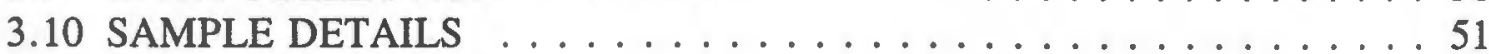

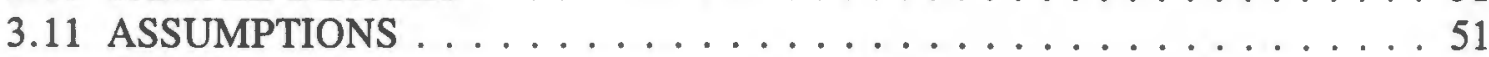

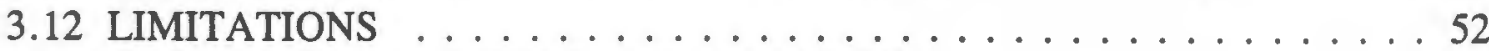

3.13 STATISTICAL PACKAGE AND ANALYSIS $\ldots \ldots \ldots \ldots 5$ 
Chapter 4

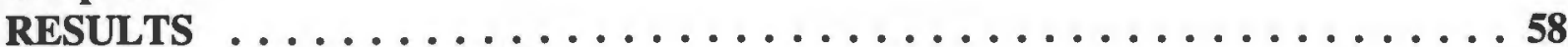

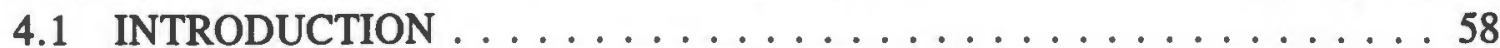

4.2 AVERAGE TIME TO UNION IN WEEKS . . . . . . . . . . . . . 59

4.3 DESCRIPTIONS OF UNIVARIATE DATA ............... 59

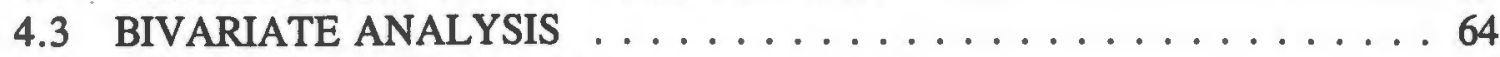

4.4 MULTIVARIATE ANOVA . . . . . . . . . . . . . . . . 69

4.5 DIAGNOSTIC CHECKING . . . . . . . . . . . . . . . . 74

4.6 RESULTS OF LOGISTIC REGRESSION MODEL . . . . . . . . . . . 74

Chapter 5

DISCUSSION ..................................... 79

5.1 EFFECTIVENESS OF INTERFERENTIAL CURRENTS . . . . . . . . 79

5.2 OTHER FINDINGS OF SIGNIFICANCE . . . . . . . . . . . . . 81

5.3 DISCUSSION OF LOGISTIC REGRESSION MODEL. . . . . . . . . . 82

Chapter 6

CONCLUSIONS AND RECOMMENDATIONS . . . . . . . . . . . . . 84

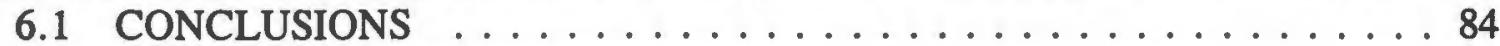

6.2 RECOMMENDATIONS . . . . . . . . . . . . . . . . . 85

6.3 SIGNIFICANCE OF THIS RESEARCH: . . . . . . . . . . . . 86

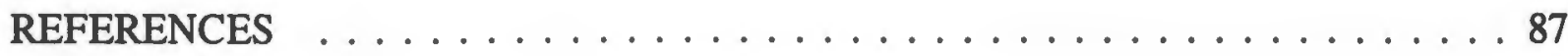

APPENDICES 


\section{LIST OF ILLUSTRATIONS AND GRAPHS}

Fig 2.1 Distribution of Electric fields $\ldots \ldots \ldots \ldots \ldots \ldots \ldots \ldots$

Fig 3.1 Electrode positioning in window of plaster cast $\ldots \ldots \ldots \ldots$

Fig 3.2 Electrode positioning with exoskeleton insitu $\ldots \ldots \ldots \ldots \ldots$

Fig 4.1 Radiological union vs clinical union $\ldots \ldots \ldots \ldots \ldots$

Fig 4.2 Time to healing vs groups $\ldots \ldots \ldots \ldots \ldots \ldots \ldots \ldots$

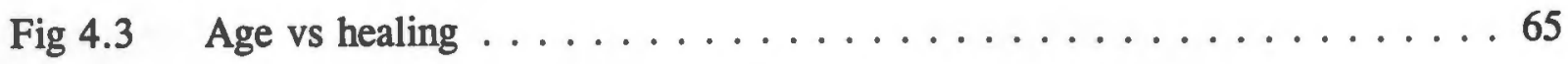

Fig 4.4 The effect of 'delay of entry' vs healing $\ldots \ldots \ldots \ldots 6$

Fig 4.5 The effect of 'crutch walking' vs healing $\ldots \ldots \ldots \ldots 7$

Fig 4.6 Normal probability plot $\ldots \ldots \ldots \ldots \ldots \ldots \ldots \ldots$ 


\section{LIST OF TABLES}

TABLE 3.1 EXAMPLE OF A BLOCK RANDOMISATION TABLE . . . . . . 42

TABLE 4.1 (a) SUMMARY STATISTICS $\ldots \ldots \ldots \ldots \ldots \ldots$

TABLE 4.1 (b) SUMMARY STATISTICS $\ldots \ldots \ldots \ldots \ldots \ldots \ldots$

TABLE 4.1 (c) SUMMARY STATISTICS $\ldots \ldots \ldots \ldots \ldots \ldots$

TABLE 4.2 ONE WAY ANOVA $\ldots \ldots \ldots \ldots \ldots$

TABLE 4.3 : ONE WAY ANALYSIS OF VARIANCE $\ldots \ldots \ldots 69$

TABLE 4.4 : ANALYSIS OF COVARIANCE . . . . . . . . . . . 69

TABLE 4.5 : COMPARISON OF HEALING TIMES ACCORDING TO RACE $\ldots 70$

TABLE 4.6 : COMPARISON OF HEALING TIMES ACCORDING TO THE MECHANISM OF INJURY $\ldots \ldots \ldots \ldots \ldots \ldots \ldots \ldots \ldots \ldots$

TABLE 4.7 : COMPARISON OF HEALING TIMES ACCORDING TO THE

TYPE OF FRACTURE $\ldots \ldots \ldots \ldots \ldots \ldots \ldots \ldots \ldots \ldots$

TABLE 4.8 : COMPARISON OF HEALING TIMES ACCORDING TO THE DEGREE OF DISPLACEMENT $\ldots \ldots \ldots \ldots \ldots \ldots \ldots \ldots$

TABLE 4.9 : COMPARISON OF HEALING TIMES ACCORDING TO ASSOCIATED INJURY $\ldots \ldots \ldots \ldots \ldots \ldots \ldots \ldots \ldots \ldots \ldots$

TABLE 4.10 : COMPARISON OF HEALING TIMES ACCORDING TO GROUPS . 72

TABLE 4.11 : LOGISTIC REGRESSION MODELS DEMONSTRATING RISK

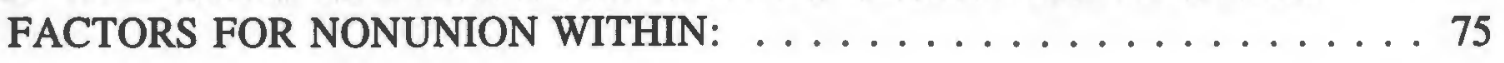

TABLE 4.12 : ESTIMATED PROBABILITIES OF NONUNION WITHIN: . . . . 76

TABLE 4.13 : VALIDATION OF LOGISTIC REGRESSION MODELS . . . . . 77

TABLE 4.14 : ESTIMATED PREDICTIONS FOR 100 SUBJECTS FROM

TABLE 4.13 (C) . . . . . . . . . . . . . . . . 78 


\section{Chapter 1}

\section{INTRODUCTION}

Interferential currents were introduced in the early 1950s in Vienna (Savage 1984), the first reported application of these currents for fracture healing took place in Bulgaria (Nikolova 1969). However, the association between electricity and healing extends back far beyond the forty years from the present research, and will be the subject of this chapter.

The objectives of this research are 1) to find out what relationship there is between interferential currents and bone healing and 2 ) to develop a model which accurately predicts those subjects whose fractures will not heal within a specific time period, this is known as nonunion.

The discovery of electricity and its application to medicine has been methodically documented by Krusen (1941), whose work is summarised in section 1.1, where the development of this association is outlined.

The historical background of the specific field of medicine involved in the present study is included in section 1.2; this history of the management of fractures is largely taken from the work of Bick (1948).

\subsection{HISTORICAL BACKGROUND TO ELECTRICITY AND MEDICINE}

Historically the association between electricity and healing extends from the reign of the Roman Emperor Tiberius (14 to 37 A.D.) At that time Anthero, a freedman, accidentally stepped on a torpedo (an electrified fish) and was thus "freed of gout". Dioscorides, a Greek army surgeon who wrote the first pharmacopeia in 78 A.D., recommended shocks from the torpedo fish for intractable headache. Six hundred years later Paul of Aegina, an outstanding 
Greek surgeon, still advocated shocks as a remedy for headache; however, it was not until about 1750 that Musschenbroek associated the shocks from the torpedo fish with electricity and likened them to the shocks from the Leyden jar.

From 690 A.D. there is no evidence of any further development in the application of electricity in the field of medicine until the phenomenon was investigated by William Gilbert (1540 - 1603), who was president of the Royal College of Physicians (England) and was considered to be the father not only of electrical science, but also of experimental philosophy and inductive reasoning. His book "De Magnete" written in Latin, was hailed as the first "physical" book to be published in England. To Gilbert we owe credit for the name electricity, after the Greek word for amber. The earliest use of electricity, which was mainly for the treatment of disease, was based on the experiments of this great physician. He contributed to the knowledge base on magnetism, including the earth's magnetic field, by his experimentation with lodestone and amber. The poet Dryden sang of him:

Gilbert shall live till loadstones cease to draw or British fleets the boundless oceans awe. Krusen (1941)

From Gilbert's time there were frequent historical references to electrotherapy, using static electricity which was produced by rubbing a sulphur ball, with a chain to lead the electricity away. This was modified by Francis Hauksbee in 1709, who used a glass globe with amber rods to produce the friction. Later the globes were replaced with glass plates, which were used in machines to produce static electricity. This method was in use right up until the twentieth century.

The so-called "Leyden jar" was discovered in 1746 by Cuneus and Musschenbroek of Leyden. Benjamin Franklin (1706 - 1790), the first American scientist, used charges from the Leyden jar for the treatment of disease. He introduced the terms "positive" and "negative" into the concept of electricity and also demonstrated the electrical origin of lightning in 1749 , when he performed his well-known kite and key experiment. By shortening the critical distance between clouds and the earth, with the use of a kite, he found that a charge passed down the string to earth. 
Jean Louis Jallabert $(1712$ - 1768) has been named as the first scientific electrotherapist, his main contribution being the use of electrical sparks to stimulate contraction of paralysed muscles.

In Italy, Luigi Galvani (1737 - 1798) and Alessandro Volta (1745 - 1827) greatly advanced the development of current electricity. They discovered that dissimilar metals, separated by sheets of cloth that had been soaked in salt or acid, were necessary to produce a current. This current was used in their experiments on the electro-physiology of nerve-muscle preparations. Volta demonstrated the ability of electrical stimuli to provoke tetanic contractions; and by doing so helped to establish the hypothesis of efferent and afferent nerve impulses.

Physical medicine had its share of "irregular practitioners" during the 18th century. One of the most notable of these was James Graham (1745 - 1794), who established elaborate quarters in Pall Mall London. He had many electrical devices, including an electric throne and a celestial bed. He claimed that a night's sleep in the celestial bed, at the modest fee of $£ 50$, would cure sterility!

Possibly the presence of these mountebanks contributed to the scepticism of the "Gentlemen of the Faculty", the physicians of the time to whom John Wesley addressed his Desideratum in 1759. John Wesley (1703 - 1791), better known for his religious activities, as founder of the Methodist Church, was a student in many fields, including electrotherapy and hydrotherapy. He concluded his Desideratum with the following passage, which is an important defence of the medical use of electricity:

I would beg one thing (if it be not too great a Favour) from the Gentlemen of the Faculty, and indeed from all who desire Help and Freedom from Pain, either for themselves or their Neighbours. It is, that none of them would condemn they know not what; That they would hear the Cause before they pass Sentence; That they would not peremptorily pronounce against Electricity while they know little or nothing about it. Rather let every candid Man take a little Pains to understand the Question before he determines it. Let him for two or three weeks (at least) try it himself in the above named Disorders. And then his own Senses will shew him whether it is a mere Plaything or the noblest Medicine yet known in the World. Krusen (1941)

This was a clear plea for the suspension of judgement until electricity had been given a fair trial in the field of medicine. Two hundred and thirty three years later, medical science is still 
"experimenting" with many facets of electricity: Laser surgery, radiotherapy, magnetic resonance imaging and interferential currents, to name a few. "The noblest medicine yet known in the world" - at first glance this appears to be an exaggeration and yet has proved well worth investigating.

\subsection{HISTORICAL BACKGROUND TO FRACTURE MANAGEMENT}

The earliest evidence of fracture management dates back to 2750 - 2625 B.C., to mummies of the 5th dynasty, which were found in the Nubian Desert. Warfare was rife at that time, which doubtless was responsible for the fractured limbs of the mummies. Some fractures had healed well whilst others were still bound in splints, which, even by today's principles of immobilisation, appear to have been very effective. The earliest known record of the use of a crutch is a carving executed in 2830 B.C. on the entrance of a portal on Hirkouf's tomb in Egypt.

The earliest medical treatise which bears any scientific worth was known as the Corpus Hippocrates, a group of books written at intervals between the 4th century B.C. and the 1st century A.D. Some of the older parts were Athenian, although the greater part was probably the product of the Alexandrian School. Little is known of Hippocrates, other than that he was born about 460 B.C. on the Island of Cos, the seat of one of the great Asklepeian establishments, that he was a prominent physician among the Greeks and that he died about 370 B.C. He was recognised as the originator of the Corpus Hippocrates. The cult of Asklepios attained prominence thoughout Graeco-Roman civilisation, its temples becoming centers of medical service. Although ostensibly religious, the cult used the best medical science at its disposal in conjunction with the divinity. The great institutions at Cos and Epidauros became the patterns after which Christianity in later centuries modelled its hospitals. Treatment was based on hygiene, hydrotherapy and heliotherapy, also the mineral spring whose curative effects were already an ancient legend. The climax of treatment was the appearance in dream or trance of the god Asklepios, who appeared in the form of a snake, the traditional symbol of the Healing Presence. 
On Fractures, one of the books in the Corpus gave detailed descriptions of bandages, splints and fracture troughs, how to apply them and the indications for their use. Compound fractures were recognised as potentially life-threatening because of the pus and sepsis that sometimes occured. For this reason probing of a compound fracture during the early days following the injury was avoided, it was felt that such interference caused irritation and provoked the formation of pus. This was long before the days of "laudable pus". To the Hippocratic school there was nothing praiseworthy about pus of any color or consistency. Wine and other applications, which today would be recognized as antiseptics, were used freely. Another practice of interest was the use of compression bandages around the limb to promote vascular stasis in cases of retarded union. As the treatise antedated Harvey by over 1500 years the circulation of blood was not understood, rather the humoral theory was accepted as indisputable fact. The practice of compression, not only of the affected thigh but also of the other entire leg, was adopted in order to force the "humors" into the required area; however, care was taken to avoid prolonged pressure. In recent times, the use of venous stasis to stimulate the healing of fractures has, with modification of the method based on the accepted physiological principles of succeeding eras, been rediscovered. Thomas of Liverpool and, a century and a half later, Bier were practitioners of venous stasis for acceleration of fracture healing. As recently as 1931 there were articles justifying the practice by research and biochemical theories accepted widely at that stage.

With the decline of Greece, the channel of scientific progress moved to Rome, with the works of Galen (131-201 A.D.) He made an immense contribution to the understanding of the nervous system, recognising for the first time that the brain, connected via the nerves to each muscle, was responsible for voluntary movement. He is believed to be responsible for coining the words kyphosis, lordosis and scoliosis to describe those deformities. Galen is recognised as the first practising anatomist. He used animals, probably pigs, for dissection and transferred the knowledge to human anatomy.

Paul of Aegina (625 - 690 A.D.) was representative of Middle Ages Medicine. He was much closer to Hippocrates in method and attitude than were most of his contemporaries or immediate pre-decessors. He made many additions to fracture management, particularly in the area of surgery, including the use of bone chisels to refracture where malunion had 
occurred, and an instrument called a meningophylax for protecting sensitive structures deeper to the bone being cut or sawn.

Following Paul of Aegina came the Arabians who because of the Mohammedan antipathy to cutting up animals, whether dead or alive, were largely physicians. The only surgeon of significance was Albukasim (11th century), whose works reflected no real advances on Paul of Aegina's writings.

Then the first rumblings of the "Great Awakening" were heard in Europe. The Universities of the Western civilization were born under the aegis of the monasteries and cathedrals. The first, Salerno, originated as a monastic hospital as early as the 10th century, but did not become a teaching hospital until the 11 th. The study of anatomy was reintroduced, still using animal cadavers. From Salerno came Roger of Parma, who wrote the first great text-book on surgery in Western medical literature toward the end of the 12th century. He taught that pus was necessary for the proper healing of wounds. Fortunately his less famous contemporary, Bruno, disagreed with him, but the debate continued until the etiological factor in sepsis was finally demonstrated scientifically in the 19 th century.

Guy de Chauliac (1300 - 1368), professor at the University of Montpellier in his book La Grande Chirurgie described for the first time the use of weights and pulleys for continuous traction in the treatment of fractures of the femur. However, four centuries were to pass before this method of treating fractures of long bones was to become widely accepted.

Leonardo da Vinci (1452 - 1519), who effected a complete review of anatomy based upon actual dissection of the human body, was described by Bick as:

A modern biologist in the disguise of a medieval artist (Bick 1948, 35.)

Ambroise Pare (1510 - 1590), one of the great surgeons of the Renaissance, wrote Dix Livres de la Chirurgie in colloquial French instead of Latin, as was the custom of medical authors before him. He made many contributions to fracture management, including ligation of arteries in amputations, to replace the tortures of cauterization. He was the first to differentiate fracture of the neck of the femur as a separate clinical entity, which he treated 
by longitudinal traction using a belt above the knee to which were attached ropes leading to pulleys.

Amongst the great names in the 17 th century were William Harvey and Niels Stenson. Harvey (1578 - 1657) to whom credit was given for the discovery of the circulation of blood, was also a great embryologist, opening up new vistas on congenital abnormalities and anomalies, which affected orthopaedic surgery directly. Niels Stenson (1648 - 1686), a Dane, was the first to demonstrate that, in isolated muscle tissue, contraction could occur not only when its nerve was stimulated but also when the muscle itself was irritated. He was also one of the first to recognise the muscular structure of the heart. Much of the modern study of the biomechanics of muscle owes its origins to Stenson's attempts to prove mathematically that the power in any given muscle was the sum total of the forces inherent in each muscle fascicle.

The 18th century, witnessed the birth of orthopaedics as a specialty, Nicholas André, Professor of Medicine at the University of Paris synthesized the term Orthopaedia (1741) from the Greek roots orthos (straight) and paidios (child), to express his belief in the theory that many of the deformities of adolescence and adult life originate in childhood. The name does not include the traumatic aspect of orthopaedics, but the specialty does. Andre contributed to the treatment of scoliosis in children by introducing graded exercise, rest and supportive apparatus. The supports were usually corsets, made with whale bones to counter the curves.

Among the contributors to orthopaedics during the 18th century was John Hunter (17281793), who studied the repair of bone after fracture, including the formation of psuedoarticulations, the peripheral circulatory mechanism, the reaction of soft tissue to inflammation and foreign bodies, and tendon repair. He became particularly interested in the last topic, after rupturing his own Achilles tendon while dancing. Hunter's influence on British surgery has been permanent. The stress placed upon accurate anatomic notation, terseness of expression, and reliance upon actual observation rather than extensive bibliography, as well as the intense interest in problems of skeletal surgery which is shown in British surgical literature, are all a direct inheritance of his teaching. 
Hugh Owen Thomas (1843 - 1891) of Liverpool came from a family of "bone-setters of excellent repute", and also had formal training and a licence for the practice of surgery. Thomas's contribution to orthopaedics as a discipline was considerable. He emphasised the importance of principles rather than methods. As Bruce Gill stated:

a mind that grasps principles well, devises its own methods. (Bick 1948)

The principles of fracture management which Thomas espoused were:

- Enforced, uninterrupted and prolonged rest until union was complete; to him, stiffness and atrophy of the immobilised limb were negligible incidentals which in properly handled cases could be corrected with very little difficulty after the bone fragments were united. The "Thomas splint", which he designed and constructed himself, was very widely used in World War I as an emergency splint during the transportation of patients with fractured femurs, and is still in common use today for the non-operative treatment of fractures of the femur.

- Uninterrupted immobilisation of the fractured limb; this was contrary to the common practice of the day, called "testing the state of union", where the fracture fragments would be manually moved to see if union had taken place, long before it was anticipated, which Thomas considered detrimental to healing.

- The necessity for preserving an active circulation to the part, which was accomplished with the use of a hammer, giving light percussion and thereby inducing a hyperaemia. This was carried out daily as long as it was necessary.

- The dangers of stretching or "forcing" contracted joints after fracture, particularly the elbow joint. Thomas recommended that active exercise, the effect of gravity and preventative exercise whilst still in the immobilisation, such as the use of fingers in arm casts or quadriceps exercises in splints or casts applied to the lower limbs, were to be used either to prevent or correct contractures of the fractured limbs.

Samual Gross (1805 - 1885), of Philadelphia USA, was probably the first surgeon on record to use a form of adhesive tape for skin traction in fracture cases. Gurden Buck, working at about the same time in a New York hospital, popularised a traction system using adhesive skin traction which became known as "Buck's traction", this was used extensively during the American Civil War (1861 - 1865).

In 1852 Antoninus Mathijsen, a Flemish army surgeon of Brabant, introduced the use of plaster of Paris bandages as a substitute for braces and splints in the immobilization of skeletal injuries. 
Just Lucas-Champonnière (1843 - 1913), a French surgeon, countered the teachings of Thomas by advocating early movement of joints adjacent to fractured bones. He favoured early massage and exercise. This reaction was doubtless prompted by the stiffness and disabilities that so frequently followed the exaggeration of immobilization methods by the followers of Thomas. Champonnière's major premise was that the prevention of muscular atrophy and contracture permitted earlier return of function to the limb; also that the slight amount of movement which would, inevitably occur between the fragments under his mobilising methods was conducive to more active osteogenesis. A powerful factor in favour of the general acceptance of Champonnière's principles in countries where industrial fractures had assumed large proportions was their promise of early rehabilitation.

It must be noted, however, that the introduction of these methods occurred shortly after the popularization of X-ray control in fracture management. This innovation so changed the end results of fracture management that older comparisons are hardly valid.

Sir Robert Jones (1855 - 1933) of Liverpool, a nephew of Thomas must be counted among the great teachers of modern orthopaedic surgery. His major contribution was to make the main principles of Thomas acceptable to the profession. By this time X-ray control and the use of anaesthetics allowed much greater freedom in manipulation of fractures. Robert Jones developed the skills and made the necessary changes to usher in "modern orthopaedic" practice.

During this period the concept of a fracture changed from the classic definition of "a break in the continuity of bone", to one in which a fracture was recognized as an injury not only to bone but also to its associated soft tissues. Treatment objectives then began to emphasize function over form, to the extent of recognising the need for treating the patient as a whole. Scudder, quoted by Bick emphasized this in the following passage:

A fracture is injury done to a complicated and intelligent mechanism. The will is involved in every fracture, it influences the recovery of function. Therefore the recovery of the normal functioning of the whole organism is at stake, not merely the healing of a broken bone. (Bick 1948) 
In 1909 Steinmann reported his method of driving a specially designed steel spike or nail, to which traction lines could be attached, through the shaft of the lower fragment of a broken bone. This was met with scepticism until a decade later, when the results of the work in Böhler's clinic in Vienna made it obvious that infection was by no means an inevitable result of inserting nails, pins or wires into bone, provided sufficient care and hygiene were used.

Böhler also shocked the world by introducing the "skin tight plaster" which allowed early ambulation in patients with fracture of the lower limb. The previously taught method had been to use layers of cotton wool between the limb and the cast, which resulted in insufficient hold of the fracture fragments to permit walking with the cast. He also popularized the injection of novocaine, a local anaesthetic, into the fresh fracture haematoma, thus reducing the reflex muscle spasm and allowing the surgeon to reduce the fragments with ease and without discomfort to the patient. Böhler restudied the problem of nonunion and observed that, contrary to the belief held by many of the earlier surgeons, pseudarthrosis of the shaft generally occured in strong healthy people and more often in men than in women.

Throughout the ages, the problem of determining the state of healing of a given fracture has been questioned. In the years before Thomas, the manual test of motion at the fracture site was probably detrimental to fracture union. The introduction of $\mathrm{X}$-ray equipment transferred judgement from the test of manual motion to the interpretation of X-ray films. However Xray evidence of massive early external callus in the femur was seen to be no guarantee against subsequent angulation, whilst the lack of early callus in a plated tibia did not always indicate inadequate functional healing.

Lippmann introduced a method of testing for the degree of structural union in 1932, when he demonstrated that a stethoscope placed over the superficial surface of one end of a long bone received the sound of a finger tap at its other end; in the presence of a fracture, the sound transmitted by the dense medium of continuous bone was interrupted at the line of discontinuity. As healing progressed, the transmitted sounds approached the pitch and amplitude of the normal bone as continuity was restored. This method of assessing union was as subjective as any other method since it depended on the hearing of a small difference in 
pitch or amplitude of vibration, which may have been interpreted differently by each auscultator. It was possibly for this reason that the method did not gain wide acceptance.

To date there is still no objective, accurate measure to determine when union has taken place, particularly since union or healing of bone is a process rather than an event. The present criteria for judging union are discussed in Chapter 3.

\subsection{THE PROBLEM AND ITS SETTING}

The objective of the present research was to investigate the relationship between bone healing and the use of interferential currents. The application of electrical currents for the stimulation of bone healing is well known and documented (Yasuda et al 1953, Basset et al 1964, Becker et al 1964, Shamos \& Lavine 1964, Friedenberg et al 1970, 1971 \& 1974, Spadaro 1977 , Brighton \& Pollack 1985, Nikolova 1969 \& 1987 and Ganne 1988). Previous research concentrated on the effects of electrical currents in the treatment of nonunion rather than for new fractures.

Ganne (1988), an Australian physiotherapist, undertook a pilot study in which 11 patients with recent fractures of the tibia were treated with interferential currents. The time taken to achieve union was compared with that required by 11 closely matched patients with similar recent fractures, who did not receive interferential treatment. A significant difference in rate of union ( $p<0,01$ ) between the two groups was demonstrated using the Student's t-test.

Despite the small sample size in the Ganne study, the present researcher's interest was captured for the following reasons:

The importance of reducing the time to bone union is of considerable interest to clinicians. If the healing potential of interferential currents could be scientifically demonstrated to reduce significantly the time to union, then it would follow that interferential currents could be used prophylactically to prevent nonunion.

Identification of the likely candidates for nonunion poses a further problem. The same data set may be used to develop a model to predict nonunion (within a specified time period), given subject characteristics such as race, mechanism of injury etc. 


\subsubsection{Reasons for studying tibial fractures}

- Tibial fractures are prone to delayed union and nonunion, especially those occuring in the lower third of the bone (Apley 1986, Heppenstall et al 1984). This results in many lost man hours, particularly for those who carry out physical work (McRae 1981). The social implications of being incapacitated for many months, with loss of income and resultant loss of self worth, a feeling of being redundant, can be devastating to the patient as well as to family and friends. If this can be obviated by applying interferential currents for 10 to 15 treatments whilst the patient is in any event hospitalised, value would accrue in terms of cost-effectiveness: financial, physical, emotional and time.

- Surgical intervention (bone grafting), albeit an effective method of managing tibial nonunion, is costly and bears the risk of infection.

\subsubsection{Justification of the problem}

The literature survey reveals the results of many studies using different electrical currents for bone healing, including interferential currents. However, well controlled, scientific studies on bone healing using interferential currents in new fractures of the tibia have not previously been conducted. Lavine \& Grodzinsky (1987) point out that:

No matter how carefully a study is done, clinical results in a series of patients are open to question until randomised studies have been performed to help control the many variables. Properly evaluated statistical evidence is a further prerequisite for establishing the clinical role of electrical stimulation in the treatment of orthopaedic problems.

Interferential therapy is in common use by physiotherapists for the treatment of a number of soft tissue injuries (Lindsay et al 1990). Ganne (1988) highlights the advantages of using interferential currents in preference to other electrical currents for bone healing:

- Electrodes are applied to the skin, rather than surgically implanted.

- Medium frequency currents are very comfortably tolerated through the skin, because of low impedance to their penetration

- Penetration is deep, demonstrated by Laabs et al (1980) to reach within the bone at the fracture site, the highest intensity being in the medullary cavity.

- Treatment of pain and swelling is simultaneous.

- There are no electrolytic effects, as with direct or interrupted direct currents. 
- The low frequency beats produce therapeutic muscle contractions which stimulate bone repair.

- Application of treatments for short periods of time may be advantageous in avoiding tissue accommodation and constant slight irritation, by activating cells at intervals.

- Favourable effects on capillary circulation and inhibition of sympathetic overactivity have been found clinically and reported experimentally (Kaindl et al 1953, Nikolova 1969 and 1987, Schoeler 1972, Ganne 1980). The significance of adequate blood supply and venous return at fracture sites for repair is well documented (Mcnab and de Haas 1974, Rhinelander 1974, Trueta 1963 and 1974, Whiteside \& Lesker 1978). The effects on bone blood flow of releasing sympathetic tone was shown by Shim \& Patterson in 1966.

\subsection{ORGANISATION OF THE STUDY}

\section{CHAPTER 2:}

A review of the literature pertaining to therapeutic use of electrical stimulation in fracture healing is given. This encompasses the impact that interferential currents have had thus far, bone healing and the factors influencing it, factors leading to nonunion, the possible predictors of nonunion and prophylactic intervention of nonunion.

\section{CHAPTER 3:}

The methodology used in the study is described in terms of the research design, population, sampling method, research procedures, variables taken into consideration, data collection and the test on equipment to ensure the required effect. Limitations are stated and assumptions made.

\section{CHAPTER 4:}

The results of the data collected and their interpretation are presented.

\section{CHAPTER 5:}

The results of this study are discussed in relation to the literature. 


\section{CHAPTER 6:}

The research is summarised and conclusions are drawn. Recommendations are made towards future research in this area. 


\section{Chapter 2}

\section{LITERATURE SURVEY}

\subsection{INTRODUCTION}

This chapter is a review of the literature pertaining to the research problem; this has been divided into sections dealing with:

- Current concepts in bone healing and the factors which influence it, including classifications of the observably important factors such as; open fractures, displacement of the fracture fragments and the extent of comminution.

- Present theoretical approaches to the therapeutic use of electrical stimulation in fracture healing; this section includes an overview of the different types of current which have been used and the problems encountered with each, as well as some controversy in the field.

- Factors which contribute to nonunion, possible predictors of nonunion and prophylactic intervention in cases of nonunion.

\subsection{CURRENT CONCEPTS IN BONE HEALING AND INFLUENCING FACTORS.}

Greenbaum and Kanat (1993) suggest that the healing fracture is one of the most interesting homeostatic functions of the human body. The process does not leave a scar, but reconstitutes the injured tissue almost identically to its original form. However, this process is dependent on a multitude of conditions. It is the responsibility of the physician, through the use of fixation, to assist in the healing process and ensure a functional result.

Hulth (1989), points out that in Index Medicus, fracture healing does not have a search word of its own but is included in wound healing because the basic mechanism for the initiation of wound healing and bone regeneration is the same, namely haematoma. 


\subsubsection{Anatomy of bone}

The architecture of bone is described morphologically as either cortical or cancellous. Cortical bone constitutes the external and internal lamellae of flat bones and external column of long bones. Cancellous bone is found between the cortical layers of flat bones and in the metaphyseal region of long bones, such as the tibia.

The basic unit of cortical bone is the osteon, consisting of the haversian canal and its associated vessels surrounded by concentric lamellae of bone in which osteocytes are imbedded. Blood vessels course between the different osteons to anastomose with haversian vessels. This specialized arrangement of cells and vascular elements provides a nutritional advantage for the osteocyte. Each osteocyte in the matrix lies within $300 \mu \mathrm{m}$ of the blood vessels that provide its nourishment. During remodelling, new haversian systems are formed by osteoclasts grouped into a resorbed wedge known as a "cutting cone", which resorbs older mineralized bone. A new tunnel is then created into which vascular elements and osteoblasts migrate and deposit new bony lamellae. (Greenbaum \& Kanat 1993)

\subsubsection{Requirements for bone healing}

Bone healing is defined as a restoration of the original integrity of bone. The prerequisite for healing is an adequate biological capacity to react, controlled by the activity of special cells called mediators, which are either chemical or electrical. During bone healing, specific physical and biomechanical signals are delivered by the mediator mechanisms, located in the tissues surrounding the deficit. These mechanisms contain their own capillary beds, lymphatic channels, various supporting cells, intercellular material, and innervation. They determine when and where to produce new osteoblasts, osteoclasts, chondroblasts, chondroclasts, and fibroblasts, in addition to the total number to be produced, the length of time, and their nourishment.

Fracture healing requires the immediate availability of all cells stimulated by the mediator mechanisms. The congregation of these cells enables new bone to be produced. In addition, adequate blood supply is essential for the mediator mechanisms to be effective. 
Immobilization of the fracture fragments is essential for proper healing of bone. The body naturally attempts to prevent movement of the fracture fragments through the physiological processes of pain, oedema and muscle spasm which acts as a splint. This, in effect, decreases movement between the fragments, allowing further immobilization through an intrinsic cellular process known as callus formation (Greenbaum \& Kanat 1993).

Fracture healing can occur by two methods. Direct or primary bone healing occurs without callus formation, when rigid internal fixation is used. Indirect or secondary bone healing occurs in natural healing, where conservative orthopaedic management has been followed.

\subsubsection{Secondary bone healing.}

Indirect or secondary bone healing occurs with a callus precursor stage and appears to proceed through six distinct stages, each of which has a characteristic histology and physiology. Greenbaum \& Kanat (1993) and Cornell \& Lane (1992), describe the stages as follows:

Stage 1. Impact:- When bone absorbs energy beyond its modulus of elasticity, a fracture occurs along the line of least resistance and the force lasts until there is complete dissipation of energy.

Stage 2. Induction:- This is characterised by the formation of haematoma, bone necrosis occurs at the ends of the fracture fragments, and cell death releases byproducts into the exudate. The haematoma has a low oxygen tension and a low pH and contains kinins, prostaglandins and noncollagenous proteins of bone, all of which are probably vital to bone repair. The inductive stage is short and ends as inflammatory cells begin to appear within the fracture site.

Stage 3. Inflammation:- This begins within 48 hours of impact and lasts until cartilage and bone appear. It corresponds clinically to the development of swelling and pain and ends when these begin to subside.

Stage 4. Soft callus:- The fracture gap becomes highly cellular, with an increased vascularity. Subperiosteal new bone formation occurs adjacent to the fracture gap, and chondroblasts begin to appear in the fracture gap, replacing the fibrovascular stroma with chondroid. Clinically, the soft callus stage is marked by a significant reduction of pain and swelling, and motion of the fractured bone ends ceases.

Stage 5. Hard callus:- Increased oxygen tension leads to the production of osteoid (woven bone) by the osteoprogenitor cells. Osteoid consists primarily of opaque calcium hydroxyapatite, making it radiologically visible. The presence of osteoid creates rigidity within the callus. At the end of this stage the bone is considered healed. 
Stage 6. Remodelling:- This involves a prolonged replacement of woven bone with lamellar bone, reconstruction of the medullary canal and restoration of the bone diameter to normal. This process which can take from several months to several years, appears to be dependent on load-induced voltages, according to Wolff's Law; and is required to restore completely the mechanical strength of the fractured bone.

\subsubsection{Primary bone healing}

With the development of stable internal fixation a new type of healing was observed, known as "primary bone healing". There is a direct reconstruction of the fragment edges by haversian remodelling. The phase of fibrocartilage formation, as seen in secondary bone healing, is bypassed. There is no significant amount of callus visible on radiographs and fragment resorption does not occur; thus, there is no fragment end shortening. Also, direct healing does not imply faster healing. (Greenbaum \& Kanat 1993)

\subsubsection{Systemic and local factors affecting bone healing}

Cornell \& Lane (1992), points out that natural bone healing is influenced by systemic and local factors. Systemically the value of adequate protein-calorie nutrition and adequate dietary calcium has been demonstrated by Singh et al (1972). Hulth (1989) suggests that old age, poor nutrition and alcohol abuse delay union.

The local factors which have an effect on bone healing include:

- Blood supply to long bones is supplied from three vessel systems: (1) the nutrient artery, (2) endosteal vessels and (3) periosteal vessels. Rheinlander et al (1968) demonstrated that periosteal neovascularization of the fracture site is most important; endosteal circulation is of only minor significance. For this reason the soft-tissue envelope should be repaired early in the fracture healing process.

O'Sullivan et al (1989) describe the blood supply to the tibia from a single nutrient artery, posterolaterally - a branch of the posterior tibial artery. Muscle attachments to the tibia are sparse, rendering the blood supply to the tibial diaphysis particularly 
precarious and liable to disruption by fracture. Furthermore, when there is poor oxygenation at a fracture site, osteoprogenitor cells tend to form cartilage rather than bone.

Black (1985) emphasised the importance of soft tissue stimulation in relation to induced osteogenesis. The early events of ostogenesis involve participation by many of the cells of soft tissue: fibroblasts, macrophages, chondroblasts, etc. It is only as fracture healing moves into the latter phases of the inflammatory stage that osteogenesis, mediated by osteoblasts, begins. Furthermore, persistent soft tissue effects are noted in conjunction with stimulated osteogenesis. Reports include observations of better collagen organization within early callus (Basset et al 1982), hyaline cartilage production in the vicinity of healing osteotomies (Friedenberg 1970), and a more rapid return of medullary circulation (Gupta et al 1982). These observations, combined with an early observation of stimulatory effects on fibroblasts in an in vitro model (Basset \& Herrmann 1968), have contributed to a wide variety of efforts to stimulate directly soft tissue repair and remodelling.

Movement of the fractured ends:- Sarmiento et al (1984), have demonstrated by clinical trial that controlled movement at the fracture site and function of the injured limb are crucial to healing of bone.

The controversy between the old principle of complete immobilization of the joint above and below the fracture, and the newer methods of functional bracing which allows movement of the joints, is postulated by Hulth's (1989) theory that the purpose of the immobilization, whether it be traction or bracing, is to maintain the external shape of the extremity and prevent the soft tissue from moving too much. The bone ends, on the contrary, are permitted to move within the soft-tissue package and even rub against each other.

Theoretically, according to Sarmiento et al (1984), motion has an irritating effect that prolongs the inflammatory response of the surrounding soft-tissue, which provokes a greater vascular response. The key lies in the degree of movement allowed. Excessive 
movement in highly unstable fractures does not allow soft-tissue healing and periosteal revascularization, leading inevitably to nonunion. Inhibition of motion, either by immobilizing the limb in a plaster cast or by rigid fixation (internal or external), also inhibits healing, probably by shortening or eliminating the inflammatory phase.

Ilizarov et al (1973), cited by Hulth (1989), discovered that daily micromanipulation of callus in a tibial lengthening procedure yielded excellent new formation of bone, impossible to achieve in any other way. Hulth therefore suggests that prolonging the time of active stimulation by the fracture exudate is probably advantageous to healing. In non operative management this can possibly be achieved to a certain extent by weight bearing, whereas delayed surgery, although implying risk of complication, seem to have the same stimulating effect.

- The role of prostaglandins as important mediators of inflammation and potent stimulators of bone resorption; Healy et al (1988) found in an animal experiment that, when $\mathrm{PGE}_{2}$ was administered with an alzel pump, a statistically significant increase in cartilage matrix production occurred in a dose-dependent fashion $(p=0.03)$. The same authors have demonstrated that the administration of Indomethacin, an antiinflammatory agent, can delay fracture healing by limiting the inflammatory phase.

- Hulth suggests that the difference between wound and bone healing lies in the emission into the exudate of osteogenic signal substances such as bone morphogenetic protein (BMP) from the fractured bone ends. Greenbaum \& Kanat (1993) explains that the importance of BMP's lies in replacing exhausted osteoblasts with new ones. Since the functional life-span of osteoblasts is 2 to 3 months, successful bone healing cannot occur until their number is increased by many thousands.

Furthermore, Hulth relates how biomechanical forces and electric currents can be translated to biochemical mediators such as prostaglandins $\left(\mathrm{PGE}_{2}\right)$, morphogens and growth factors. The molecular activity of the fracture exudate is the most decisive factor for bone healing. Movement of the bone fragments increases the fracture exudate with its migrating cells and sprouting vessels resulting in exuberant callus. Cartilage is 
formed in the well-vascularized granulation tissue due to its ability to repel vessels. Rigid fixation minimizes granulation tissue and external callus. Rigid plates may also retard effusion of morphogens and growth factors from bone ends. Reaming of the intramedullary canal and nailing may cause additional bone damage, which may increase the osteogenetic activity. Weight bearing stimulates growth factors and $\mathrm{PGE}_{2}$. The molecular activity of the exudate can be impeded by diastasis, infections and soft tissue crushing injuries, which cause extensive activation of macrophages and active mediators, disturbing the osteogenesis and promoting fibroplasia.

Finally, Hulth suggests that in the future, orthopaedic surgeons will probably use injectable, healing-promoting substances $\left(\mathrm{PGE}_{2}\right.$ and other imflammation-promoting factors) locally, to activate fracture exudate. This may be possible early (after three to four weeks) in severe fractures with a known tendency for delayed healing, or once delayed healing has been established.

An attempt to assess objectively the extent of disruption of the blood supply to the fracture fragments has been made by classifying the severity of soft tissue damage, as well as the nature and severity of the fracture.

\subsubsection{Classification of open fractures:}

Gustilo et al (1984), classified open fractures into:

Type I: Clean, with a wound less than one centimeter long.

Type II: Laceration more than one centimeter long without extensive soft-tissue damage, flaps, or avulsions.

Type IIIA: Adequate soft-tissue coverage of a fractured bone, despite extensive softtissue laceration or flaps, or high-energy trauma irrespective of the size of the wound.

Type IIIB: Extensive soft-tissue loss with periosteal stripping and bone exposure. This is usually associated with massive contamination. 
Type IIIC: Associated arterial injury requiring repair.

This classification assists in accurate documentation and decision making about orthopaedic management, as well as standardisation in clinical trials. Gustilo's Classification which is used by the orthopaedic department of Groote Schuur Hospital, assisted the author in making decisions about exclusion criteria for the present trial.

\subsubsection{Classification of fracture displacement.}

The degree of initial fracture displacement is often difficult to judge because the limb may have been semi-reduced at the site of trauma, in order to transport the patient. Thus, the first radiographs taken may not indicate the full degree of initial displacement. The literature devotes very little space to this aspect of fracture severity. Clinically it is usually described as full diameter, half diameter or quarter diameter, and the description of configuration in terms of shift, tilt, twist or shortening (Apley 1986 and Marks 1990).

The greater the degree of displacement, the greater the likelihood of soft tissue damage and thus the greater possibility of disruption to the blood supply of the fracture fragments.

\subsubsection{Classification of comminution.}

Pankovitch et al (1979) classify comminution in the following way:

- Unicortical comminution: Fractures with a single butterfly fragment or the cortex comminuted on only one side.

- Bicortical comminution: Fractures in which comminution involves the entire circumference of the cortex, often with multiple butterfly fragments; their tendency for shortening is commensurate with the length of the comminuted segment.

Johner and Wruhs (1983) base their classification on morphological criteria related to the mechanism of the accident as well as the degree of comminution.

Fractures produced by indirect trauma have a better prognosis than those produced by direct trauma. (Johner and Wruhs 1983) 
Neither of these two classifications however grade the length of comminution. This could possibly be expressed as a fraction of the total bone length or simply a measure in centimetres of the extent of bone comminution.

\subsection{BACKGROUND TO THE THERAPEUTIC USE OF ELECTRICAL STIMULATION IN FRACTURE HEALING}

Behari (1991) notes that living cells have been described as a device to convert electrical energy into mechanical work and conversely that bone converts mechanical energy to an electrical signal, and it is postulated that the changes in the electrical environment of mesenchymal cells may control, to a large degree, their mitotic and functional activity. In conformity with the above electrogenesis in the bone, more than in any other tissue, has become a favourite subject of investigation.

Yasuda et al (1953) found that bone produced electrical potentials when deformed and concluded, as did Becker et al and Basset et al (1964), that these potentials were involved in controlling bone cells. These results seemed to suggest that bone electrical activity, and hence its remodelling and growth, can be controlled by external stimuli. Conversely, Siff (1990), points out that little is known about electrical fields at the subcellular level. The sensitivity of the body to external electric, magnetic and electromagnetic fields cannot be explained satisfactorily in terms of action potentials, which are not affected directly by these fields. There is also no explanation of the mechanism whereby electric and other fields stimulate biological processes such as the repair of fractures, the healing of wounds and the reduction of thromboses. Siff, citing Carley \& Wainapel (1985), suggests that microstimulation (current below 1 milliamp) has been demonstrated to accelerate wound healing by $150-250$ percent.

Savage (1984) notes that the therapeutic effects of electrical energy have occupied an important position in physical medicine for many years, and a wide range of frequencies, from direct current (DC) to radio and even microwave frequencies, have been used. The two principal therapeutic effects of electrical energy are 1) the generation of heat and 2) the 
body will give rise to the dissipation of heat, the heat generated being the product of the square of the current and the resistance of the tissue through which it flows. The stimulation of excitable tissue is only possible at relatively low frequencies, and therefore frequencies of up to about $150 \mathrm{~Hz}$ are generally used.

Nordenström (1983) maintains that currents can stimulate the flow of ions along the blood vessels and through the cell membranes, which constitute the body's closed electric circuits, which are postulated by his theory. In contrast macrostimulation (current exceeding 1 milliamp) tends to act primarily as a stressor, which in the short term causes the typical alarm response described by Selye (1975). This alarm response may then be followed by enhanced adaptation or what is often termed superadaptation or supercompensation, provided the stimulus is not excessive for the tissue concerned. If it is too intense, too prolonged or inappropriately applied, adaptation energy stores may be insufficient to cope at the required rate, so that adaptation may not occur, and onset of the exhaustion stage will then be accelerated. Continued application of electrostimulation at this point could conceivably deplete both the superficial and deep adaptation energy stores, thereby causing permanent tissue damage or death. This theory exemplifies the Arndt-Schulz law which states that:

Weak stimuli excite physiological activity; moderately strong stimuli favour it; strong stimuli retard it and very strong ones arrest it (Liggins 1988).

The theory seems to be substantiated by the fact that interferential currents, which would be considered strong stimuli, are recommended for no longer than 30 minutes per day, due to the exhausting effect that longer periods of stimulation are reported to have on the patient (Savage 1984 and Ganne 1988).

\subsubsection{Theory of interferential currents}

Savage (1984) notes that the concept of interferential therapy was first introduced by Nemec in Vienna in the early 1950's, and was subsequently practised by a few physiotherapists in Great Britain. The introduction of this technique, however, coincided with the arrival of powerful new drugs such as cortisone and phenylbutazone (butazolidin) and this, combined with the fact that electrotherapy was considered to be mainly a palliative form of treatment at that time, led to its virtual disappearance. During the late 1960 s and 1970s, many of these 
at that time, led to its virtual disappearance. During the late 1960 s and 1970 s, many of these drugs, though effective, were found to have limitations as well as unwanted side-effects. At the same time, work on pain mechanisms by Melzak, Wall and others, led to the discovery that pain could be relieved by stimulating primary afferent neurones. These and other factors have given rise to a resurgence of interest in interferential currents. Interferential currents are now being widely used in physiotherapy practices: for example, Lindsay et al (1990), in a survey of electromodality usage in private physiotherapy practices in Brisbane, Australia, found that interferential usage is second only to ultrasound. This highlights the necessity for controlled experimental trials to validate such usage.

The application of interferential therapy is, by the use of two medium-frequency alternating currents of slightly differing frequencies, applied to the body in such a way that they cross and interact to produce a low-frequency therapeutic current, known as a "beat" frequency. Frequencies of around $4,000 \mathrm{~Hz}$ are used as "carrier waves" for the low-frequency current, due to the low impedance of the skin to these frequencies, making treatment much more comfortable than is the introduction of low-frequency currents directly into the skin. De Domenico (1981) gives the following figures:

At $50 \mathrm{~Hz}$ skin resistance is approximately $3,000 \mathrm{ohms} / 100 \mathrm{~cm}^{2}$, at $4,000 \mathrm{~Hz}$ skin resistance is as low as $40 \mathrm{ohms} / 100 \mathrm{~cm}^{2}$.

The physiological effects of using different "beat" frequencies, (the difference between the two medium frequency currents ie. $4,150-4,000=150 \mathrm{~Hz}$ ), have been empirically noted to be stimulatory. Savage (1984) stated that for each type of excitable tissue there is an optimum frequency at which the maximum response will be elicited. Some typical examples are quoted below:

Sympathetic nerves

$0-5 \mathrm{~Hz}$

Voluntary muscle

0-10 Hz

Parasympathetic nerves

$10-150 \mathrm{~Hz}$

Motor nerves

$10-50 \mathrm{~Hz}$

Sensory nerves

90-110 Hz

Nocioceptive system

$130 \mathrm{~Hz}$ 
De Domenico (1981) notes that interferential currents in excess of $80 \mathrm{~Hz}$ are thought to have a marked depressive effect on sympathetic activity. Since the smooth muscle of the small arterioles of the vascular system are supplied by the sympathetic nervous system, it is reasonable to expect that depression of this activity will have an effect on the blood vessels supplied by those fibres. An increase in the sympathetic "tone" of small arterioles, produces vasoconstriction, and thereby a decrease in blood flow through the part. In contrast, a decrease in sympathetic "tone" of the vessels will produce profound vasodilation. The possible suppressive effect of sympathetic nervous system activity produced by the interference current can thus produce a marked hyperaemia in the area requiring treatment.

\subsubsection{Research into interferential currents}

Nikolova (1969), working in Bulgaria, in a trial involving 812 patients with fracture complications, was the first to demonstrate the effects of interferential currents. Two hundred and sixty of the total number were classified as having "retarded callus formation", of which 150 were treated with interferential currents, with the result that $75 \%$ were "restored", $22 \%$ "greatly improved", and 3\% "improved". The method used was quadripolar, treating segmentally, using $100 \mathrm{~Hz}$ beat frequency for $15-20$ minutes daily, for 15 to more than 20 treatments.

This work was apparently unknown in most of the western medical world and like all of the clinical trials of that era, had no "controls" to ensure an even spread of variables; there was also no time given for the definition of "retarded callus". Nikolova (1969) also treated 20 patients who were still in the plaster cast. All of them showed good callus formation within the normal period of time and arrived at quick functional restoration following removal of the cast.

This demonstrates that the interference current is a very valuable aid in the prophylaxis of fracture complications. (Nikolova 1969)

This statement carries little credibility due to the "unscientific" methodology and small sample size. 
Hansjürgens \& Meyer-Waarden (1980), calculated the electric field strength of interferential currents by applying 4 electrodes to a heterogeneous model, which included skin, muscle and bone tissue, with an osteotomy in the bone. The electric field intensity, which is closely coupled with the current density by conductivity, was used to specify the effect of the interference field. In Fig 2.1 the curves represent positions of equal electric field strength measured in volts per unit length. The unit length is that on which the system of coordinates is based. 10 volts was selected for each circuit, with a beat frequency of $0.25 \mathrm{~Hz}$. As can be seen from the figure, there is a relatively high field strength in the bone, and particularly at the osteotomy.

Laabs et al (1980), in an animal experiment using 34 sheep, demonstrated that the highest IFT field strength occurred in the gap between the fracture fragments.

The radius was osteotomised, then fixed with a 4-hole AO-plate leaving a gap of at least $1 \mathrm{~mm}$. A needle with two isolated

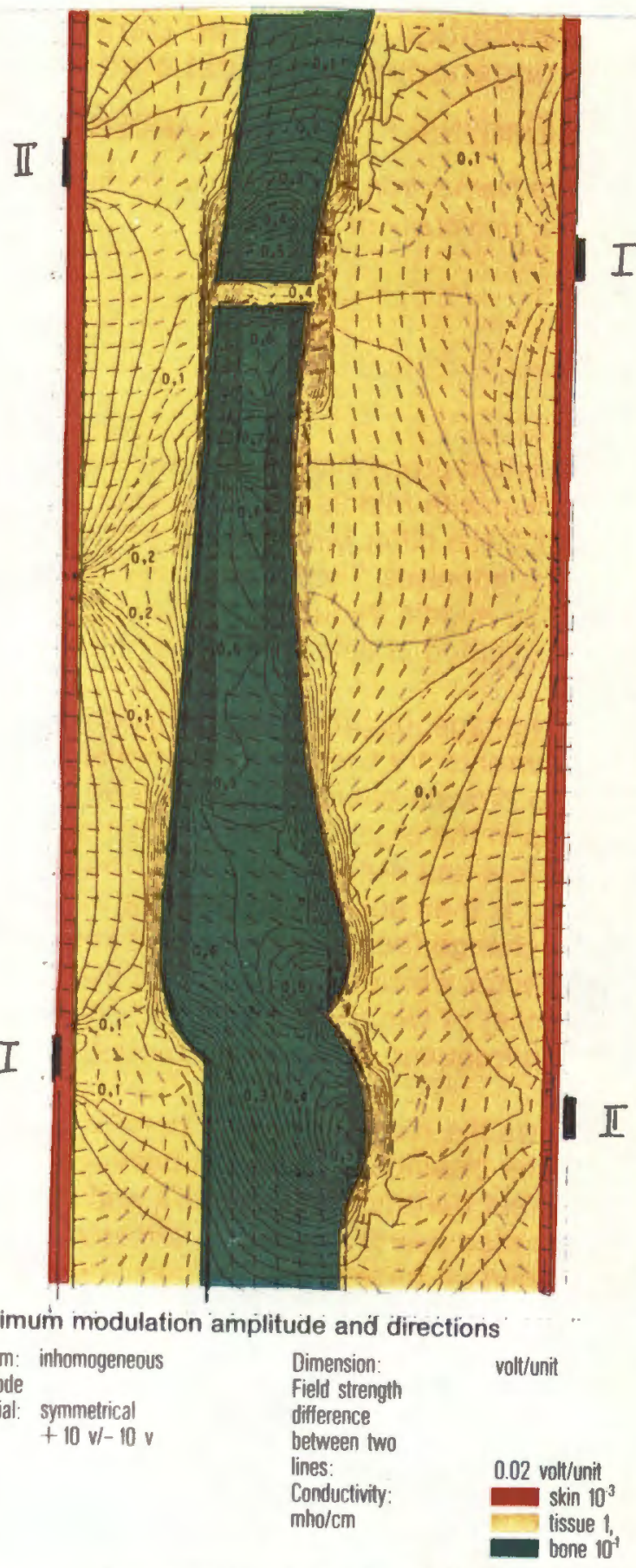

Fig 2.1 Distribution of electric field strengths in static interference (Hansjürgens \& Meyer-Waarden 1980).

probes was placed in the gap to measure field strength and check the amplitude of the frequency modulation on oscilloscope. The modulation amplitude remained constant in spite of the metal implant. Furthermore, there were no undesirable side effects on the adjacent tissue; no heat developed and there was no ectopic mineralisation, alteration in the metal or apparent detriment to cells. 
Ganne (1988), continued Nikolova's work and reported on further work done in Australia, using interferential currents: Firstly, 25 patients with delayed union or nonunion were referred, of which $22(88 \%)$ healed without further management and had no residual loss of function. Of those, 9 cases were diaphyseal fractures of the tibia and fibula, 7 of which healed with an average length of treatment of 7.9 weeks (shortest period of stimulation being 4 weeks and longest 13.5 weeks). The time interval from injury or surgery to referral averaged 20 weeks (minimum: 11 weeks and maximum: 33 weeks). Treatment was given 3 times a week for 30 minutes.

In this present trial, none of these patients would have been considered to have nonunion, since the time period was under 40 weeks. The cases cited may have healed without intervention, within the time periods stated. Since Ganne's study had no "controls" and the sample size was small, its validity is also questionable, but it holds clinical interest.

Secondly Ganne reported on a study of 11 matched acute fractures, where the group who received interferential treatment demonstrated a significant difference in rate of union $(p<$ 0.01) according to the Student's t-test. It was this, second of Ganne's reports which resulted in the present research and an attempt, based on "scientific" methodology, to answer the question of whether interferential currents can indeed be used to increase the rate of union and prevent nonunion.

Beer et al (1990), reporting on the effectiveness of electrical stimulation on the healing of 20 rabbit osteotomies, demonstrated by determining the total alkaline phosphatase in the serum and its bone iso-enzyme that the effect was greater using interferential currents than bipolar rectangular impulses. A non-stimulated group served as control. Although the methodology here appeared sound, the sample size was small.

\subsubsection{Direct current.}

Brighton and associates (1975, 1980, 1982a and 1982b) initially confirmed that direct current (DC) served as an effective stimulus to bone formation and fracture healing in laboratory animals. This technique was then extended to the treatment of human patients suffering from 
The technique described by Brighton requires the percutaneous insertion of Kirschner - wire electrodes directly into the site to be stimulated. The electrodes protrude from the skin and are attached to an external battery pack. The disadvantages of this technique appear to be:

1) An operative procedure, although relatively minor, is required, with the attendant risk of infection.

2) Immobilization of the affected part is necessary to prevent electrode breakage and soft tissue irritation around the electrodes.

3) A foreign object protruding through the skin provides an avenue for possible bone infection (Steinberg et al 1984).

Paterson et al (1977) reported another approach to the use of direct current to stimulate fracture healing. This involves the use of a totally implantable bone growth stimulator, consisting of a multistrand titanium helix electrode, used as a cathode. This is directly connected to a self-contained power source housed within a small titanium capsule. Together, these are surgically implanted at the site to be stimulated. This procedure is frequently used in conjunction with a local bone graft. The power pack has to be removed when it is no longer supplying a current - usually six months from the time of insertion. Here the disadvantages are:

1) If the current generated is insufficient, reoperation for insertion and attachment of a new power source is necessary.

2) It is also not practical to use more than one, or at most two power packs at one location, a factor that limits the effective current delivered.

Nevertheless, results using the implanted power source with a bone graft have generally been favourable and similar to those obtained with the use of Kirschner-wire electrodes and an external power source (Paterson et al 1977, Paterson et al 1980, Collins et al 1981, Paterson 1982).

Ganne (1988) points out that in these reports there is usually no comment on the overall functioning of limbs on the completion of treatment, as well as the ability of the patient to resume work. This absence of comment must be taken into consideration. Prolonged immobilisation and non-weight bearing do not favour functional recovery of joints and 
muscles, and therefore, if there is an alternative, it should be considered when deciding on management.

The mechanism by which DC is thought to be effective in the osteogenic healing process is the production of an electronegative field in the tissues surrounding the cathode, which simulates the "normal" endogenous response of fracture healing (Black 1985 and Walter 1985). This does not explain how other types of current, where polarity is not used, have demonstrated equal osteostimulation. In this regard Black proposes the following working hypothesis:

Exogenously generated constant electrical signals might be expected to act as healing stimuli in the early stages of fracture healing, whereas, exogenously generated timevarying electrical signals might be expected to have a greater effect on the later stages. (Black 1985)

The implication of this statement for the present clinical trial could be that IFT is being applied too early in the healing phase.

\subsubsection{Pulsed electromagnetic fields. (PEMF)}

Basset et al (1974) developed a non-invasive technique using pulsed electromagnetic fields (PEMF's). This technique involves external placement of induction coils on the skin over the site to be treated. A pulsing current through these coils creates an electromagnetic field, which induces a weak electrical current at the site of nonunion. Results have been comparable to those obtained with the other types of electrical stimulation described, with a success rate of $80 \%-85 \%$ and more recently a $90 \%$ success rate (Basset 1985). The disadvantages of this method include:

1) At least 10 hours of daily use is necessary, with the patient connected to a standard plug at home. There are many homes in South Africa which do not have electricity.

2) The treatment is administered for at least three months and no weight bearing is allowed on the limb during this period.

3) A further possible disadvantage relates to epidemiological evidence suggesting that there is a significant link between power line fields and leukaemia (Wertheimer and Leeper 1982, Tomenius 1986). 
3) A further possible disadvantage relates to epidemiological evidence suggesting that there is a significant link between power line fields and leukaemia (Wertheimer and Leeper 1982, Tomenius 1986).

A strong correlation between risk of suicide and increasing field strength has been shown (Perry 1981 and Perry \& Pearl 1988). This has created an often heated international debate regarding the possible ill effects of non-ionising electromagnetic radiation (NI-EMR).

Other investigators (Smith \& Best 1989, Coghill 1990) seem convinced that 'electro-pollution' (NI-EMR) is the main contributory factor to many modern illnesses such as the allergies, multiple sclerosis and many forms of cancer. Their argument is that such diseases have shown a sharp rise in incidence during this century, with the curve becoming ever steeper. The 'electro-pollution' advocators maintain that such rising curves parallel the rise of exposure to increasing levels of NI-EMR from all sources. Their assumption is one of a causal relationship between the curves, despite the lack of proven mechanism (Charman 1991).

On the other side of the debate are authors such as Cartensen (1987) and Tar-Ching (1988), who consider that the epidemiological evidence does not stand up to dispassionate scrutiny. Barker (1985), in a sceptical discussion of NI-EMR therapy claims, stated that there had been no convincing demonstrations to that date of long-term exposure hazards from low-frequency signals at power levels below those required to produce thermal effects.

The pulsed electromagnetic field strengths of between 0.1 and 20 gauss ( $1-10$ millivolts per centimeter) which are produced within the limb are far below those required to cause thermal effects (Black 1985). Although the modality has been in use for less than 20 years, Lavine \& Grodzinsky (1987) stated that there had been no evidence to date of malignant change in any of the experiments on animals or in the treatment of any humans. This calls into question the fact that the animals are sacrificed at the conclusion of the experiment, so that no longterm studies are available. The present author has also not found any reported literature on long term follow up studies of patients who received this form of pulsed electro-magnetic field, thus no conclusive scientific evidence can be drawn upon to settle this debate. 
De Haas et al (1979), in a well controlled animal experiment, using freshly created osteotomies of the rabbit radius, found that in pulsed electromagnetic fields of $1 \mathrm{~Hz},(0.1$ and $4 \mathrm{~Hz}$ were also evaluated), initiation of the healing process can be accelerated but that this effect is not maintained, and that the total period of time required for union is not significantly shortened. In view of these findings, this form of treatment is not recommended for clinical use in the treatment of recent fractures of long bones.

\subsubsection{Capacitively coupled - 60 Kilohertz sine wave.}

Brighton \& Pollack (1985) describe the use of what they term "capacitively coupled" electric field, which is a displacement current as well as a conduction current through the skin (60 $\mathrm{KHz}$. sine wave). It is applied to the skin through two windows on opposite sides of the plaster at the level of nonunion. The power unit is small; strapped to the limb proximally, and supplied by a 9 volt battery, it is replaced each day by the patient, who also reapplies electrode gel to the $3 \mathrm{~cm}$ diameter electrodes. The stimulation is continuous, with an average of 22.5 weeks of treatment. The authors report a $77 \%$ success rate, and conclude that this non-invasive technique, has the distinct advantage over other methods of allowing weight bearing.

The disadvantages are:

1) Weakness in the cast at the level of the fracture.

2) Patient compliance, which demands completion of daily tasks by the patient.

3) Unwillingness of patients to participate (in Brighton's clinical trial) because of a 50 per cent chance of being in the control sample.

\subsubsection{Pulsed short wave diathermy.}

Sharp (1983) reported on the use of pulsed radio frequency energy (Pulsed short wave diathermy) which was originally reported on by Ginsberg (1940) but which fell into disfavour for many years, according to Sharp, because of the extravagant claims made without any adequately controlled trials. Ironically, Sharp's trial was also not controlled, and is not included in the later reviews on electro-stimulation of bone repair. The technique required 
twelve hours of treatment, daily for periods of six months, or more if necessary. A $75 \%$ success rate was reported in 16 cases and Sharp concludes:

Now that the efficacy of electrical stimulation in the treatment of nonunion has been established it seems to us to be ethically improper to undertake controlled clinical trials. (Sharp 1983)

This is a view shared by some orthopaedic surgeons with whom the present author had discussions, in preparation for the trial described in this thesis. Lavine \& Grodzinsky (1987), however recognise that, no matter how carefully a study is done, clinical results in a series of patients are open to question, until randomised studies have been done to help to control the many variables;

Properly evaluated statistical evidence is a further prerequisite to establishing the correct clinical role of electrical stimulation in the treatment of orthopaedic problems. (Lavine \& Grodzinsky 1987)

\subsubsection{Piezoelectric internal fixation plate.}

Cochran et al (1987) report on the development and describe design specifications of a device which combines the modalities of mechanical fixation and electrical stimulation in a single implant. The piezoelectric internal fixation plate represents a new concept in orthopaedic implants, the purpose of which is to provide stable bone fixation while delivering internally generated microampere direct currents to prevent or treat nonunion of a fracture or osteotomy. The "piezoplate" contains an integral piezoelectric element that generates current in response either to physiological loading such as weight bearing or to externally applied ultrasound. Currents are processed by a rectifying circuit for delivery to bone by electrodes. Specially designed series/parallel piezoelectric elements and dual processing circuits are required to generate optimum rectified currents for the low-frequency, high-voltage signals generated by weightbearing, as well as the high-frequency, low-voltage signals produced by ultrasound.

The effectiveness of this combination will need to be assessed in years to come. 


\subsection{NONUNION}

Nonunion occurs when healing at the fracture site ceases before bone continuity has been established. (Weissman \& Sledge 1981)

\subsubsection{Criteria for nonunion of the tibia}

Lavine \& Grodzinsky (1987) stated that the most commonly used criterion for nonunion of the tibia was that the fracture showed no evidence of union after at least nine months (39 weeks) of immobilisation, and no evidence of radiographic changes during the last two months of treatment.

Kuhlman et al (1988) considered that nonunion should be suspected clinically, when pain and tenderness persists at the fracture site beyond the time for normal healing, generally more than 6 months ( 26 weeks).

Blick et al (1989) stated that traditionally, delayed union is diagnosed at 20 weeks from injury.

Marks (1990) states that the average healing time for tibial fracture is 16 weeks. At this stage, if no evidence of union can be detected, bone grafting is considered.

\subsubsection{Factors which contribute to nonunion.}

Heppenstall et al (1984) in a retrospective evaluation of 185 cases of nonunion treated with constant direct current, list the prognostic factors in nonunion of the tibia as follows:

1) There is a definite male predominance for nonunion of the tibia

2) This condition affects the young to middle-aged patient.

3) There is no particular predilection for extremity involvement.

4) The majority of established nonunions of the tibia are secondary to motor vehicle accidents. 
5) The severity of the injury plays a dominant role in the development of nonunion of the tibia, according to the criteria of Ellis' (1958); the initial displacement, extent of the open wound, and severity of comminution are all important parameters.

6) Proper management of concomitant soft-tissue injuries is extremely important in the prevention of nonunion. Open fractures were present in 126 of the 185 cases. Staged wound coverage is important.

7) Associated injuries were felt to be a contributing factor.

8) Infection resulted in $29 \%$ of the open cases. Primary closure of open injuries is dangerous and resulted in a high incidence of infection, 27 of 37 cases.

9) The distal third of the tibia was more frequently involved with nonunion. The most common fracture pattern was that of the oblique and transverse varieties. Segmental fractures appeared to have a higher incidence of nonunion of the distal fracture.

10) An intact fibula was present in $28.5 \%$ of the cases and may have contributed to the development of nonunions.

11) A true synovial pseudarthrosis accounted for $5 \%$ of the cases. (The etiology of this condition is unknown at the present time).

12) The majority resulted in acceptable alignment but the varus pattern was the most common in the malaligned group.

13) One of the most striking findings in this study was the high incidence $(92.4 \%)$ of patients presenting with an initial delay to weight bearing beyond 6 weeks. This was felt to be a definite contributory factor in the development of nonunion of the tibia.

The average duration of nonunion in Heppenstall's series was 2.6 years, which according to other studies (Kuhlman et al, 1988 and Lavine \& Grodzinsky 1987) is extremely high.

Nicoll (1964) emphasises the following causes of nonunion:

- infection and

- distraction of the fracture fragments;

and Walter (1985), suggests:

- irregularity of endocrine secretions and

- metabolic abnormality leading to derangement of normal calcium and phosphorus mechanisms. 
Other authors, such as Pearson \& Austin (1979), state that soft tissue interposition across the fracture line will result in non-union, and is probably the only absolute indication for risking primary internal fixation. Additional causes of delayed union and nonunion are listed as:

- Excessive periosteal stripping in displaced fracture causing death of the bone ends.

- Avascular necrosis of one fragment (scaphoid and neck of femur).

- Excessive movement at the fracture site.

Apley (1986) state that nonunion may follow bone loss or deep infection, but a common cause is faulty treatment. Either delayed union has not been recognized and splintage discontinued too soon, or the patient with a recently united fracture has walked with a stiff equinus ankle.

The common thread running through the above recommendations by text book authors and Heppenstall's clinical trial is that there are many recognisable factors leading to nonunion. However, these are not always consistent and have not yet been collated into a clinical "severity index". Such an index could accurately indicate early intervention, whether by electrical stimulation or bone graft.

\subsubsection{Possible predictors of nonunion}

Kyrö et al (1989), report on tibial shaft fracture repair imaged by magnetic resonance. Magnetic Resonance Imaging (MRI) is sensitive to blood flow, and to changes in the local molecular environment of the tissues. Six randomly chosen patients with solitary, closed tibial diaphyseal fractures were studied with MRI scans during the first week after injury, and thereafter at 1-month intervals until union of the fracture. The fractures were treated conservatively with closed reduction and immobilization by a long-leg plaster cast.

The fractures of the six patients studied healed without delay, the mean clinical union time being 14 (10-18) weeks. The intramedullary cavity showed a marked decrease in signal intensity from the first week, which continued until the 2-month scan, when the signal intensity stayed at the same reduced level. The decrease in signal intensity was probably a consequence of a partial interruption in medullary blood flow. The MRI scans suggested that 
consequence of a partial interruption in medullary blood flow. The MRI scans suggested that resumption of this flow is a fairly slow process. On the first scan, a very high signal intensity was generated in the soft tissues around the fracture. The intensity decreased on the 1-month scan. On the 1- and 2- month scans, the soft tissues showed low intensity nodules. These seemed to correspond to the location of the first areas of the callus to be mineralized, as could be seen on plain radiographs several weeks later.

This baseline for normal fracture repair may have significant implications for future early detection of delayed union. MRI is a costly method of making routine decisions, but could possibly be indicated in high risk cases, once more is known about the difference in signal intensity between "normal" and "delayed" healing. To date, however, there is no model which takes into consideration the large number of variables, and which can predict with any degree of accuracy those cases that will go to nonunion.

\subsubsection{Prophylactic intervention in nonunion}

Rittman et al (1979), in an attempt to avoid inherent complications of open fractures, found that with primary internal fixation, irrigation and drainage there remained $7 \%$ of 200 cases, sequentially entered, which due to bone infection took an average of 27 (range 4-72) months to heal. The question here is: How many of these fractures would have healed without complication, if treated non-operatively (ie. without internal fixation)?

\subsection{SUMMARY}

Evidence for the value of interferential currents as a treatment modality and the mechanisms by which it may provide beneficial effects, both in the initial stages of bone healing and as a prophylactic measure to nonunion, have been sought in the literature.

Despite encouraging results in the use of interferential currents in animal trials, for reducing healing time, no valid scientific studies on humans have been done. Together with many other 
types of electric currents, interferential currents have been suggested as a possible means of promoting healing in cases of nonunion.

Bone healing is examined from a biological and biomechanical perspective, with recent discoveries that biomechanical forces and electric currents can be translated into biochemical mediators such as prostaglandins and other growth factors.

The causative factors contributing to nonunion are many and complex. They include external, systemic and local factors.

External factors are those imposed by the injury and the subsequent management of the injured limb. Systemic factors include the internal environment in which the fracture must heal, including the metabolic, nutritional and calcium status of the patient. Local factors are those determinants at the fracture site, in the exudate, such as prostaglandins, interleukin and growth factors that are seemingly critical in determining the time taken for bone healing.

No accurate predictive index has been established to enable early determination of nonunion. All of the recognised causative factors seldom appear together. Sometimes the odds seem to be stacked in favour of nonunion, but it does not occur. Doubtless there are yet unknown factors. Hulth's (1989) suggestion of injecting healing promoting factors at the fracture site, in high risk cases, to promote exudate and thereby fracture healing, is an attractive option for the future. However, it remains an invasive procedure which thus carries the risk of infection, and may also result in unwanted side effects, which will remain obscure until clinical trials demonstrate its safety. 


\section{Chapter 3}

\section{METHODOLOGY}

\subsection{RESEARCH DESIGN}

This comparative experimental clinical trial, which was conducted on the double blind basis, set out to establish whether or not the use of interferential currents reduced the time taken for fractures of the tibia to heal and in fact prevented nonunion. Subjects entered into the clinical trial were randomly assigned to one of three groups:

i) Experimental group - subjects received interferential currents via suction electrodes.

ii) Placebo group - subjects had suction electrodes applied, without the interferential currents and

iii) Control group - subjects were entered as a check on the possible effect of suction and received no intervention.

\subsection{HYPOTHESES}

\subsubsection{Null Hypothesis (Ho)}

The use of interferential currents in the treatment of new fractures of the tibial shaft demonstrates no significant relationship with healing time.

\subsubsection{Alternative Hypothesis (Ha)}

Interferential currents significantly reduce the healing time from fracture to clinical and radiological union in new fractures of the tibial shaft. 
(Proposal: Appendix B)

(i) The title was changed from; "Stimulation of bone healing with interferential therapy in new fractures of the tibial shaft" to "Stimulation of bone healing in new fractures of the tibial shaft using Interferential currents".

(ii) Associate Professor W Shepherd-Wilson retired from the Department of Orthopaedics, which necessitated a change of supervisor. Dr R Marks accepted the position and later Associate Professor ML Thompson was also included as a supervisor.

(iii) During the first six months of the trial, subjects who had received the placebo (suction) commented on a feeling of relief. This may be explained by the intermittent suction producing a massage effect. The decision was thus made to strengthen the design by the addition of a control group, who would receive no intervention.

(iv) Only one female was entered in the first six months of the trial and it was thus decided to only include men in the study. As a result it is not possible to estimate the gender effect.

(v) Entry into the trial within 5 days of injury proved to be unrealistic. The major factor was the severity of soft tissue injury, resulting in the need to leave dressings undisturbed until split skin grafting had been judged successful. Other factors were inaccessibility of the subject in intensive care units and lack of cooperation from the patient due to head injury or delirium tremens.

(vi) Fifteen treatments per subject were reduced to 10 at the outset of the trial, owing to the need for beds in a tertiary care institution. Many subjects were discharged home, or to institutions providing care for chronic conditions, within the first three weeks post injury.

(vii) Segmental fractures were included, provided both fractures were within the shaft area of the tibia and not the metaphysis.

\subsection{STUDY SAMPLE}

A population may be defined as the total collection of individuals who are potentially available for observation and who have the attributes in common that a particular research hypothesis examines (Huysamen, 1989). 
The sample was drawn from available patients with fractures of the tibia, who were admitted to the orthopaedic wards of Groote Schuur Hospital during the trial period (January 1989 to October 1991), and were found to be suitable for the trial (Actual sample details achieved are detailed in Chapter 4, section 4.3). The population to which the results of this study are applicable is thus subject to the same constraints.

\subsubsection{Inclusion and exclusion criteria}

\section{a) Inclusion criteria}

Subjects were considered for inclusion into the trial, on admission into the orthopaedic wards, if they had sustained a fracture of the tibia or fractures of both tibiae. Those included were:

(i) Men only

(ii) Between 12 and 86 years of age.

b) Exclusion criteria

(i) Pathological fractures: the result of Pagets disease, bone cysts, malignancy etc.

(ii) The presence of the following associated medical factors: Diabetes mellitus, tuberculosis, deep vein thrombosis, compartment syndrome or a "pacemaker".

(iii) Fractures of the tibial metaphysis, which demonstrate a shorter healing time.

(iv) Subjects not resident in the Cape Town area, due to the likelihood of attrition from the trial.

(v) More than two manipulations within the first $2-3$ week period, in order to achieve acceptable reduction.

(vi) Type III B and C fractures, according to Gustilo's Classification (Chapter 2.2.6).

\subsubsection{Sampling method}

Patients matching the inclusion criteria and not exhibiting any of the exclusion criteria, were sequentially allocated by a previously constructed block randomisation table, for the experimental and placebo groups. This ensured equal numbers in each group. eg. 
TABLE 3.1 EXAMPLE OF A BLOCK RANDOMISATION TABLE

\begin{tabular}{cccccc}
\hline 1 & 2 & 3 & 4 & 5 & 6 \\
\hline $\exp$ & plac & exp & plac & exp & plac \\
$\exp$ & plac & plac & $\exp$ & plac & exp \\
plac & $\exp$ & $\exp$ & plac & plac & exp \\
plac & exp & plac & exp & exp & plac \\
& & & & & (Zelen 1974)
\end{tabular}

The control group consisted of all suitable patients who were admitted prior to, or during, vacations when the researcher was not available to apply treatment. This was considered to be random entry as there was no selection other than the in- and exclusion criteria.

\subsection{ETHICAL CONSIDERATIONS}

There is no evidence in the literature to suggest that interferential therapy is detrimental to the patient with fractures, metal implants or skin grafts. The only known contraindications to this modality are: pacemakers, deep vein thrombosis and any disseminating infection, eg. tuberculosis.

Since interferential therapy had not yet been established as a proven and effective method of treatment for healing fractures, there were insufficient grounds for belief that withholding treatment of the control and placebo groups would be detrimental.

\subsubsection{Verbal consent}

- Each patient was informed that he was the subject of a study which aimed to evaluate an electrical treatment and, if he so wished he was at liberty to decline or withdraw at any time. The assurance was given that personal information would be treated with scrupulous confidentiality. Verbal consent was attained. The subject was also informed that his attendance at the Outpatient department on a monthly basis, would be highly valued. 
- Verbal agreement was also obtained from the Head of Department of Orthopaedics at Groote Schuur Hospital

\subsubsection{Written consent}

Written consent was obtained from the:

- Medical Superintendant of Groote Schuur Hospital,

- Ethics and Research Committee, Medical School, UCT. (refer Appendix C)

\subsection{TRIAL PROCEDURE}

The researcher checked the orthopaedic ward list each weekday morning for new subjects with fractures of the tibia. The files were then consulted for exclusion criteria which, if present, resulted in exclusion from the trial. Subjects found to be suitable had their details recorded on the subject proforma (refer Appendix B). The post reduction radiograph was examined, lateral and antero-posterior view, in order to identify the fracture type and level. The method of application of interferential currents followed that of Ganne (1988), except for the use of suction electrodes, where Ganne preferred flat electrodes. All treatments were carried out by the researcher.

\subsubsection{Measurements using a metric tape measure}

The level of the fracture was measured on the antero-posterior radiograph, by taking the exact distance from the tip of the medial malleolus to the distal limit of the fracture, and again from the tip of the medial malleolus to the proximal fracture line. These measurements were recorded on the subject's proforma and then transferred to his plaster of Paris or dressings, depending on the type of immobilisation in use. Markings made with a pen indicated the level and extent of the fracture. 


\subsubsection{Positioning of electrodes}

Four suction electrodes were used, which necessitated the cutting of windows in the plaster of Paris (POP). This was performed by an orthopaedic technician after the researcher had drawn diagrams on the POP, using the following method:

(i) Longitudinally the electrodes were at least $2 \mathrm{~cm}$ proximal and distal to the span of the fracture.

(ii) Anteriorly the medial edges of the electrodes would just overlap the anterior borders of the tibia - the lateral edge of the electrode was approximately in line with the 4th toe.

(iii) Posteriorly the medial edges of the electrodes would overlap the medial border of the tibia.

(iv) Size of the windows was $6 \mathrm{~cm}^{2}$.

Once cut, the windows were carefully orientated for the positions into which they would be strapped, immediately after treatment. (Note that windows were not too large, nor over the fracture as this may have weakened the fixation and altered the reduction). Illustrated in Fig 3.1 .

\subsection{TREATMENT PROCEDURE}

The parameters required for an interferential treatment regime include: intensity, beat frequency, mode (constant or swing), duration and number of treatments.

\section{(i) Beat frequency and mode}

As described in Chapter 2, interferential therapy is thought to have specific effects at different beat frequencies. Nikolova (1969) used $100 \mathrm{~Hz}$ for delayed union, as did Ganne (1988) initially, but the latter subsequently changed to $20 \mathrm{~Hz}$ as recommended by Yasuda (1974). In the present study a swing of 10 to $25 \mathrm{~Hz}$ was used with the swing mode 656 , to incorporate the muscle contraction effect and at the same time, to reduce "accommodation", which is a likely result of a continuous beat frequency. 


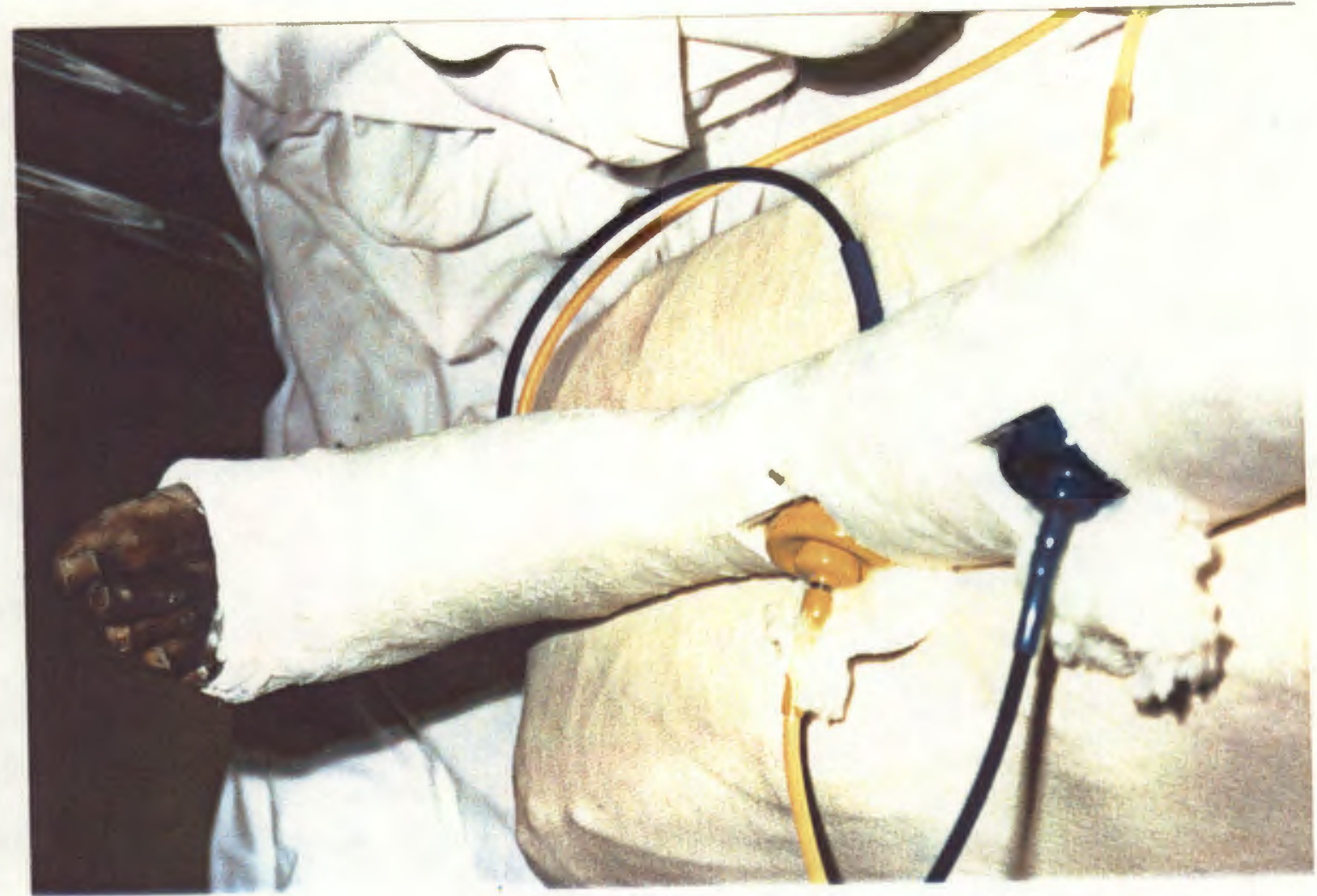

\section{Fig 3.1 Electrode positioning in windows of plaster cast}

The use of an exoskeleton as fixation of an open fracture allowed ready application of the electrodes, provided there was minimal bandaging, as seen in Fig 3.2. Where bandaging was extensive, and a POP backslab in situ as well, measurements similar to those for plaster were applied and the bandaging was cut to allow windows for treatment.

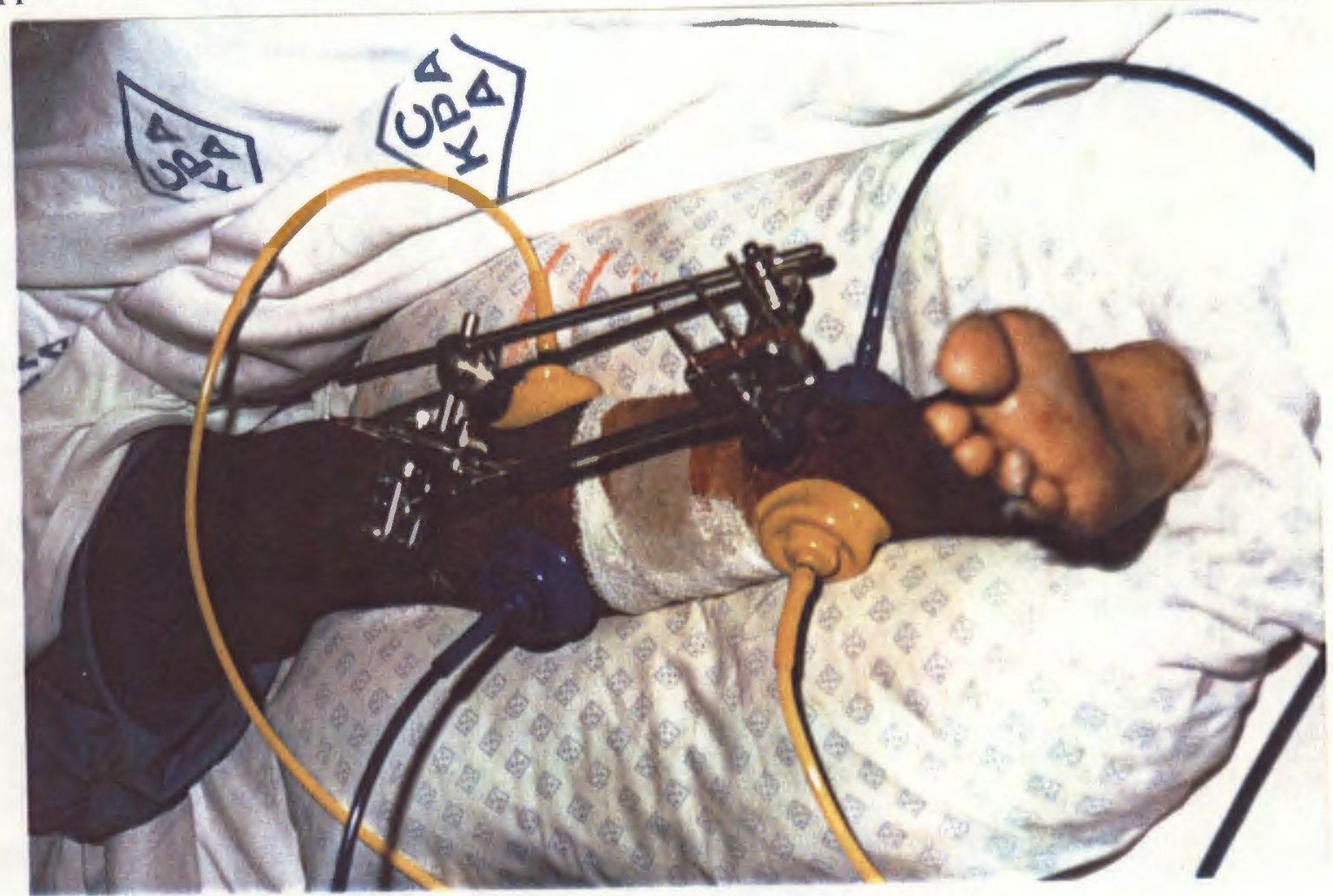

Fig 3.2 Electrode positioning with exoskeleton in-situ 


\section{(ii) Intensity}

The intensity was gauged by the subjective response of the patient, a comfortable contraction of the muscles and a definite awareness of vibraton across the fracture site. The safe upper limit is considered to be $50 \mathrm{~mA}$. However, $25 \mathrm{~mA}$ was the highest intensity used in the present trial.

\section{(iii) Duration and frequency of treatment}

Treatment was administered five days a week, for 30 minutes per session, until 10 treatments had been given. This is in accordance with Ganne's study (1988) as well as a personal communication with her concerning the number of treatments.

\subsubsection{Interferential application}

(i) Apparatus used:

- Two EMS (Electro Medical Supplies) interferential units. Portable model 52, Type BF. Channel A - $4.0 \mathrm{kHz}$ - blue suction electrodes Channel B - 4.10 to $4.25 \mathrm{kHz}$ - yellow suction electrodes 4 electrode application $100 \mathrm{~mA}$ rms. 60 volt peak max.

Swing pattern: $151 \quad 656 \quad 6 \wedge 6$

Digital display: time, frequency and intensity output

- Two EMS suction units

Type BF Class 1, portable

Select: continuous or intermittent suction

- Webcol, an alcohol preparation for cleaning of the suction cups between applications was used, to minimize the chance of cross infection.

- Sponge inserts for the suction cups were washed in warm soapy water and rinsed between each patient application.

(ii) Testing of equipment

- The machines had an internal circuit check which bleeped if there was any fault in the circuit or method of application. However, as an extra precaution each machine was tested daily by the researcher to ensure that the current was being delivered to the patient.

- At the conclusion of the trial both interferential machines were tested to ensure that the frequency modulation was in accordance with the specifications, initially checked by the 
supplier. Both pieces of equipment were found to be correct, refer to appendix D (Ganne, 1989 personal communication).

\subsubsection{Method of application of interferential currents (Experimental group).}

- The suction electrodes with damp sponge inserts were placed on a flat protected surface and the vacuum option turned to maximum and intermittent.

- The two blue suction cups were released simultaneously and applied to the prepared areas on the subject's limb. The yellow suction cups were then released in the same way and applied to the appropriate places on the limb. The intensity of the suction was reduced immediately to the most comfortable level for the patient.

- The timer was set for 30 minutes, the beat frequency and swing mode were selected and the intensity was slowly increased. Interaction with the patient was then necessary to judge when sufficient intensity was being delivered. At the conclusion of the treatment, both interferential and suction units were switched off, the electrodes were removed and the area of application was checked for the usual erythema.

- Thorough cleaning of the apparatus then took place in preparation for the next subject.

\subsubsection{Placebo group using suction electrodes.}

Utilising the same equipment as for the experimental application, the suction electrodes were applied and the interferential timer was switched on; the beat frequency selection was made, but no intensity switched on.

\subsubsection{Standard exercise regime}

The ward physiotherapist taught bed maintenance exercises, isometric contractions for muscles unable to function normally due to immobilisation, and crutch walking at the appropriate stages. 


\subsection{VARIABLES.}

\subsubsection{Independent variable:}

The application of interferential currents, delivered via suction electrodes, as treatment to the experimental group.

\subsubsection{Dependent variable:}

The duration in weeks from the initial fracture to clinical and radiological union.

\subsubsection{Extraneous variables:}

(i) Demographic variables:

- Age: Patients between the ages of 15 and 80 years.

- Race: All racial groups: Black, Coloured, Asian or White.

- Gender: Only men were entered.

(ii) Explanatory variables:

- Delay to entry: The number of days between fracture and entry into the trial.

- Firm: The Orthopaedic Surgery Department is divided into an A and a B firm, each of which consists of a Head of the firm, consultants, registrars and housemen. Assignment of the patient to the A or B firm depends on which firm is on duty when the patient is admitted to the trauma unit.

- Mechanism of injury: Direct trauma is recognised as causing a more severe injury than indirect trauma.

- Side of injury: Left side, right side, or both tibiae in the same patient (bilateral) may be fractured.

- Type of fracture: Refers to the pattern of the break, eg. transverse, spiral, oblique or comminuted.

- Closed or compound: The extent to which the soft tissue and particularly the skin is damaged. 
- Level of fracture: The tibia is arbitrarily divided into upper, middle and lower thirds.

- Presence of a fibular fracture: In some instances, where a fractured fibula is not present, it is thought to delay healing of the tibia (Heppenstall 1984).

- Degree of displacement: refers to the extent to which the distal fracture fragment is moved in relation to the proximal fracture fragment, at the time of injury. Displacement was measured as a fraction of the whole, on the initial radiographs.

- Immobilisation: After reduction of the fracture, the fragments are immobilised to allow healing to take place. This is achieved with plaster of Paris (POP), an exoskeleton (Exo) or open reduction and internal fixation (ORIF)

- Associated injuries: The severity of the trauma may result in fractures of other areas of the body. This variable considers in which area another fracture has occurred and if multiple areas are involved.

- Associated medical conditions: Medical conditions, such as epilepsy or cardiac disease, which may have an effect on bone healing, were noted. The presence of diabetis mellitus, tuberculosis or any disseminating infection, resulted in exclusion from the trial.

- Alcohol abuse: Malnutrition due to dietary deficiency and, more likely to malabsorption of vitamins, especially water-soluble vitamins, contributes to the clinical abnormalities of cirrhosis, gastritis and pancreatitis (Katzung 1989). This may have an effect on bone healing.

- Crutch walking: In an attempt to measure the rate of weight bearing the time in weeks from injury to the subject's walking with crutches was measured.

- Clinical union: This is a subjective measure in weeks from the date of injury until the surgeon recognises that clinical union has taken place.

- Radiological union: This is also a subjective measure in weeks from the date of injury until the radiologist recognises that radiological union has taken place.

- Discharge: The date of discharge from GSH was not always recorded, the subject often being referred to another hospital, from which the date of discharge was unknown. The value of this variable was thus reduced and omitted.

- Average time taken to union: Average of radiological and clinical union time in weeks. 


\subsection{DATA COLLECTION}

Subject proforma were kept by the researcher, with all relevant documentation completed, until the last year of the trial, when the subject files were scrutinised in batches of ten, at regular intervals to ascertain the dates for clinical union and crutch walking. A single radiologist reported on the dates of radiological union for the experimental $(n=41)$, placebo $(n=35)$ and original control $(n=32)$ groups, by evaluating each subject's series of radiographs. The criteria for both clinical and radiological union were to be satisfied for a fracture to be judged united.

\subsubsection{Clinical union - the measure}

Clinical union is a subjective measure, carried out by the doctor on duty at the outpatient clinic at GSH. The criteria that are taught (Marks, 1990) are that:

- The part moves as one, ie. there is no perceived movement at the fracture site, on valgus or varus stress performed by the doctor.

- There is no, or minimal, pain experienced by the subject, when the fracture site is stressed.

- There is minimal tenderness on palpation over the fracture site, where a "hump" of callus is palpable.

No inter- or intra-observer reliability tests were performed, to assess consistency in this judgement. (Refer to limitations in Chapter 3, section 3.12.1.ii)

\subsubsection{Radiological union - the measure}

Union is a gradual process, which is judged radiologically by the identification of periosteal callus as an area of faint increase in density in the soft tissues on either side of the fracture line. In lower extremity fractures, more solid and mature callus, with the outer margins sharp and continuous across the fracture site, is necessary before the extremity can be judged to be united. The fracture fragments should have remained constant on serial films, but the fracture line itself may still be visible. 
Once the trabecular pattern across the fracture line becomes continuous, remodelling has taken place (Rockwood and Green 1984, Weissman and Sledge 1986).

\section{- Inter and Intra-observer reliability of radiographs}

A radiologist assessed 108 of the 227 cases in order to validate the subject records, which had been documented by many different doctors. The result demonstrated a strong correlation. The radiographs for each subject were taken at monthly intervals. The radiologist reassessed 46 of 108 cases, of which 43 were consistent with the initial report, giving a $94 \%$ reliability, which is considered to be within acceptable limits.

\subsection{SAMPLE DETAILS}

During the trial period 258 cases were entered into the trial, strict adherence to inclusion and exclusion criteria being followed.

227 cases (208 subjects) were analysed at the conclusion of the trial period. Exclusion of the remaining 31 cases took place for the following reasons:

- Attrition - 17 cases did not attend the outpatient clinic regularly until clinical and radiological union were evident.

- Osteitis/sepsis - 6 cases developed sepsis of soft tissue or bone during the period of the trial.

- Internal fixation - 3 cases required internal fixation in the form of interlocking intramedullary nails, within weeks of entry into the trial.

- Deceased - 1 case died due to a nasopharyngeal carcinoma, which extended into the cerebrum.

- Tuberculosis - 1 case was found to have pulmonary TB after inclusion into the trial. 
3.11.2 The assessment of clinical union was assumed to be a consistent measure between patients, despite the fact that there were many doctors making this subjective decision. Testing of inter-observer reliability was impracticable, given the nature and time contraints of this clinical trial.

3.11.3 The study assumes that one can interpret observed differences between the dependent variable scores of the three groups as being due to the manipulation of the treatment regime (independent variable), rather than to some unknown confounding variables, which are potentially present in any clinical trial. This assumption is made on the basis of the internal validity of the experimental design.

3.11.4 It was assumed that, from the nature of the interferential currents and suction apparatus utilised for the trial, the researcher applying the treatment was aware of whether the application was a placebo or not. However, neither the assessing researcher nor the subject was aware of the treatment received. The trial was thus effectively double-blind (Bland 1987).

\subsection{LIMITATIONS}

\subsubsection{Study design}

(i) The research design required that the sample be drawn from an experimentally accessible population. It therefore follows that the findings of the research are applicable to that restricted population only. Thus, while it is likely that inferences drawn may be applicable to the general population, it is necessary that care be taken to prevent over-generalisation of findings i.e. external validity is limited.

(ii) The study attempted to assess as a single event that which is a process over time i.e. union. It is possible that the findings may express variability in the measurements rather than changes in the attributes being measured. In order to reduce this type of variation, 
drawn may be applicable to the general population, it is necessary that care be taken to prevent over-generalisation of findings i.e. external validity is limited.

(ii) The study attempted to assess as a single event that which is a process over time i.e. union. It is possible that the findings may express variability in the measurements rather than changes in the attributes being measured. In order to reduce this type of variation, clearly defined standardised procedures were encouraged throughout the trial. However, the judgement of clinical union was accepted without intra- or inter-observer reliability testing, which must be seen as a limitation.

(iii) The dependent variables of radiological and clinical union were recorded at monthly intervals after a series of treatments. It was not possible to control all events occurring between these occasions. As far as possible the design of the trial was such that any events that may have influenced the outcome of the trial were controlled or were taken into consideration in the final analysis. Unfortunately, the time period that the subject stayed in hospital may be one of the factors which owing to insufficient record keeping, was not taken into account and must therefore be regarded as a limitation of this study.

(iv) The trial was concerned with the effects of interferential therapy on bone healing only. No functional return of movement or muscle strength was measured owing to the time constraints placed on the researcher in terms of attending the outpatient clinic. This must be considered a limitation of this study.

\subsubsection{Treatment limitations}

(i) The study required that interferential currents be applied once a day. However, on some occasions it was necessary to apply the treatment twice a day, due to the immense pressure on beds in a "high care institution". The application was then made first in the morning and latest in the afternoon and never for more than 4 of the 10 treatments. 


\subsubsection{Subject limitations}

It was not possible to standardise the amount of activity performed during the trial, or the amount of weight bearing once the patient was allowed up on crutches. However, as emphasized throughout Chapter 3, every effort was made to ensure that practical standardised procedures were employed.

\subsubsection{Equipment limitations}

(i) The interferential machines utilised for the study were new at the commencement of the trial and had been calibrated by the manufacturer. They were not tested during the trial period, but at the end an independent test was done to confirm interference frequency modulation.

(ii) The interferential apparatus used had no "vector scanning" option, which may have limited the extent of the electrical field in the tissues.

\subsubsection{Limitations of the statistical analysis}

The power of a statistical test may be defined as the probability of rejecting the null hypothesis when the null hypothesis is false. Of the factors affecting the power of the statistical test, only the significance level and the sample size are under the direct control of the researchers (Huysamen 1989).

The sample size utilised was based on the number of subjects suitable for the trial in a limited time period. It was therefore not possible to increase the level of power of the statistical analysis by increasing the number of subjects. 


\subsection{STATISTICAL PACKAGE AND ANALYSIS}

The STATGRAPHICS programme on the author's personal computer was used to analyse the data.

For the present study the term "significance" is used to denote results associated with a pvalue of $<0.05$.

\subsubsection{Collapse of variable categories:}

Initial exploratory analyses resulted in collapsing some of the levels of the extraneous variables, where there were no significant differences in outcome over the levels. This resulted in the following categorizations:

- $\quad$ Race - i) Black and ii) Asian, coloured and white.

- Mechanism of injury - i) MVA (driver, passenger, pedestrian struck by a motor vehicle and motorbike rider) and ii) Bicycle rider, gunshot, pushed from a train, sports injury, industrial accident, fall and assault.

- Fracture type/pattern - i) Spiral or oblique and ii) transverse or comminuted

- Compound - i) Closed, type I or type II and ii) type IIIA

- Degree of displacement - i) none or minimal and ii) half diameter or full diameter

- Associated injury - i) none or a single other fracture of any body part and ii) multiple fractures.

\subsubsection{Statistical analysis}

a) The appropriate tool of statistical methodology for assessing the effect of treatment on time to union, in the presence of covariates, is analysis of covariance (ie. ANOVA with continuous covariates), which requires the residuals from the model to be normally distributed. 


\subsubsection{Statistical analysis}

a) The appropriate tool of statistical methodology for assessing the effect of treatment on time to union, in the presence of covariates, is analysis of covariance (ie. ANOVA with continuous covariates), which requires the residuals from the model to be normally distributed.

As part of this procedure, it was necessary to transform the dependent variable (average time to union) to achieve normality. Through a process of trial and error the "inverse square root" transformation was found to be appropriate in this case.

b) The availability of the above data set also lent itself to a logistic regression analysis, with the objective of establishing whether it is possible to predict nonunion of a fractured tibia within 24,32 or 40 weeks, based on the information that can be collected about the subject and his fracture on entry into hospital.

The sample consisted of 208 of the 227 cases. Only one record was used for each individual, so that if a subject had bilateral fractures, only the record for one of the (randomly chosen) legs was used. This was because there was clear correlation between the fracture healing times of the same individual (they were frequently identical) which would be problematic in the statistical analysis. These data were then randomly subdivided into an estimation sample $(n=118)$ and a validation sample $(n=90)$.

The estimation sample was used to provide estimates of the parameters in a logistic regression model to predict the probability of nonunion and the validation sample was used to assess the sensitivity and specificity of the fitted model in predicting nonunion on an independent data set.

The logistic regression model considered at, for example 24 weeks, was as follows: $P$ (no union within 24 weeks, given $\left.x_{1}, x_{2}, \ldots . x_{k}\right)=\exp \left(\beta_{0}+\beta_{1} x_{2}+\ldots+\beta_{k} x_{k}\right.$ ) / $\left[1+\exp \left(\beta_{0}+\beta_{1} x_{1}+\beta_{2} x_{2}+\ldots+\beta_{k} x_{k}\right)\right]$

where $x_{1}, x_{2} \ldots x_{k}$ are predictor variables such as race, age, time until crutch walking etc. 
Using the estimation sample, for each of three cutoffs 24,32 and 40 weeks, the best-fitting subset of the predictor variables was chosen so as to minimise the Akaike Information Criterion (Akaike 1973). Associate Professor ML Thompson used the SAS procedure PROC LOGISTIC, for these analyses (SAS/STAT User's Guide V.6). In each case the particular fitted model was then applied to the validation sample to assess how well it could predict nonunion. 


\section{Chapter 4}

\section{RESULTS}

A statistical analysis, properly conducted, is a delicate dissection of uncertainties, a surgery of suppositions. The surgeon must guard carefully against false incisions with his scalpel. Very often he has to sew up the patient as inoperable. The public knows too little about the statistician as a conscientious and skilled servant of true science....... We shall try to see the scientist with no axe to grind other than the axe of truth and no product to advertise save the product of honest and careful enquiry. (Moroney 1970)

\subsection{INTRODUCTION}

This chapter deals with data presentation and analysis, which is divided into six sections dealing with:

- The use of average time to union rather than clinical union and radiological union.

- Descriptions of univariate data (Summary statistics),

- Bivariate analysis

- Multivariate analysis

- Diagnostics which confirm the assumption of normality and the use of average union as representing radiological and clinical union.

- A logistic regression analysis modelling the probability of nonunion and using the same data is also presented in order to assess the possibility of early screening for ultimate union status (eg. to flag individuals for alternative treatment such as application of interferential currents or invasive therapy ie. internal fixation). 


\subsection{AVERAGE TIME TO UNION IN WEEKS}

The dependent variable in this study consists of two measurements, ie. clinical and radiological union. Fig 4.1 shows a plot of radiological versus clinical union: There is visual evidence of a strong positive relationship with unit slope between these two variables, which together with a Spearman Rank Correlation value of $0.8911(p<0.00005)$ indicates a satisfactory agreement between the assessment of radiological and clinical union. It was thus felt to be appropriate to use 'average time until union in weeks' as the single dependent variable, rather than time until radiological and clinical union.

\subsection{DESCRIPTIONS OF UNIVARIATE DATA}

\section{TABLE 4.1(a) SUMMARY STATISTICS}

\begin{tabular}{||l|c|c|c||}
\hline \multicolumn{4}{|c|}{ Comparison of the mean time taken to union for each group } \\
\hline & EXPERIMENT & PLACEBO & CONTROL \\
\hline Sample size & 41 & 35 & 151 \\
\hline & $\frac{\text { Med.(Range) }}{\text { weeks }}$ & $\frac{\text { Med.(Range) }}{\text { weeks }}$ & $\frac{\text { Med.(Range) }}{\text { weeks }}$ \\
\hline Radiological union & $19(6.7-51)$ & $21(12.6-54)$ & $21.5(7-102)$ \\
\hline Clinical union & $18(7.6-51)$ & $21(12-56)$ & $22(7-102)$ \\
\hline Average union & $19(7.6-51)$ & $21(12.6-55)$ & $21(7-102)$ \\
\hline
\end{tabular}

Average union in weeks was calculated as the mean of radiological and clinical union, for each entry. Table 4.1(a) indicates a very slight difference in the median no of weeks (one week) for the different measures of time to union within the experimental and control groups, with no variation at all within the placebo group. 
Fig 4.1 RaDiolosical WhiON vs CLINICA

LHIOH

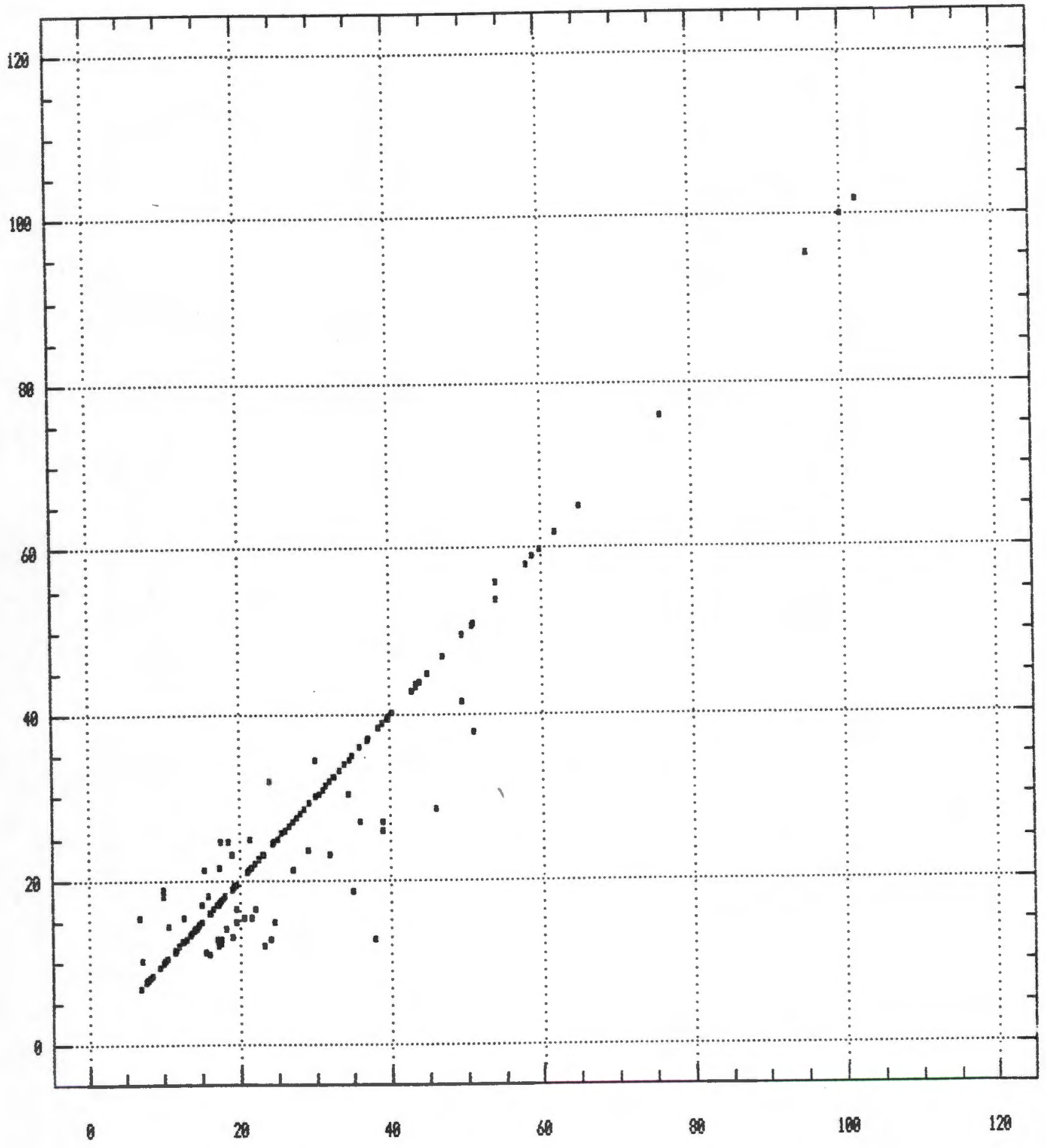

Radiological union in wetks 
The very slight improvement (approximately 2 weeks) for the dependent variable in the Experimental group (Table 4.1.(a)) might possibly have been associated with other important clinical factors such as the potentially confounding variables listed in Table 4.1(b) and Table 4.1(c)

TABLE 4.1(b) SUMMARY STATISTICS

\begin{tabular}{||l|c|c|c||}
\hline \multicolumn{4}{|c|}{ Demonstrating extraneous, continuous variables for each group } \\
\hline & EXPERIMENT & PLACEBO & CONTROL \\
\hline & Med (Range) & Med (Range) & Med (Range) \\
\hline Age in years & $35(13-57)$ & $31(14-67)$ & $35(12-86)$ \\
\hline $\begin{array}{l}\text { Delay from day of injury } \\
\text { to day of entry into trial }\end{array}$ & $6(2-13)$ & $5(1-16)$ & $5(5-5)$ \\
\hline $\begin{array}{l}\text { Injury to crutch walking } \\
\text { in weeks }\end{array}$ & $6(0-17.8)$ & $5(0-20.1)$ & $2(0-17.5)$ \\
\hline
\end{tabular}

TABLE 4.1(c) SUMMARY STATISTICS

\begin{tabular}{|c|c|c|c|c|}
\hline \multicolumn{5}{|c|}{ Demonstrating extraneous categorical variables } \\
\hline & & & PERCENT & \\
\hline & $\begin{array}{c}\text { ROW } \\
\text { TOTAL }\end{array}$ & \begin{tabular}{|c|} 
EXPERIM. \\
$\mathrm{N}=41$ \\
\end{tabular} & \begin{tabular}{|c|} 
PLACEBO \\
$\mathrm{N}=35$ \\
\end{tabular} & $\begin{array}{c}\text { CONTROL } \\
\mathrm{N}=151\end{array}$ \\
\hline $\begin{array}{l}\text { Race } \\
0=\text { Asian, White, Coloured } \\
1=\text { Black }\end{array}$ & $\begin{array}{r}138 \\
89 \\
\end{array}$ & $\begin{array}{l}41.5 \\
58.5 \\
\end{array}$ & $\begin{array}{l}42.9 \\
57.1 \\
\end{array}$ & $\begin{array}{l}70.2 \\
29.8 \\
\end{array}$ \\
\hline $\begin{array}{l}\text { Firm } \\
0=A \\
1=B\end{array}$ & $\begin{array}{r}166 \\
61\end{array}$ & $\begin{array}{l}56.1 \\
43.9 \\
\end{array}$ & $\begin{array}{l}60.0 \\
40.0\end{array}$ & $\begin{array}{l}80.8 \\
19.2 \\
\end{array}$ \\
\hline $\begin{array}{l}\text { Mechanism of injury } \\
1=\text { MVA (Motor vehicle accident) } \\
2=\text { Other }\end{array}$ & $\begin{array}{r}162 \\
65 \\
\end{array}$ & $\begin{array}{l}82.9 \\
17.1 \\
\end{array}$ & $\begin{array}{l}80.0 \\
20.0\end{array}$ & $\begin{array}{l}66.2 \\
33.8 \\
\end{array}$ \\
\hline $\begin{array}{l}\text { Side } \\
1=\text { right } \\
2=\text { left } \\
3=\text { bilateral }\end{array}$ & $\begin{array}{r}105 \\
80 \\
42 \\
\end{array}$ & $\begin{array}{l}36.6 \\
31.7 \\
31.7\end{array}$ & $\begin{array}{l}37.1 \\
40.0 \\
22.9\end{array}$ & $\begin{array}{l}51.0 \\
35.1 \\
13.9 \\
\end{array}$ \\
\hline $\begin{array}{l}\text { Type } \\
0=\text { Spiral and oblique } \\
1=\text { Transverse and comminuted }\end{array}$ & $\begin{array}{r}77 \\
150 \\
\end{array}$ & $\begin{array}{l}31.7 \\
68.3\end{array}$ & $\begin{array}{l}45.7 \\
54.3\end{array}$ & $\begin{array}{l}31.8 \\
68.2\end{array}$ \\
\hline
\end{tabular}




\begin{tabular}{|c|c|c|c|c|}
\hline \multicolumn{5}{|c|}{ Demonstrating extraneous categorical variables } \\
\hline & & \multicolumn{3}{|c|}{ PERCENT } \\
\hline & $\begin{array}{c}\text { ROW } \\
\text { TOTAL } \\
\end{array}$ & $\begin{array}{c}\begin{array}{c}\text { EXPERIM. } \\
N=41\end{array} \\
\end{array}$ & $\begin{array}{c}\text { PLACEBO } \\
\mathbf{N}=35\end{array}$ & $\begin{array}{c}\text { CONTROL } \\
\mathrm{N}=151\end{array}$ \\
\hline $\begin{array}{l}\text { Compound } \\
0=\text { Closed, and Type I \& II } \\
1=\text { Type IIIA }\end{array}$ & $\begin{array}{r}194 \\
33 \\
\end{array}$ & $\begin{array}{l}80.5 \\
19.5 \\
\end{array}$ & $\begin{array}{l}77.1 \\
22.9 \\
\end{array}$ & $\begin{array}{l}88.7 \\
11.3 \\
\end{array}$ \\
\hline $\begin{array}{l}\text { Level } \\
1=\text { Proximal third } \\
2=\text { Middle third } \\
3=\text { Distal third }\end{array}$ & $\begin{array}{l}46 \\
96 \\
85\end{array}$ & $\begin{array}{l}19.5 \\
61.0 \\
19.5 \\
\end{array}$ & $\begin{array}{r}8.6 \\
42.9 \\
48.6 \\
\end{array}$ & $\begin{array}{l}23.2 \\
37.1 \\
39.7 \\
\end{array}$ \\
\hline $\begin{array}{l}\text { Fibula } \\
0=\text { No fracture } \\
1=\text { Fracture present }\end{array}$ & $\begin{array}{r}42 \\
185 \\
\end{array}$ & $\begin{array}{l}22.0 \\
78.0 \\
\end{array}$ & $\begin{array}{r}0.0 \\
100.0 \\
\end{array}$ & $\begin{array}{l}21.9 \\
78.1 \\
\end{array}$ \\
\hline $\begin{array}{l}\text { Displacement } \\
0=\text { None } \\
1=\text { Minimal } \\
2=\text { Half \& full diameter }\end{array}$ & $\begin{array}{r}15 \\
69 \\
143 \\
\end{array}$ & $\begin{array}{r}7.3 \\
36.6 \\
56.1 \\
\end{array}$ & $\begin{array}{r}2.9 \\
25.7 \\
71.4 \\
\end{array}$ & $\begin{array}{r}7.3 \\
29.8 \\
62.9 \\
\end{array}$ \\
\hline $\begin{array}{l}\text { Immobilisation } \\
1=\text { POP } \\
2=\text { Exoskeleton } \\
3=\text { ORIF } \\
\quad \text { (Open reduction internal } \\
\quad \text { fixation) } \\
\end{array}$ & $\begin{array}{r}67 \\
151 \\
9\end{array}$ & $\begin{array}{r}26.8 \\
73.2 \\
0.0\end{array}$ & $\begin{array}{r}11.4 \\
88.6 \\
0.0\end{array}$ & $\begin{array}{r}34.4 \\
59.6 \\
6.0\end{array}$ \\
\hline $\begin{array}{l}\text { Associated injury } \\
0=\text { None, single \# elsewhere } \\
1=\text { Multiple trauma }\end{array}$ & $\begin{array}{r}203 \\
24 \\
\end{array}$ & $\begin{array}{l}80.5 \\
19.5 \\
\end{array}$ & $\begin{array}{l}88.6 \\
11.4 \\
\end{array}$ & $\begin{array}{r}92.1 \\
7.9 \\
\end{array}$ \\
\hline $\begin{array}{l}\text { Associated medical condition } \\
0=\text { None } \\
1=\text { Epilepsy }\end{array}$ & $\begin{array}{r}215 \\
12 \\
\end{array}$ & $\begin{array}{r}92.7 \\
7.3 \\
\end{array}$ & $\begin{array}{r}91.4 \\
8.6 \\
\end{array}$ & $\begin{array}{r}96.0 \\
4.0 \\
\end{array}$ \\
\hline $\begin{array}{l}\text { Alcohol abuse } \\
0=\text { None known } \\
1=\text { Inebriated at time of injury } \\
2=\text { Delirium tremens }\end{array}$ & $\begin{array}{r}126 \\
90 \\
11\end{array}$ & $\begin{array}{c}41.5 \\
53,7 \\
4.9\end{array}$ & $\begin{array}{r}54.3 \\
42.9 \\
2.9\end{array}$ & $\begin{array}{r}59.6 \\
35.1 \\
5.3\end{array}$ \\
\hline
\end{tabular}

Table 4.1 (b) and (c): In the random allocation of individual patients to the experimental, placebo or control groups, it transpired that few of these categorical extraneous variables were advantageously associated with the experimental group, and such minor apparently nonsignificant differences as did occur seemed to favour the placebo and control groups, in the sense that, for instance, crutch walking took place earlier in the placebo and control groups. The experimental group demonstrated higher percentages in alcohol abuse; inebriated at the time of injury, where the control group showed a higher percentage in the delirium tremens category. 
Fig 4.2 THE EFECT of: groups vs

HEAING

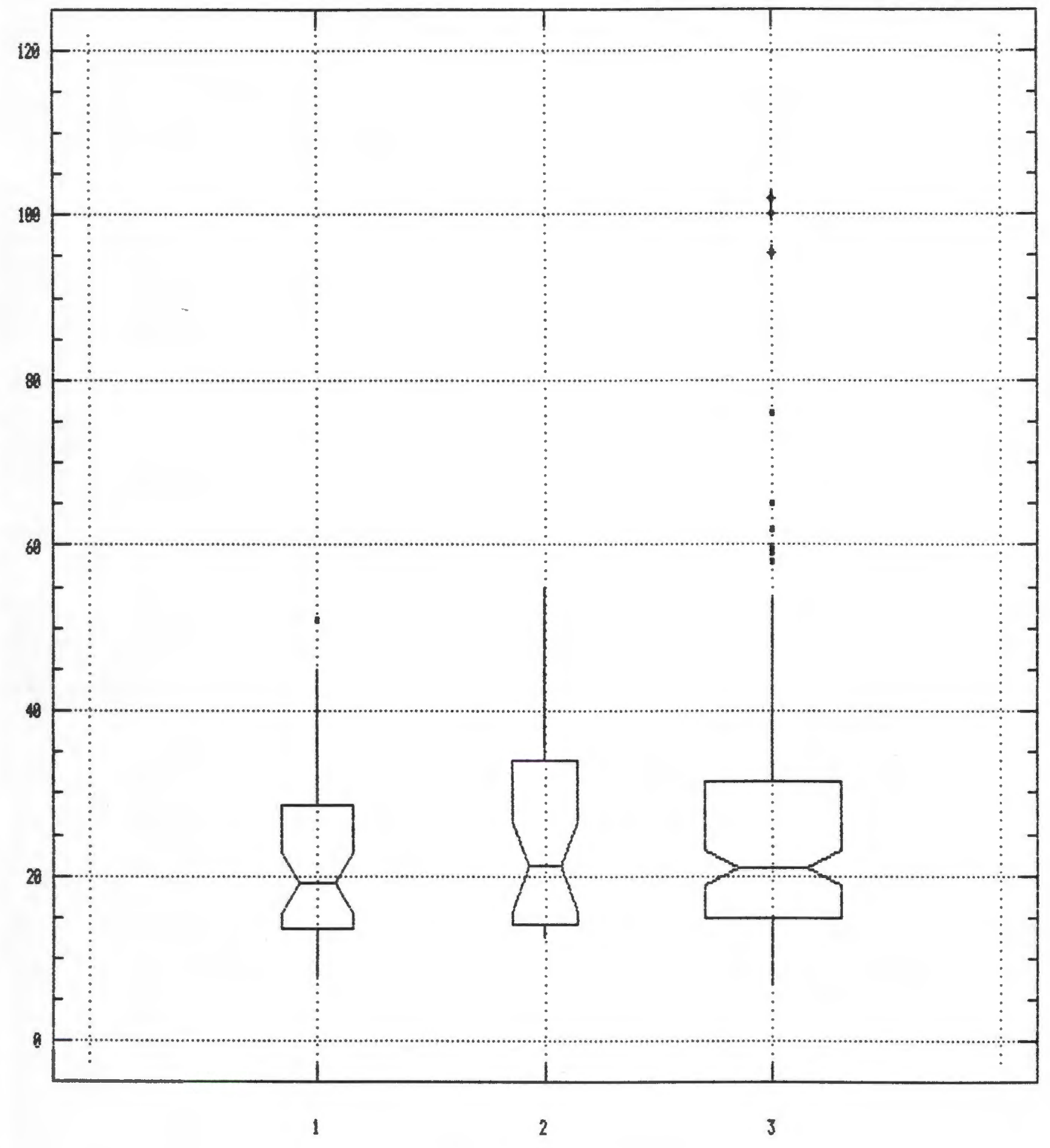

Grous: $1=$ Experiwent $2=P$ laceto $3=C$ Control

A notch in the "notched box and whisker plot" is added to each box at the median. The length of the notch represents an approximate $95 \%$ confidence interval for the median. The width of the box is proportional to the square root of the number of observations in the group. (Statgraphics Version 5 1991) 
The "notched box and whisker plot" in Fig 4.2 demonstrates that healing time following treatment with interferential currents is shorter, but not substantially so. There is considerable overlap in the healing times of the 3 groups. There is also a positive "skewed" nature to the healing time.

\subsection{BIVARIATE ANALYSIS}

Demonstrated in Figs. 4.3 to 4.5 as well as Table 4.2 and 4.3

Fig 4.3 Shows a plot of age versus time to union: This scatter plot demonstrates no visual evidence of a relationship between healing time and age in this population sample.

The effect of delay of entry into the trial versus time to healing is shown in Fig 4.4. The control group were arbitrarily entered into the trial on day 5 ; this demonstrates an artificially strong line - which nevertheless has little effect on the lack of visual evidence of a relationship between these two variables.

Fig 4.5 A plot of time until crutch walking versus time until union. There is no visual evidence of a relationship, taking into account these two variables on their own. 
Fig 4.3 THE EFEET OF: AGE vS HERING

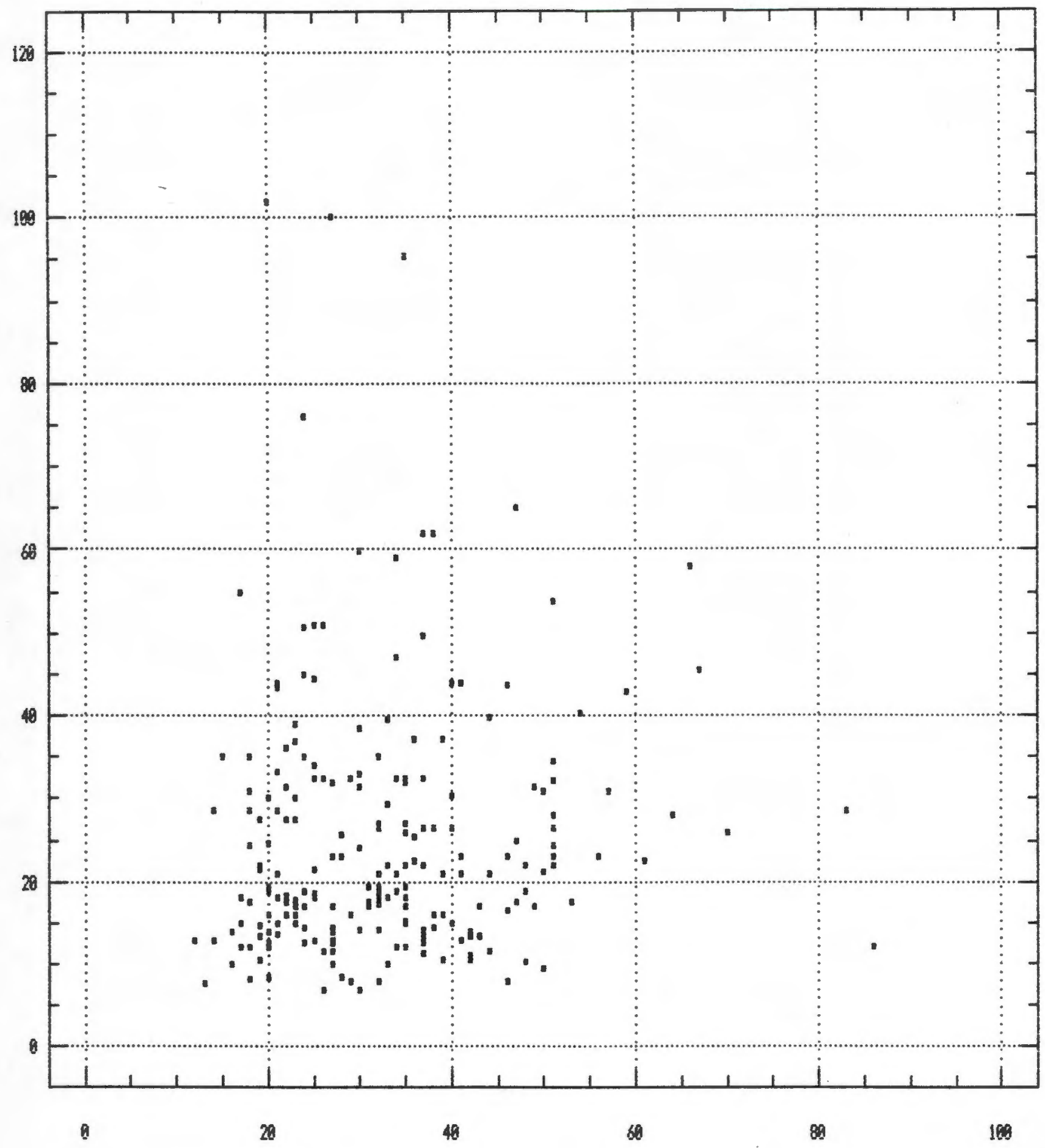

Age in years 
Fig 4.4 THE EFECT OF: DElAY of EITRY

IMTO THE TRIAL YS FELIMG

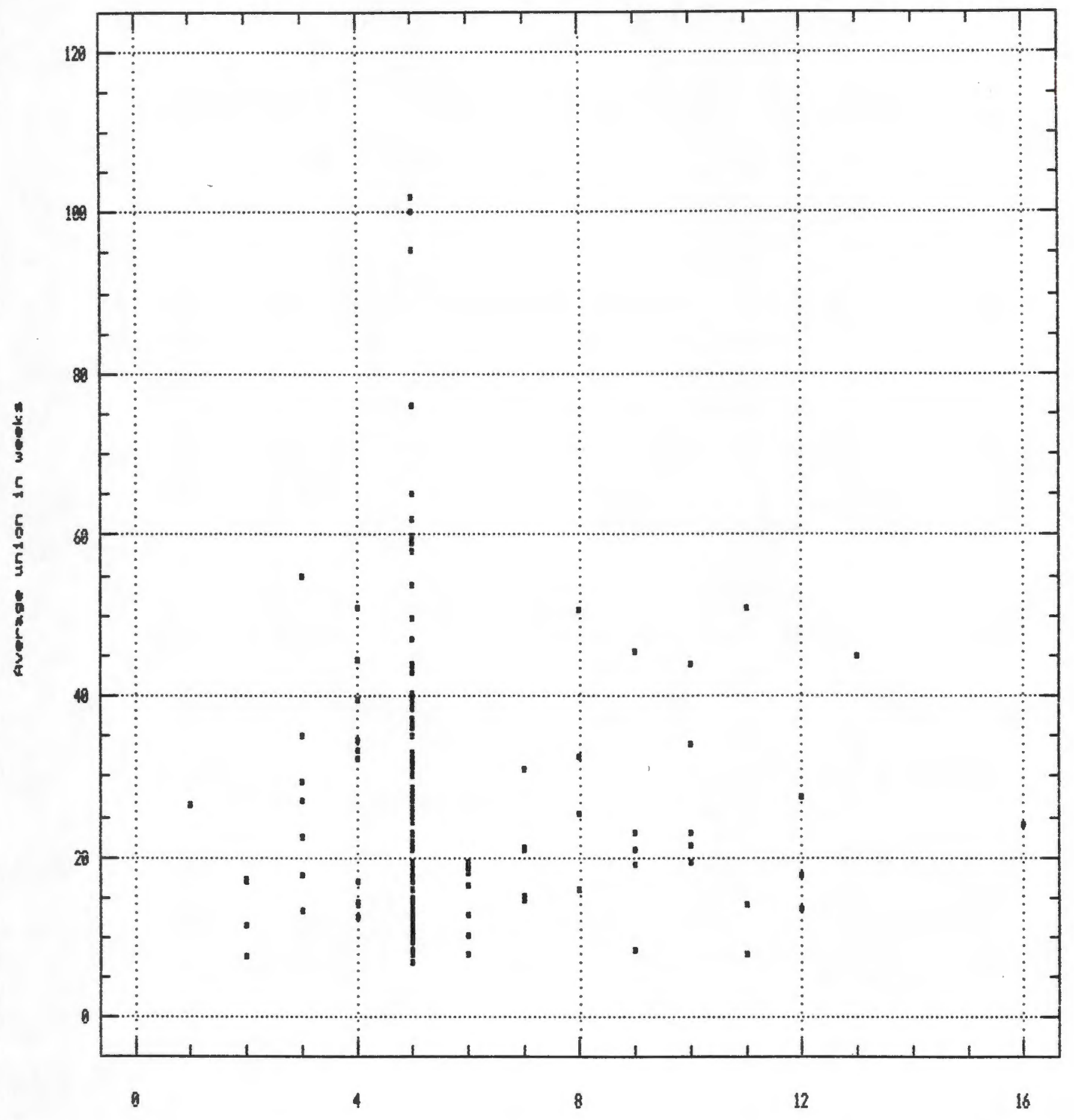

Delay of entry into the trial in days 
Fig 4.5 IFE EFECT OF: COUTCH MAKING

V FEAIMG

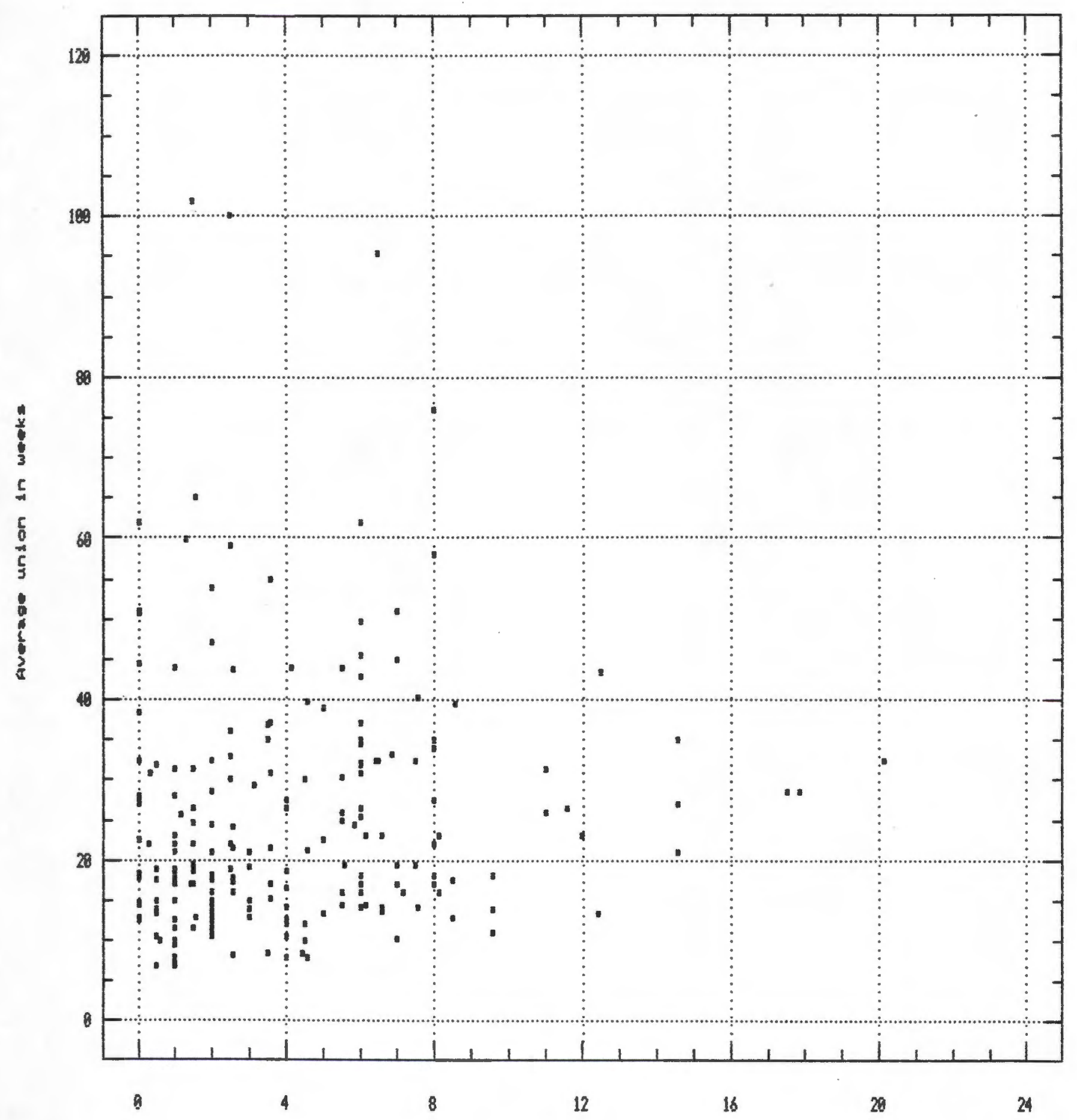

Day of injury to crutch walking in weeks 
TABLE 4.2 ONE WAY ANOVA

\begin{tabular}{||l|c|c||}
\hline \multicolumn{3}{|c|}{ Inverse square root of average time until union vs: } \\
\hline VARIABLES & F-RATIO & p-VALUE \\
\hline Race & 3.550 & 0.0608 \\
\hline Firm & 0.954 & 0.3403 \\
\hline Mechanism of injury & 17.329 & $0.0000^{*}$ \\
\hline Side (L), (R) or both & 0.659 & 0.5185 \\
\hline Type of fracture & 5.981 & $0.0152^{*}$ \\
\hline Compound & 3.527 & 0.0617 \\
\hline Level of fracture & 0.379 & 0.6853 \\
\hline Presence of \# fibula & 5.012 & $0.0262^{*}$ \\
\hline Displacement & 15.736 & $0.0000^{*}$ \\
\hline Immobilisation method & 2.400 & 0.0931 \\
\hline Associated injuries & 5.352 & $0.0216^{*}$ \\
\hline Medical condition & 2.136 & 0.1453 \\
\hline Alcohol abuse & 2.144 & 0.1196 \\
\hline Groups (Experiment, placebo, Control) & 1.365 & 0.2574 \\
\hline \hline
\end{tabular}

Table 4.2 Summary results of a one way ANOVA relating the transformed average time until union, with each of the categorical extraneous variables separately, as well as the independent variable. The variables demonstrating a significant* relationship with healing time are: mechanism of injury, type of fracture, the presence of a fractured fibula, degree of displacement of a fracture and associated injuries. However, there is no significant difference in the treatment variable and on a closer look into the mean levels of the three groups in Table 4.3 there is also no evidence of a significant difference.

Thus, on the bivariate level, there is no evidence of significant association between treatment and outcome. 
TABLE 4.3 : ONE WAY ANALYSIS OF VARIANCE

\begin{tabular}{||l|c|c|c||}
\hline \multicolumn{4}{|c||}{ Comparison of healing times according to the 3 groups } \\
\hline LEVEL & COUNT & $\begin{array}{c}\text { EST. MEAN } \\
\text { TRANSFORMED } \\
\text { UNITS }\end{array}$ & $\begin{array}{c}\text { EST. MEDIAN } \\
\text { (WEEKS) }\end{array}$ \\
\hline 1 = experimental & 41 & 0.2353 & 18.1 \\
\hline 2 = placebo & 35 & 0.2155 & 21.5 \\
\hline 3 = control & 151 & 0.2207 & 20.5 \\
\hline
\end{tabular}

\subsection{MULTIVARIATE ANOVA}

Demonstrated in Tables 4.4 to 4.10 and Fig 4.6

The value of multivariate analysis is that it allows estimation of the effect of a variable, adjusted for the impact of other variables.

TABLE 4.4 : ANALYSIS OF COVARIANCE

\begin{tabular}{|c|c|c|}
\hline \multicolumn{3}{|c|}{ Demonstrating the transformed average union versus } \\
\hline COVARIATE & F-RATIO & P-VALUE \\
\hline Age in years & 7.336 & 0.0073 \\
\hline Race & 4.882 & 0.0282 \\
\hline Mechanism of injury & 4.800 & 0.0295 \\
\hline Type of fracture & 6.046 & 0.0147 \\
\hline Degree of displacement & 15.130 & 0.0000 \\
\hline Associated injury & 10.413 & 0.0014 \\
\hline Groups & 2.050 & 0.1312 \\
\hline
\end{tabular}


Table 4.4 summarises the analysis of covariance model relating (transformed) average time until union to treatment and those extraneous variables which (in the joint model) were found to be significant (i.e. associated with $\mathrm{p}<0.05$ ).

Tables 4.5 to 4.10 show multiple range analyses, demonstrating the mean levels of transformed average union for each level of the significant variables, adjusted for the other variables in the model. In interpreting these results, it is necessary to take cognizance of the fact that the results change direction due to modelling of the Inverse square root (eg. a transfer back to the original units for race provides an estimate of the median healing time for "other" races: $1 /(.23)^{2}=19$ weeks and for the black race: $1 /(.25) 2=16$ weeks.

TABLE 4.5 : COMPARISON OF HEALING TIMES ACCORDING TO RACE

\begin{tabular}{||l|c|r|c||}
\hline LEVEL & COUNT & $\begin{array}{c}\text { EST. MEAN } \\
\text { TRANSFORMED } \\
\text { UNITS }\end{array}$ & $\begin{array}{c}\text { EST. MEDIAN } \\
\text { (WEEKS) }\end{array}$ \\
\hline $0=$ Asian, Col, White & 138 & 0.2285 & 19 \\
\hline $1=$ Black & 89 & 0.2461 & 16 \\
\hline
\end{tabular}

In Table $\mathbf{4 . 5}$ it can be seen that healing time for black subjects is significantly shorter than for other race groups.

TABLE 4.6 : COMPARISON OF HEALING TIMES ACCORDING TO THE MECHANISM OF INJURY

\begin{tabular}{||l|c|c|c||}
\hline LEVEL & COUNT & $\begin{array}{c}\text { EST. MEAN } \\
\text { (TRANSFORMED } \\
\text { UNITS) }\end{array}$ & $\begin{array}{c}\text { EST.MEDIAN } \\
\text { (WEEKS) }\end{array}$ \\
\hline $1=$ MVA & 162 & 0.2292 & 19 \\
\hline $2=$ Other & 65 & 0.2453 & 16 \\
\hline
\end{tabular}


Table 4.6 Healing time for subjects who were involved in Motor vehicle accidents, whether as driver, passenger, pedestrian or motorbike rider, is significantly longer than for other mechanisms of injury which included: cycle rider, gunshot wound, fall from a train, sports injury, industrial accident, a fall or assault.

TABLE 4.7 : COMPARISON OF HEALING TIMES ACCORDING TO THE TYPE OF FRACTURE

\begin{tabular}{|l|c|c|c|}
\hline LEVEL & COUNT & $\begin{array}{c}\text { EST. MEAN } \\
\text { TRANSFORMED } \\
\text { UNITS }\end{array}$ & $\begin{array}{c}\text { EST. MEDIAN } \\
\text { (WEEKS) }\end{array}$ \\
\hline $1=$ trans, comm, segment & 150 & 0.2287 & 19 \\
\hline $0=$ spiral, oblique & 77 & 0.2463 & 16 \\
\hline
\end{tabular}

Table 4.7 Healing time for transverse, comminuted or segmental fractures is longer than for spiral or oblique type fractures.

TABLE 4.8 : COMPARISON OF HEALING TIMES ACCORDING TO THE DEGREE OF DISPLACEMENT

\begin{tabular}{||l|c|r|c||}
\hline LEVEL & COUNT & $\begin{array}{c}\text { EST. MEAN } \\
\text { TRANSFORMED } \\
\text { UNITS }\end{array}$ & $\begin{array}{c}\text { EST. MEDIAN } \\
\text { (WEEKS) }\end{array}$ \\
\hline $2=1 / 2$ to full diameter & 143 & 0.2051 & 24 \\
\hline $1=$ minimal & 69 & 0.2318 & 19 \\
\hline $0=$ none & 15 & 0.2756 & 13 \\
\hline
\end{tabular}

Table 4.8 Healing time for no displacement of fracture fragments is significantly less than for minimal displacement, which is significantly less than for half or full diameter displacement. 

TABLE 4.9 : COMPARISON OF HEALING TIMES ACCORDING TO
ASSOCIATED INJURY

\begin{tabular}{||l|c|c|c||}
\hline \hline LEVEL & COUNT & $\begin{array}{c}\text { EST. MEAN } \\
\text { TRANSFORMED } \\
\text { UNITS }\end{array}$ & $\begin{array}{c}\text { EST. MEDIAN } \\
\text { (WEEKS) }\end{array}$ \\
\hline $1=$ multiple injury & 24 & 0.2194 & 21 \\
\hline $0=$ single other injury & 203 & 0.2556 & 15 \\
\hline
\end{tabular}

Table 4.9 Healing time for an associated fracture of a single other area of the body or limb is significantly shorter than for multiple fractures sustained by a patient.

TABLE 4.10 : COMPARISON OF HEALING TIMES ACCORDING TO GROUPS

\begin{tabular}{||l|c|r|c||}
\hline LEVEL & COUNT & $\begin{array}{c}\text { EST. MEAN } \\
\text { TRANSFORMED } \\
\text { UNITS }\end{array}$ & $\begin{array}{c}\text { EST. MEDIAN } \\
\text { (WEEKS) }\end{array}$ \\
\hline $1=$ interferential & 41 & 0.2501 & 16 \\
\hline $2=$ placebo & 35 & 0.2282 & 20 \\
\hline $3=$ control & 151 & 0.2342 & 18,5 \\
\hline
\end{tabular}

Table 4.10 Healing time for the experimental group demonstrated no significant difference from that of the placebo or control groups. There is also no significant difference between the placebo and control groups. Thus, although there appears to be a marginal improvement in healing time for the experimental group in the summary statistics eg. Table 4.1(a) and Fig 4.2 , the bivariate and multivariate levels of statistical analyses indicate that the null hypothesis of no treatment effect cannot be rejected. 
Fig 4.6 PPOBABLILTY PLOT

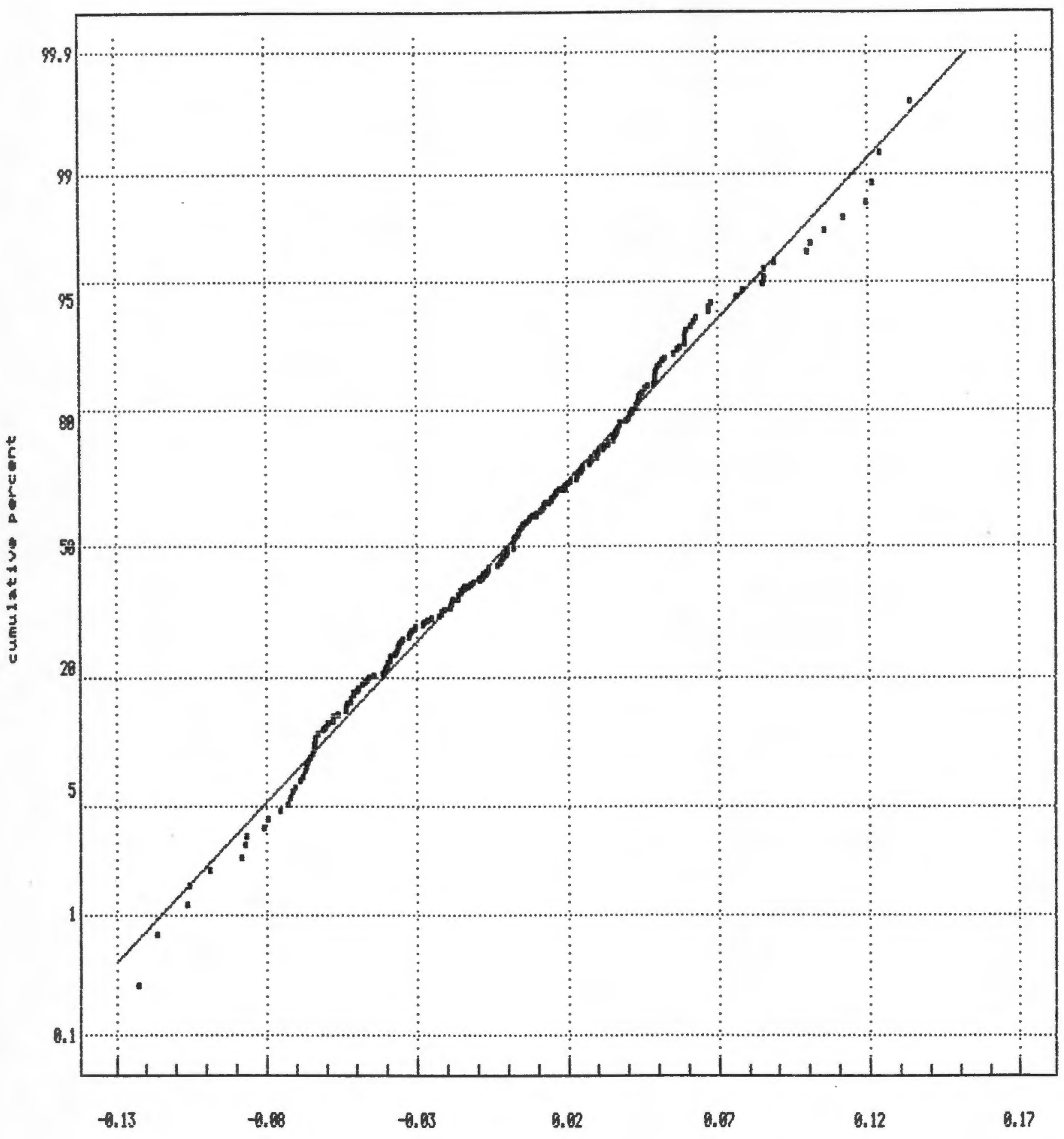

Residuals frow nodel used in Table 4.4 


\subsection{DIAGNOSTIC CHECKING}

The analysis of variance (ANOVA) methodology and the associated F-tests rest on the assumption of at least approximate normality of the underlying outcome measure. This assumption needs to be validated before the results of the analysis can be accepted. As a measure of outcome the average time to union (transformed by the inverse square root) has been used.

Further, there is the need to assess whether the results of this outcome measure are consistent with those of the original radiological and clinical union.

\subsubsection{Checking ANOVA model assumption of normality.}

Fig 4.6 shows the normal probability plot of the residuals from the model in Table $\mathbf{4 . 4}$ indicating satisfactory agreement with the normal distribution.

\subsubsection{Validating the use of average time to union as outcome variable}

The model shown in Table 4.4 was fitted to the transformation of time until radiological union and clinical union. In neither case were additional variables (to those included in the model for average time until union) found to be significant. The residuals from these models were then examined via a normal probability plot, with similar results as Fig 4.6 (refer Appendix E: Fig A.1 and A.2) These results again support the contention that the choice of average union as the dependent variable does not affect results.

\subsection{RESULTS OF LOGISTIC REGRESSION MODEL}

The predictor variables that were included in each of the fitted models and their associated logistic regression coefficients and odds ratios are given in Table 4.11. 
TABLE 4.11 : LOGISTIC REGRESSION MODELS DEMONSTRATING RISK FACTORS FOR NONUNION WITHIN:

\begin{tabular}{|c|c|c|c|}
\hline A. 40 WEEKS & $\begin{array}{l}\text { Logistic } \\
\text { coefficient }\end{array}$ & $\begin{array}{l}\text { Odds } \\
\text { ratio }\end{array}$ & p-value \\
\hline $\begin{array}{l}\text { Intercept } \\
\text { Compound } \\
\text { type } 0, I, I I=0 \\
\text { type } I I A=1 \\
\text { Alcohol } \\
\text { none/inebriated = } 0 \\
\text { delirium tremens = } 1\end{array}$ & $\begin{array}{r}-2.409 \\
1.231 \\
\\
2.409\end{array}$ & $\begin{array}{r}1.0 \\
3.4 \\
\\
1.0 \\
11.1 \\
\end{array}$ & $\begin{array}{l}0.0774 \\
0.024 \\
\end{array}$ \\
\hline \multicolumn{4}{|l|}{ B. 32 WEEKS } \\
\hline $\begin{array}{l}\text { Intercept } \\
\text { Displacement } \\
\text { none/minimal }=0 \\
1 / 2 / \text { full diametre }=1 \\
\text { Assoc. injuries } \\
\text { single other } \\
\text { fracture }=0 \\
\text { multiple other } \\
\text { fracture }=1 \\
\end{array}$ & $\begin{array}{r}-2.838 \\
1.887 \\
\\
1.303\end{array}$ & $\begin{array}{l}1.0 \\
6.6 \\
\\
1.0 \\
3.7 \\
\end{array}$ & $\begin{array}{l}0.006 \\
0.088 \\
\end{array}$ \\
\hline \multicolumn{4}{|l|}{ C. 24 WEEKS } \\
\hline $\begin{array}{l}\text { Intercept } \\
\text { Race } \\
\text { white, Asian,col. =0 } \\
\text { black }=1 \\
\text { Displacement } \\
\text { none/minimal }=0 \\
\text { 1//full diameter }=1 \\
\text { Associated injuries } \\
\text { one other fracture = } 0 \\
\text { multiple other } \\
\text { fractures }=1\end{array}$ & $\begin{array}{c}-1.5114 \\
-1.0023 \\
1.671 \\
1.973\end{array}$ & $\begin{array}{l}1.0 \\
0.37 \\
1.0 \\
5.32 \\
1.0 \\
7.19\end{array}$ & $\begin{array}{l}0.024 \\
0.001 \\
0.010\end{array}$ \\
\hline
\end{tabular}

These results are based on the estimation sample. Note that factors associated with odds ratios less than unity are protective, ie. they are positive factors working towards union rather than risk factors working against union.

The fitted model allows one to predict, for a given individual, the probability of his not going to union within the specified time. The fitted probabilities are given in Table 4.12 below. 
TABLE 4.12 : ESTIMATED PROBABILITIES OF NONUNION WITHIN:

\begin{tabular}{|c|c|c|c|c|}
\hline \multicolumn{5}{|c|}{ A. 40 WEEKS } \\
\hline CUTOFF & PROBABILITY & \multicolumn{2}{|c|}{ COMPOUND } & ALCOHOL \\
\hline $1^{*}$ & $=0.0825$ & \multicolumn{2}{|r|}{0} & 0 \\
\hline 2 & $=0.235$ & \multicolumn{2}{|r|}{1} & 0 \\
\hline 3 & $=0.5$ & \multicolumn{2}{|r|}{0} & 1 \\
\hline 4 & $=0.774$ & \multicolumn{2}{|r|}{1} & 1 \\
\hline \multicolumn{5}{|c|}{ B. 32 WEEKS } \\
\hline CUTOFF & PROBABILITY & \multicolumn{2}{|c|}{ DISPLACEMENT } & ASSOC.INJURY \\
\hline 1 & $=0.055$ & \multicolumn{2}{|r|}{0} & 0 \\
\hline 2 & $=0.177$ & \multicolumn{2}{|r|}{0} & 1 \\
\hline 3 & $=0.279$ & \multicolumn{2}{|r|}{1} & 0 \\
\hline 4 & $=0.587$ & \multicolumn{2}{|r|}{1} & 1 \\
\hline \multicolumn{5}{|c|}{ C. 24 WEEKS } \\
\hline CUTOFF & PROBABILITY & RACE & DISPLACEMENT & ASSOC. INJURY \\
\hline 1 & $=0.07$ & 1 & 0 & 0 \\
\hline 2 & $=0.18$ & 0 & 0 & 0 \\
\hline 3 & $=0.30$ & 1 & 0 & 1 \\
\hline 4 & $=0.37$ & 1 & 1 & 0 \\
\hline 5 & $=0.54$ & 0 & 0 & 1 \\
\hline 6 & $=0.61$ & 0 & 1 & 0 \\
\hline 7 & $=0.76$ & 1 & 1 & 1 \\
\hline 8 & $=0.89$ & 0 & 1 & 1 \\
\hline
\end{tabular}

For instance, the fitted model for nonunion within 40 weeks will predict that the probability of nonunion (by 40 weeks) for an individual* with compound $=$ closed, Type I or Type II and who does not have DT's is 0.0825 , whereas the same probability for an individual with compound = Type III and with DT's is 0.774 . 
In order to use these models as a screen for ultimate union status (eg. to flag individuals for alternative treatment such as immediate invasive therapy or the application of electrical currents) a cutoff probablility must be specified. One might, for instance, specify that all individuals with probability of nonunion greater than 0.5 will receive alternative therapy. In order to assess how useful such a screening device is, one needs to assess its properties in terms of characteristics such as sensitivity, specificity, as well as positive and negative predictive values.

\section{TABLE 4.13 : VALIDATION OF LOGISTIC REGRESSION MODELS FOR: (Estimation sample $n=118$, validation sample $n=90$ )}

\begin{tabular}{|c|c|c|c|c|c|c|}
\hline \multicolumn{7}{|c|}{ A. NONUNION AT 40 WEEKS (13\%) } \\
\hline Cutoff* $^{*}$ & $P(D N U)$ & P(CORRECT) & $\begin{array}{c}P(D N U \mid N U) \\
\text { Sensitivity }\end{array}$ & $\begin{array}{l}P(D U \mid U) \\
\text { Specificity }\end{array}$ & $\begin{array}{c}\text { P(NU | DNU) } \\
\text { PPV }\end{array}$ & $\begin{array}{c}\mathbf{P ( U} \mid \mathbf{D U}) \\
\mathbf{N P V}\end{array}$ \\
\hline 1 & . 18 & .76 & .25 & .83 & .19 & .88 \\
\hline 2 & .07 & .82 & .08 & .94 & .17 & .87 \\
\hline 3 & .01 & .86 & .00 & .99 & .00 & .87 \\
\hline \multicolumn{7}{|c|}{ B. NONUNION AT 32 WEEKS (22 \%) } \\
\hline Cutoff* & $P(D N U)$ & P(CORRECT) & $\begin{array}{c}\text { P(DNU | NU) } \\
\text { Sensitivity }\end{array}$ & \begin{tabular}{|c|}
$P(D U \mid U)$ \\
Specificity
\end{tabular} & $\begin{array}{c}\text { P(NU } \mid \mathrm{DNU}) \\
\text { PPV }\end{array}$ & $\begin{array}{c}P(\mathbf{U} \mid \mathrm{DU}) \\
\mathrm{NPV}\end{array}$ \\
\hline 1 & .66 & .48 & .80 & .39 & .27 & .87 \\
\hline 2 & .61 & .50 & .75 & .43 & .27 & .86 \\
\hline 3 & .06 & .77 & .10 & .96 & .40 & .79 \\
\hline \multicolumn{7}{|c|}{ C. NONUNION AT 24 WEEKS (43 \%) } \\
\hline Cutoff* & $P(D N U)$ & P(CORRECT) & $\begin{array}{c}\text { P(DNU | NU) } \\
\text { Sensitivity }\end{array}$ & \begin{tabular}{|c|}
$P(D U \mid U)$ \\
Specificity
\end{tabular} & $\begin{array}{c}\mathrm{P}(\mathrm{NU} \mid \mathrm{DNU}) \\
\mathrm{PPV}\end{array}$ & $\begin{array}{c}P(\mathbf{P} \mid \mathrm{DU}) \\
\mathrm{NPV}\end{array}$ \\
\hline 1 & .86 & .51 & .92 & .20 & .47 & .77 \\
\hline 2 & .66 & .56 & .74 & .41 & .49 & .67 \\
\hline 4 & .46 & .62 & .59 & .65 & .56 & .67 \\
\hline 5 & .16 & .58 & .13 & .92 & .56 & .58 \\
\hline 6 & .06 & .60 & .10 & .98 & .80 & .59 \\
\hline
\end{tabular}


Table 4.13 shows the results regarding the sensitivity and specificity of the fitted models, based on the validation sample for a variety of possible cutoffs. For the model predicting nonunion by 24 weeks and a probability cutoff of 4 in the region of [0.37-0.54) we have, eg., that $62 \%$ of subjects are correctly classified (as union or nonunion), $59 \%$ of the subjects who actually did not unite within 24 weeks were identified and $56 \%$ of the subjects who were diagnosed as nonunion did, in fact, not unite within 24 weeks.

It is perhaps easiest to visualise the impact of the implementation of these models by considering the allocation that would result with 100 fictitious subjects. Table 4.14 shows the results for prediction of nonunion with 24 weeks and a cutoff in the range [0.37-0.54)

\section{TABLE 4.14 : ESTIMATED PREDICTIONS FOR 100 SUBJECTS FROM TABLE 4.13 (C)}

DNU 24

DU 24

\begin{tabular}{|c|c|}
\hline NU 24 & U 24 \\
\hline $\begin{array}{c}\text { Correct } \\
25\end{array}$ & 20 \\
\hline 18 & $\begin{array}{c}\text { Correct } \\
37\end{array}$ \\
\hline 43 & 57 \\
\hline
\end{tabular}




\section{Chapter 5}

\section{DISCUSSION}

\subsection{EFFECTIVENESS OF INTERFERENTIAL CURRENTS}

Interferential currents have been shown to be effective for bone healing of new fractures in animal experiments (Laabs et al 1980; Beer et al 1990) and in the treatment of nonunion of tibial fractures in humans (Ganne 1988). Following this, it was expected that in new fractures of the tibial shaft in humans, a causal relationship would be demonstrated between the application of interferential currents and the rate of healing.

The results of this research, however, indicate otherwise. In the univariate data there appeared to be a marginal improvement in healing time for the experimental group in relation to both the placebo and control groups (Table 4.1(a) median $=2$ weeks improvement \& Fig 4.2 visual evidence). However, the statistical analyses (Table 4.3 and Table 4.10) demonstrated no significant difference for the interferential group, so that the null hypothesis could not be rejected. As this was not the expected finding, possible reasons for the outcome were sought.

\subsubsection{Number of treatment sessions}

The recommended number of treatment sessions was 15 (3 weeks of daily application: Nikolova 1969; Hassler et al 1977; Ganne 1988) which was not possible (see Chapter 3.3.vi). This may have limited the effect of the treatment.

\subsubsection{Beat frequency and mode.}

The beat frequency selected was 10 to $25 \mathrm{~Hz}$ with a swing mode of 656 in order to elicit a muscle contraction and yet prevent "accommodation". A beat frequency of $100 \mathrm{~Hz}$ may 
have induced a greater treatment effect. According to De Domenico (1981) $100 \mathrm{~Hz}$ has a depressive effect on sympathetic activity, thus producing vasodilatation and stimulating healing in bone and surrounding soft tissue.

\subsubsection{Time interval between injury and the application of interference currents.}

Black (1985) suggests that interference type currents should be used in the later stages of bone healing, in contrast to direct current which should be used early. However Hulth (1989) emphasised that electrical currents can be translated to biochemical mediators ( $\mathrm{PGE}_{2}$, morphogens and growth factors) in the fracture exudate, to stimulate bone growth for as long as possible in the initial stages of healing. The results of this trial cannot address either of these suggestions, thus the optimal time interval between injury and application of interference currents remains unsure.

\subsubsection{The combined effect of alcohol abuse and multiple fractures.}

Particular mention should be made of the three subjects (one of which incurred bilateral fractures of the tibiae) in the experimental group who exceeded the 36 week healing time, and would therefore be classified as nonunion according to Lavine \& Grodzinsky (1987). The three subjects shared the following variables:

i) Alcohol: All three subjects were inebriated on admission, with one commencing delirium tremens within the first week thereafter. Ethanol depresses bone formation by a direct effect on osteoblasts (Riggs and Melton 1986, p1681).

ii) Multiple injuries: All three subjects sustained multiple injuries. Heppenstall et al (1984) found that multiple injuries were associated with an increased rate of tibial nonunion. Furthermore, Table 4.9 demonstrates a significantly shorter time till union in cases where a subject sustained a single other fracture, rather than multiple fractures.

iii) Age: All subjects were between 21 and 25 years of age in support of Heppenstall et al's (1984) finding that nonunion of the tibia affects young to middle aged patients. This is probably because this group tends to sustain high violence fractures. 


\subsection{OTHER FINDINGS OF SIGNIFICANCE}

\subsubsection{Race:}

In Table 4.5 healing time for blacks was demonstrated to be significantly shorter than for other race groups, which was an unexpected finding. However, possible explanation may be considered in that South African blacks have been found to have greater bone turnover than their white counterparts, meaning that trabecular bone in blacks would be renewed more frequently, be subjected to fewer loading cycles and be less prone to fatigue failure (Schnitzler et al 1990). American blacks have been found to have higher bone mass, greater bone density, and thicker bone cortex than other races (Cummings et al 1985). Cummings found support from Bloom \& Pogrund (1982) in that the lowest reported rate of hip fractures are found among the South African blacks. There is a strong positive correlation between hip fracture and osteoporosis (Gallagher et al 1980). However, the relationship between the higher bone mass and healing is unclear to date. There does seem to be a genetic influence in the greater bone turnover and greater bone volume in black men, which may result in faster healing.

\subsubsection{Mechanism of Injury:}

"The majority of established nonunions of the tibia are secondary to motor vehicle accidents" (Heppenstall et al 1984). Motor vehicle accident victims in this trial clearly demonstrated a significantly longer healing time in Table 4.6. A possible explanation for this finding may be sought in the relationship between the forces involved at the time of injury and the severity of the resultant fracture and soft tissue damage. The formula:

$$
\text { Kinetic energy (of wounding force) }=\frac{\text { Mass } \mathrm{x} \text { Velocity }^{2}}{2}
$$

(Rockwood \& Green 1984), indicates the relationship between mass and velocity, both of which tend to be relatively high in most motor vehicle accidents. 


\subsubsection{Severity of the injury:}

The 'severity of the injury' is evaluated by: i) the type of fracture, ii) the degree of initial displacement and iii) the extent of the open wound. All three of these variables were found to have significance in relation to the healing time.

i) Type of fracture: Table 4.7 demonstrates that transverse, comminuted and segmental fractures take longer to heal than do spiral or oblique.

ii) Degree of displacement: In Table 4.8 there is clear evidence that half to full diameter displacement takes significantly longer to heal than minimal displacement, which in turn takes significantly longer than no displacement.

iii) Extent of open wound: In the bivariate analysis (Table 4.2) this variable demonstrated a marginally significant relationship with healing time $(p=0.06)$, however, in the multivariate analysis (Table 4.4) where there is adjustment for other significant variables, the compound aspect demonstrated no significance. This finding cannot be satisfactorily explained.

\subsubsection{Associated injuries:}

Heppenstall et al (1984) felt that associated injuries were a contributing factor towards nonunion, which is substantiated in this trial. Clearly, Table 4.9 indicates that healing time for an associated fracture of a single other area of the body or limb is shorter than for a subject with multiple fractures.

\subsection{DISCUSSION OF LOGISTIC REGRESSION MODEL.}

These models have augmented the knowledge obtained from the Interferential ANOVA in providing information as to factors impacting on union of fractures. That the type of compound and level of alcohol consumption play a role in determining whether a fracture unites within 40 weeks or not is plausible, from the discussion in 5.1.4.i) and 5.2.3.iii). Similarly, the features affecting union by 32 weeks, displacement and associated injuries can be understood from the discussion in 5.2.3.ii) and 5.2.4. It is troubling, however, that the two models do not coincide, in terms of the risk factors selected. This is a cautionary 
reminder of the complexity of factors impacting on the likelihood of a fracture uniting. The model predicting nonunion within 24 weeks (Table $4.11 \mathrm{C}$ ) appears the most useful, since it attains generally the highest levels of accurate prediction of union and nonunion. Race is the only protective variable, which is consistent with the ANOVA Table 4.4. The rest are risk factors and coincide with the 32 week nonunion Table 4.11 B.

The assessment of the usefulness of these models depends on the therapy that will be chosen if an individual is screened as "nonunion". If it were to be invasive therapy, then one would particularly want to protect against unnecessary therapy and the positive predictive value of the screen would be an important focus. For instance, if the $40 \%$ cutoff were used in the model for nonunion by 24 weeks (Table 4.14), $20 \%$ of subjects would be diagnosed as nonunion who would, in fact, unite within 24 weeks. Using the proportions reflected in the sample, for every 100 subjects, this cutoff would result in:

25 subjects diagnosed as nonunion who do not unite

37 subjects diagnosed as union, who do unite

20 subjects diagnosed as nonunion who do unite

18 subjects diagnosed as union who do not unite. 


\section{Chapter 6 \\ CONCLUSIONS AND RECOMMENDATIONS}

\subsection{CONCLUSIONS}

\subsubsection{The effect of interferential currents on bone healing}

The primary objective of this research was to determine the effect of interferential currents on the rate of bone healing in new fractures of the tibial shaft. Many external, systemic and local factors which affect bone healing were recognised (Chapter 2.2.4). Of these factors, only some which were clinically observable were recorded as variables (Chapter 3.8.3), and the complexity of applied research (non-laboratory) where variables are not perfectly controlled was accepted. The results however, demonstrated that the treatment failed to show any statistically significant effect on bone healing. Furthermore three of the forty one subjects in the experimental group went beyond the 40 week healing time to classified nonunion (Lavine 1987).

The positive aspect of the results of this trial may be sought in the fact that there was some improvement in the healing time, albeit not statistically significant (Fig 4.2, Table 4.3 and Table 4.10). At least the experimental group did not take longer to heal than the placebo and control groups, which is encouraging for further research.

\subsubsection{Prediction of nonunion}

The second objective of this research was to develop a model using a set of variables with which nonunion, within a specified time period, could be predicted early with a high degree of certainty. 
It is evident from Table 4.14 that at best $20 \%$ of subjects who would be diagnosed by the model as nonunion, would unite within 24 weeks. From a surgical perspective the risks of infection are too high for the use of invasive therapy, on these subjects who would have united anyway. A further consideration is that of the unnecessary cost to individual or state in such a circumstance. The cost of open reduction and internal fixation with bonegrafting at present gazetted rates would be in the region of R5,000.00.

Furthermore, 18 subjects diagnosed by the model as union do not unite, which places a large financial burden on the subject or state, particularly when the subjects work is of a physical rather than sedentary nature, which means loss of earnings and dependence on unemployment benefits.

However, safe, low-cost, noninvasive intervention, such as interferential therapy could well be considered an appropriate option, if it were demonstrated to be significantly effective in the future. At the present gazetted schedule the cost of 15 sessions of interferential therapy would be R333.00.

\subsection{RECOMMENDATIONS}

Further study into the effect of Interferential currents on bone healing is recommended, due to the fact that a limited number of possible treatment parameters were used in the present trial, and should include the following:

\subsubsection{Number of treatment sessions:}

Treatment should be administered for the full three week period, which is recommended in the literature (Nikolova 1969; Hassler et al 1977; Ganne 1988). 


\subsubsection{Variety of beat frequencies and mode:}

Only one beat frequency was used in the present trial (Chapter 5.1.2). The use of a variety of beat frequencies would establish if there is a significant difference in treatment effect. The literature is not specific on this aspect of interferential currents, since to date only empirical data are available on treatment for new fractures of the tibial shaft in humans (Ganne 1988). In order to sample the wide range of possible and potentially effective frequencies, the recommended beat frequencies for four groups would be:

$\begin{array}{lll}\text { - } & 100 \mathrm{~Hz} & \text { constant mode } \\ \text { - } & 10-25 \mathrm{~Hz} & \varsigma \text { mode } \\ \text { - } & 5-100 \mathrm{~Hz} & \ulcorner\text { mode } \\ \text { - } & 50-150 \mathrm{~Hz} & \ulcorner\text { mode }\end{array}$

\subsubsection{Appointment of a research assistant:}

The appointment of a research assistant would improve the possibility of continuing with treatment, after the subject is discharged from hospital, in order to complete the series of 15 treatments.

\subsubsection{Number of subjects in each group:}

The placebo effect would not need to be retested, but a sample size of 50 in each group is needed to have $80 \%$ power for detecting a difference in mean healing time of at least five weeks between any two treatments.

\subsection{SIGNIFICANCE OF THIS RESEARCH:}

Although the difference in time to union in experimental subjects was not found to be statistically different from those in the control and placebo groups, the observed median difference of 2 weeks demonstrates that interferential treatment does not have a detrimental effect, it could be worth persuing this research implementing the recommendations given in 6.2. 


\section{REFERENCES}

Adams JC. (1983), Outline of Fractures, 8th Ed. Churchill Livingstone, Edinburgh, 258.

Akaike H. (1973), Information theory and an extension of the maximum likelihood principle. In Petrov and Czaki (Eds): Proceedings of the 2nd International Symposium on Information Theory, 267-281.

Apley AG. (1986), Apley's System of Orthopaedics and Fractures, 6th Ed. Butterworths, London, 466 \& 465.

Barker AT. (1985), 'Non-ionising electromagnetic therapy: Fact or fantasy?' Physics Bulletin, 36 251-253.

Bassett CAL. (1985), The development and application of pulsed electromagnetic fields (PEMFs) for ununited fractures and arthrodeses, Clinical Plastic Surgery, 12 (2) 259-277.

Bassett CAL; Mitchell SN; Gaston SR. (1981), Treatment of ununited tibial diaphyseal fractures with pulsating magnetic fields, Journal of Bone and Joint Surgery, 63A (4) 511-523.

Bassett CAL; Pawluk RJ; Becker RO. (1964), Effects of electrical current on bone in vivo, Nature, 204652.

Basset CAL; Herrmann I. (1968), The effect of electrostatic fields on macromolecular synthesis by fibroblasts in vitro, Journal of Cell Biology, 39 9A.

Bassett CAL; Pawluk AJ; Pilla AA. (1974), Acceleration of fracture repair by electromagnetic fields, Annals of the New York Academy of Science, 238 243-252.

Bassett CAL; Mitchell SN; Schink MM. (1982), Salvage of persistent nonunions with bone graft and pulsing electromagnetic fields (PEMFs), AAOS 49th Annual Meeting, New Orleans. 
Becker RO; Bassett CAL; Bachman CH. (1964), The bioelectric control system regulating bone growth, In Frost H.(Ed): Proceedings of the International Symposium on Biodynamics in Bone, Little, Brown and Company, Boston, 209.

Beer L; Hintner J; Kleditzsch J; Lorenz T. (1990), Behaviour of the alkaline serum phosphatase and its bone isoenzyme by the healing in the osteotomised tibia of the rabbit an animal experimental study, Z. exp. Chir. Transplant. künstl. Organe, 23 (4) 230-232.

Behari J. (1991), Electrostimulation and bone fracture healing, Biomedical Engineering, 18 (4) $235-254$.

Bick EM. (1948), Source book of Orthopaedics, 2nd Ed. Williams and Wilkins Company, Baltimore, USA.

Black J. (1985), Electrical stimulation of hard and soft tissues in animal models, Clinics in Plastic Surgery, 12 (2) 243-257.

Bland M. (1987), An Introduction to Medical Statistics, Oxford University Press, Oxford.

Blick S; Brumback RJ; Lakatos R; Poka A; Burgess AR. (1989), Early prophylactic bone grafting of high-energy tibial fractures, Clinical Orthopaedics and Related Research, 24021 41.

Bloom RA; Pogrund H. (1982), Humeral cortical thickness in female Bantu: its relationship to the incidence of femoral neck fracture, Skeletal Radiology, 8 56-62.

Brighton CT; Friedenberg ZB; Zemsky LM; Pollis RP. (1975), Direct current stimulation of non-union and congenital pseudarthrosis. Exploration of its clinical application, Journal of Bone and Joint Surgery, 57A (3) 368-377.

Brighton CT. (1980), Treatment of non-union of the tibia with constant direct current, The Journal of Trauma, 21 (3) 189-195. 
Brighton CT. (1982a), The use of constant direct current in the treatment of nonunion. In Frankel VH (Ed): AAOS Instructional Course Lectures. Vol XXXI, CV Mosby Company, St Louis, 94-103.

Brighton CT. (1982b). Present and future of electrically induced osteogenesis. In Straub LR \& Wilson PD Jr. (Eds): Clinical Trends in Orthopaedics, Thieme-Stratton, New York, 1-15.

Brighton CT; Pollack SR. (1985), Treatment of recalcitrant non-union with a capacitively coupled electrical field - A preliminary report, Jounal of Bone and Joint Surgery, 67A (4) 577-585.

Carley PJ; Wainapel SF. (1985). Electrotherapy for acceleration of wound healing: Low intensity direct current, Archives of Physical Medicine. 66 443-446.

Cartensen EL. (1987), Biological Effects of Transmission Line Fields, Elsevier, NewYork.

Charman RA. (1991), Part 7: Environmental Currents and Fields - Man-made, Physiotherapy, 77 (2) $129-140$.

Cochran GV; Johnson MW; Kadaba MP; Palmieri VR; Mahaffey G. (1987), Design considerations in development of a prototype, piezoelectric internal fixation plate: a preliminary report, Journal of Rehabilitation Research and Development, 24 (2) 39-50.

Coghill R. (1990), 'Killing Fields - Biophysical evidence', Electronics World + Wireless World, February, 112-118.

Collins PC; Paterson DC; Vernon-Roberts B; Pfeiffer D. (1981), Bone formation and impedance of electrical current flow, Clinical Orthopaedics and Related Research, 155196.

Connolly JF. (1981), A multicenter study of the treatment of nonunion with constant direct current, Journal of Bone and Joint Surgery, 63A 2. 
Cornell CN; Lane JM. (1992), Newest factors in fracture healing, Clinical Orthopaedics and Related Research, 277 297-311.

Cummings SR; Kelsey JL; Nevitt MC; O’Down KJ. (1985), Epidemiology of osteoporosis and osteoporotic fractures, Epidemiologic Reviews, 7 178-208.

Currier DP. (1990), Elements of Research in Physical Therapy, Williams and Wilkins, Baltimore, Maryland. USA.

De Domenico G. (1981), Basic Guidelines for Interferential Therapy, Theramed Books, Sydney, 5 .

De Haas WG; Lazarovici MA; Morrison DM. (1979), The effect of low frequency magnetic fields on the healing of the osteotomized rabbit radius, Clinical Orthopaedics and Related Research, 145 245-251.

Ellis H. (1958), The speed of healing after fracture of the tibial shaft, Journal of Bone and Joint Surgery, 58A 42-46.

Farley JR; Fitzsimmons R; Taylor AK; Jorch UM; Lau K-HW. (1985), Direct effects of ethanol on bone resorption and formation in vitro, Archives Biochemical Biophysics, 238 305314.

Friedenberg ZB; Andrews ET; Smolenski BI; Pearl BW; Brighten CT. (1970), Bone reaction to varying amounts of direct current, Surgery, Gynecology and Obstetrics, 131894.

Friedenberg ZB; Roberts PG; Didizian NH; Brighton CT. (1971), Stimulation of fracture healing by direct current in the rabbit fibula, Journal of Bone and Joint Surgery, 53A 1400.

Friedenberg ZB; Zemsky LM; Pollis RP; Brighton CT. (1974), The response of nontraumatized bone to direct current, Journal of Bone and Joint Surgery, 56A 1023. 
Friedman GD. (1978), Primer of Epidemiology, McGraw Hill, San Francisco, 31.

Gallagher JC; Melton LJ; Riggs BL; Bergstrath E. (1980), Epidemiology of fractures of the proximal femur in Rochester, Minnesota, Clinical Orthopaedics and Related Research, 150 163-171.

Ganne J-M. (1980), An Examination of the Effects of Treatment by Interferential Currents on the Healing of Tibial and Mandibular Fractures, A preliminary investigation, Unpublished thesis.

Ganne J-M. (1988), Stimulation of bone healing with interferential therapy, Australian Journal of Physiotherapy, 34 (1) 9-20.

Ginsberg AJ. (1940), A description of my athermic shortwave apparatus with clinical application, New York Academy of Medicine, New York.

Greenbaum MA; Kanat IO. (1993), Current concepts in bone healing - Review of the literature, Journal of American Podiatric Medical Association, 83 (3) 123-128.

Gupta RC; Gupta SC; Mital KK. (1982), Osteomedullagraphic studies in electrically stimulated experimental fracture healing. Indian Journal of Medical Research, 75 446-452.

Gustilo RB; Anderson JJ. (1976), Preventon of infection in the treatment of 1,025 open fractures of long bones, Journal of Bone and Joint Surgery, 58A (4) 454.

Gustilo RB; Mendoza RM; Williams DN. (1984), Problems in the management of type III (severe) open fractures, The Journal of Trauma, 24 (8) 742.

Hansjürgens A; Meyer-Waarden K. (1980), Field distribution of selected parameters of middle frequency interferential currents in inhomogeneous (heterogeneous) biological media, Biomedizinische Technik (Supplementary volume), 25 298-293. 
Hassler CR; Rybicki EF; Diegle RB; Clark LC. (1977), Studies of enhanced bone healing via electrical stimuli, Clinical Orthopaedics and Related Research, 124 9-19.

Healey JH; Juhn A; Lane JM; Baker C; Mohler D. (1988), Prostaglandin $E_{2}$ and bone regeneration, An experimental study in the rat, Poster presented at the 34th Annual Meeting, Orthopaedic Research Society, Atlanta, Georgia, USA.

Heppenstall RB. (1980), Fracture treatment and healing, WB Saunders, Philadelphia, 35.

Heppenstall RB; Brighton CT; Esterhai JL; Muller G. (1984), Prognostic factors in nonunion of the tibia: An evaluation of 186 cases treated with Constant Direct Current, The Journal of Trauma, 24 (9) 793.

Huckstep RL. (1982), A simple guide to Trauma, Churchill Livingstone, Edinburgh, 336.

Hulth A. (1989), Current concepts of fracture healing, Clinical Orthopaedics and Related Research, 266 265-284.

Huysamen GK. (1989), Introductory statistics and research design for the behavioural Sciences 2nd Ed., Vol 2, H and R Academica, Cape Town.

Ilizarov GA; Makuskin VD; Kuffiryer LM; Popov PS. (1973), Recovery of post traumatic bony defects of the tibia by the lengthening of a bone fragment, Jubilee of Practical Medical Sciences Conference Book, Kurgan, USSR.

Johner R; Wruhs O. (1983), Classification of tibial shaft fractures and correlation with results after rigid internal fixation, Clinical Orthopaedics and Related Research, 178 8-9.

Kaindl F; Partan J; Warum F. (1953), Behandeling der peripheren Kretslaufstorungen, Wiener Zeitschrift fur innere medizin und ihre grenzgebiete, 12465. 
Katzung BG. (1989), Basic and Clinical Pharmacology 4th Ed, Appleton and Lange a Publishing Division of Prentice Hall, Connecticut, 280.

Krusen FH. (1941), Physical Medicine, The employment of physical agents for diagnosis and therapy, W B Saunders Co., Philadelphia, USA.

Kuhlman JE; Fishman EK; Magid D; Scott WW; Brooker AF; Siegelman SS. (1988), Fracture nonunion: CT assessment with multiplanar reconstruction, Radiology, 167 (2) 483 488.

Kyrö A; Laasonen E; Böstman O; Korhola O. (1989), Tibial shaft repair imaged by magnetic resonance, Acta Orthopaedica Scandinavica, 60 (Supplement) 231.

Laabs WA; Richter K; May E; Höhling H; Apthoff J; Barckhaus R; Quint P. (1980), New technique to stimulate healing of fractures by means of dynamic interferential current (DIC), 8th International Congress of Physical Medicine on Rehabilitation, Stockholm 25 - 29 August, 441-442.

Lavine LS; Grodzinsky AJ. (1987), Current concepts review - Electrical stimulation of repair of bone, Journal of Bone and Joint Surgery, 69A (4) 626-630.

Liggins C. (1988), Light Amplification by Stimulated Emission of Radiation, Student notes, University of Durban-Westville, Durban, RSA, 11.

Lindsay D; Dearness J; Richardson C; Chapman A; Cuskelly G. (1990), A survey of electromodality usage in private physiotherapy practices, Australian Journal of Physiotherapy, 36 (4) $249-256$.

MacNab I; De Haas WC. (1974), The role of periosteal blood supply in the healing of fractures of the tibia, Clinical Orthopaedics and Related Research, 105 27-33. 
Marks RK (Ed). (1990), Manual of Orthopaedic Surgery. University of Cape Town Printers, Cape Town, RSA, 15.

Moroney MJ. (1970), Facts from figures, Cox and Wyman Ltd, London.

McKibben B. (1978), The biology of fracture healing in long bones, Journal of Bone and Joint Surgery, 60B 150.

McRae R. (1981), Practical Fracture Treatment, Churchill Livingstone, London, 261.

Melzack R; Wall PD. (1965), Pain mechanismss: A new therapy. Science, New York, 150 971-979.

Nicoll EA. (1964), Fractures of the tibial shaft: A survey of 705 cases, Journal of Bone and Joint Surgery, 45B 373-387.

Nikolova L. (1969), Physiotherapeutic rehabilitation in the presence of fracture complications, Munchener Medizinische Wochenshrift, (Special English reprint) III (II), 592-599.

Nikolova L. (1987), Treatment with Interferential Current. Churchill Livingstone, Edinburgh.

Nordenström B. (1983), Biologically Closed Electric Circuits, Nordic Medical Publications, Sweden.

O'Sullivan ME; Chao EYS; Kelly PJ. (1989), Current concepts review - The effects of fixation on fracture-healing, Journal of Bone and Joint Surgery, 71A (2) 306-310.

Pankovitch AM; Goldflies ML; Pearson RL. (1979), Closed Ender nailing of femoral-shaft fractures, Journal of Bone and Joint Surgery, 61 A (2) 222-232. 
Paterson D; Hillier TM; Carter RF; Ludbrook J; Maxwell GM; Savage JP. (1977), Experimental delayed union of the dog tibia and its use in assessing the effect of an electrical bone growth stimulator, Clinical Orthopaedics and Related Research, 128340.

Paterson D; Lewis GN; Cass CA. (1980), Treatment of delayed union and non-union with an implant direct current stimulator, Clinical Orthopaedics and Related Research, 148117 128.

Paterson D. (1982), Clinical use of the Osteostim, an implanted bone growth stimulator, for impaired bone healing, In Frankel VH. (Ed): AAOS Instructional Course Lectures. Vol XXXI, CV Mosby Co., St Louis, 103-113.

Pearson JR; Austin RT. (1979), Accident Surgery and Orthopaedics for Students, Lloyd-Luke (Medical Books) Ltd., London, 20.

Perry FS. (1981), Environmental power, frequency, magnetic, fields and suicide, Health Physics, 41 267-277.

Perry FS; Pearl L. (1988), Health effects of ELF fields and illness in multistorey blocks, Public Health, 102 11-18.

Rheinlander FW; Phillips RS; Steel WM; Beer JC. (1968), Microangiography in bone healing 2, Displaced closed fractures, Journal of Bone and Joint Surgery, 50A 643.

Rhinelander FW. (1974), Tibial blood supply in relation to fracture healing, Clinical Orthopaedics and Related Research, 105 34-80.

Riggs BL; Melton III LJ. (1986), Involutional osteoporosis, The New England Journal of Medicine, 314 (26) 1676-1685.

Rittmann WW; Schibli M; Matter P; Allgower M. (1979), Open fractures, long-term results in 200 consecutive cases, Clinical Orthopaedics and Related Research, 138 132-140. 
Rockwood CA; Green DP. (1984), Fractures in Adults, Lippincott, Philadelphia, USA.

Sarmiento A; Latta LL; Tarr RR. (1984), The effects of function in fracture healing and stability, AAOS Instruction Course Lecture, Vol XXXIII, CV Mosby CO., St Louis, 83.

SAS/STAT User's Guide, Version 6, Vol 2, Sas Institute Inc, Cary, North Carolina, USA.

Savage, B. (1984), Interferential Therapy, Faber and Faber Ltd., London, 16.

Schnitzler CM; Pettifor JM; Mesquita JM; Bird MDT; Schnaid E; Smyth AE. (1990), Histomorphometry of iliac crest bone in 347 normal black and white South African adults, Bone and Mineral, 10 183-199.

Schoeler H. (1972), Physical block of the sympathetic chain, Technik in der Medizin, No 1.

Selye H. (1975), Stress without Distress, Hodder \& Stoughton, England.

Shamos MH; Lavine LS. (1964), Physical basis for bioelectric effects in mineralized tissues, Clinical Orthopaedics and Related Research, 35177.

Sharp IK. (1983), Stimulation of bone union by externally applied radio-frequency energy, Injury, 14 523-530

Shim SS; Patterson FP. (1966), Bone blood flow in the limb following complete sciatic nerve section, surgery; Gynaecology and Obstetrics, 123 333-335.

Shulman S. (1990), Cancer risks seen in electromagnetic fields, Nature, 3456275463 (See US EPA).

Siff MC. (1990), Modern advances in electrical stimulation, Communication Studies Division, University of the Witwatersrand, Johannesburg. 
Singh M; Riggs BL; Beabout JW; Jowsey J. (1972), Femoral trabecular pattern for evaluation of spinal osteoporosis, Annals of Internal Medicine, 7763.

Smith CW; Best S. (1989), Electromagnetic Man: Health and hazard in the electrical environment, J M Dent and Sons, London.

Spadaro JA. (1977), Electrically stimulated bone growth in animals and man, Clinical Orthopaedics and Related Research, 122325.

Statgraphics User Manual MDK 33-5 (1991), Manugistics Inc-2115, Rockville, Maryland, USA.

Steinberg ME; Brighton CT; Steinberg DR; Tooze SE; Hayken GD. (1984), Treatment of avascular necrosis of the femoral head by a combination of bone grafting, decompression and electrical stimulation, Clinical Orthopaedics and Related Research, 187 137-153.

Tar-Ching AW. (1988), 'Living under pylons', British Medical Journal, 197 804-805.

Tomenius L. (1986), $50 \mathrm{~Hz}$ Electromagnetic environment and the incidence of childhood tumours in Stockholm county, Bioelectromagnetics, 7181 - 207.

Trueta J. (1963), The role of the vessels in osteogenesis, Journal of Bone and Joint Surgery, 45B (2) 407-409.

Trueta J. (1974), Blood supply and the rate of healing of tibial fractures, Clinical Orthopaedics and Related Research, 105 11-26.

Walter H. (1985), Bioelectrical osteogenesis: Acceleration of fracture repair and bone growth, Clinics in Podiatry, 2 41-57

Weissman BN; Sledge CB. (1981), General Principles in Orthopaedic Radiology, Saunders, Philadelphia, USA, (6) 21-25. 
Wertheimer N; Leeper E. (1982), Adult cancer related to electrical wires near the home, International Journal of Epidemiology, 11 345-355.

Whiteside LA; Lesker PA. (1978), The effects of extraperiosteal and sub-periosteal dissection, I) On blood flow in muscle, II) On fracture healing, Journal of Bone and Joint Surgery, 60A (1) 23-30.

Yasuda I; Noguchi K; Sata T. (1953), Dynamic callus and electric callus, Journal of Bone and Joint Surgery, 37A 1292.

Yasuda I. (1974), Mechanical and electrical callus, Annals of the New York Academy of Sciences, 238 457-465.

Zelen M. (1974), The randomization and stratification of patients to clinical trials, Journal of Chronic Disorders, 27 365-375. 


\section{APPENDIX}

APPENDIX A - PROPOSAL

APPENDIX B - SUBJECT PROFORMA

APPENDIX C - CONSENT

APPENDIX D - EQUIPMENT TESTING

APPENDIX E - DIAGNOSTIC CHECKING

Normal probability plots for residuals from radiological union and clinical union. 
APPENDIX A 


\section{STIMULATION OF BONE HEALING WITH INTERFERENTIAL THERAPY IN NEW FRACTURES OF THE TIBIAL SHAFT}

\section{INVESTIGATDFi}

Mrs Jeanette Ann Fourie

\section{FACILITY}

Groote Schuur Hospital - Department of Drthopaedics

\section{SUFEFUISDFS}

Miss Fatricia Bowerbank:, Head of Department of Fhysiotherapy, UCT.

Prof $W$ Shepherd-Wilson, Frrincipal Consultant, Orthopaedics, A Firm, Groote Schuur. Hospital.

\section{MOTIVATION FOF STUDY (including 1 iterature survey)}

\section{Why use inter.ferential therapy? (IFT)}

"Experimental work concerned with the healing potential of electric currents has been most prolific in the area of stimulation of bone repair., where the problem of ununited fractures becomes a serious financial and social burden". (Ganne 1988). Different electrical currents have been studied:

I Direct current: administered by surgical implantation of the cathode (Faterson et al 1980) as well as percutaneous insertion of 4 cathodes at the fracture site. (Brighton 1980).

" Fulsed electro-magnetic fields: the unit is fixed to the plaster of paris but no weight bearing is allowed through the $1 \mathrm{imb}$, for up to 3 months. (Bassett et al 1981).

60 kil lohertz symmetrical sine wave (capacitively coupled) using two sur.face electrodes. Has the advantage over the first two, in that it is non invasive and the patient may weight bear whilst treatment is administered. However the treatment is continuous, and unit must be strapped to the 1 imb proximally. (Brighton and Follack 1985).

Interferential currents. Nikolova 1969 \& 1987 \& Ganne 1988 , report on the use of interferential currents used for. non/delayed union. 80 percent and 88 percent, respectively, had full functional mecovery as well as bone union. The advantages of interferential over other methods of electrical stimulation are presented: (Ganne 1988). 
Electrodes are applied on the surface and the medium frequency currents are very comfortably tolerated through the skin because of the low impedance to their penetration.

The treatment is therefore surgically non-invasive but has deep penetration (it was later demonstrated by Laabs (1980) that the interferential field is present within the bone at the fracture site, the highest intensity being in the medullary cavity).

The whole fracture site and areas of bone around it can be exposed to the currents, including the osteogenetic periosteal cells and the soft tissues around the fracture, allowing also treatment of any pain and swel I ing.

There are no electrolytic effects.

The nature of the currents with a range of low frequency beats produces therapeutic muscle contractions and this also stimulates bone repair.

Apart from saving time, application of treatment for only short periods of time, eg 20 - $30 \mathrm{~min} / \mathrm{day}$, may be advantageous in avoiding tissue accommodation and constant slight irritation, but activating cells at intervals.

Favourable effects have been found clinically and reported experimentally on capillary circulation and inhibition of sympathetic overactivity. (Kaindl et al 1953, Nikolova $1968 \% 1987$, Schoeler 1972, Ganne 1980). The significance of adequate blood supply and venous return at fracture sites for repair is well documented. (McNab : de Haas 1974, Fihinelander 1974, Trueta 1963 品 1964 , Whiteside Lester 1978). The effects on bone blood flow of releasing sympathetic tone was shown by Shim and Fatterson in 1966.

\section{Why investigate new fractures?}

\section{Ganne (1988) reports further in her pilot study:}

The effects of IFT stimulation on 11 patients with acute fractures of the tibial shaft, compared with 11 closely matched patients with similar acute fractures who did not receive IFT. A significant difference in rate of union ( $p<0,01$ ) between the two groups was demonstrated using the student t-test.

This is the aspect of Ganne's study that captured the author's interest - if IFT can be demonstrated to significantly reduce time taken to union, as well as prevent non union in a broad spectrum of fracture types (all of the tibial diaphysis and in sufficient numbers), it can be used prophylactically in conjunction with conservative orthopaedic management. 


\section{Why study fractures of the tibia?}

- Tibial fractures are prone to delayed and non union (Apley 1986). This results in many lost man hours, particularly for labourers. (McFiae 1981).

- Surgical intervention (bone grafting) is costly and bears the risk of infection.

- The social implications of being incapacitated for many months, with loss of income and resultant loss of self worth, a feeling of being redundant, can be devastating to family and friends.

For all of the above reasons, the author feels that it is worthwhile investing time, energy and money in this project - in order to establish that interferential therapy can make a significant difference in reducing the time period to clinical and radiological union in fractures of the tibia hypothesis (experimental).

Null Hypothesis: IFT does not make any significant difference in reducing time from fracture to clinical and radiological union.

\section{QBJECTIVES OF THE STUDY - short term}

* To investigate the effect of interferential therapy (IFT) on bone healing as an adjunct to conservative orthopaedic treatment in patients admitted to Groote Schuur Hospital (GSH) with fractured tibia over a period of two years (January 1989 - December 1990).

* To determine characteristics of the population physical factors/medical factors. Distribution relation to age/sex/?alcohol/type \#/ mechanism/method of fixation.

To determine the factors, either singly, in combination or by interaction that are associated with decreased healing tine.

\section{QBJECTIVES DF THE STUDY - lang term}

Data obtained will be used to:

- Influence decision maling; whether to use IFT as an adjunct to orthopaedic treatment of all tibial

fractures, prophylactically.

: Shorten costly hospitalisation.

" Determine which patients are prone to delayed/non union - combinations/interactions of extraneous variables may provide this clue. Cost effectiveness of using IFT prophylactical Iy should be considered and compared with surgical treatment. 
Determine the value of transfer to fractures of . other. bones, eg stress fractures in sports people, anxious to get bacl: to sport. (The external validity should be reliable).

\section{METHODOLOGY}

\section{Study Structure}

Fandomised clinical trial of experimental design, using single blind. (Double blind would involve two operators, one setting up the equipment and another switching off the control group. This is too demanding in terms of clinical timel.

\section{Sampling}

The study population will consist of all patients admitted to the orthopaedic wards of GSH in the period beginning January 1989 to December 1990. Fatients fulfilling selection criteria will be entered randomly with the study as they are referred by the doctors of the $A \& B$ firm. (Two firms representing the orithopaedic department, each with its own consultants, registrars and housemen).

\section{SELECTION CFITERIA}

:

\# tibial shaft: transverse/spiral/oblique/comminuted.

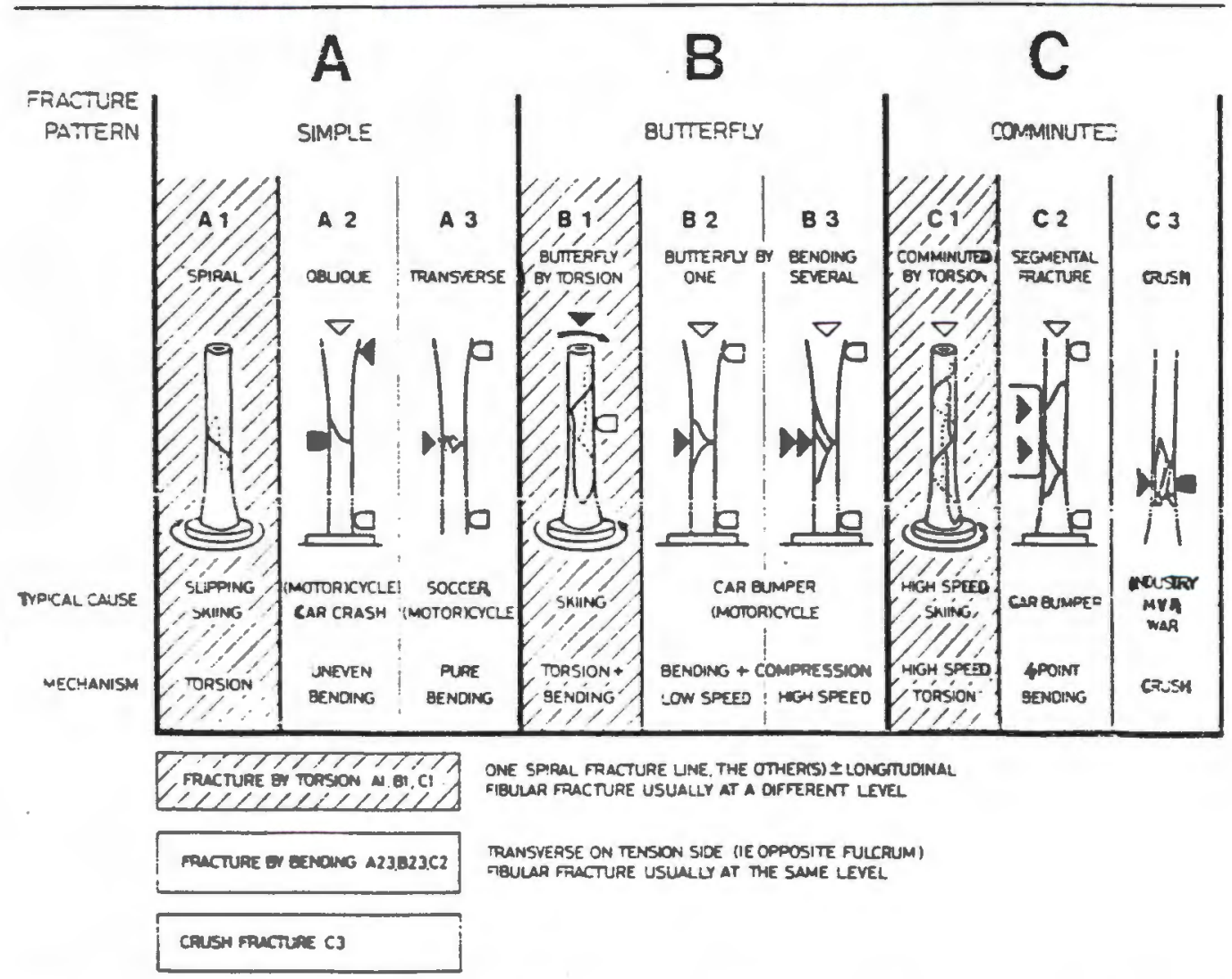

FIG. 2. The 9 main fracture groups. The fractures were divided into 9 groups according to degree of comminution and etiology.

JOHNER \& WRUHS - 1983. Clinical Orthopaedics \& Related/ 
\# tibial shaft: open/closed.

Classification of open \# - Gustilo (1976).

Type I: An open wound, less than one centimetre Iong and clean.

Type II: Laceration more than one centimetre long without extensive soft-tissue damage, $f 1$ aps or avulsions.

Type III: External trauma producing a severe wound with an additional functional deficit due to damage to vessels, nerves or entire muscle groups.

(Gustilo, Mendoza, Williams, 1984).

Tyoe II A: Adequate soft-tissue coverage of a fractured bone despite extensive soft-tissue 1 aceration or flaps, or high energy trauma irrespective of the size of the wound.

Type III B: Extensive soft-tissue injury loss with periosteal stripping and bone exposure. This is usually associated with massive contamination.

Type II C: Dpen fractures associated with arterial injur.y requiring repair.

- \#ibial diaphysis: upper/10wer/mid.

8 Johner and Wruhs

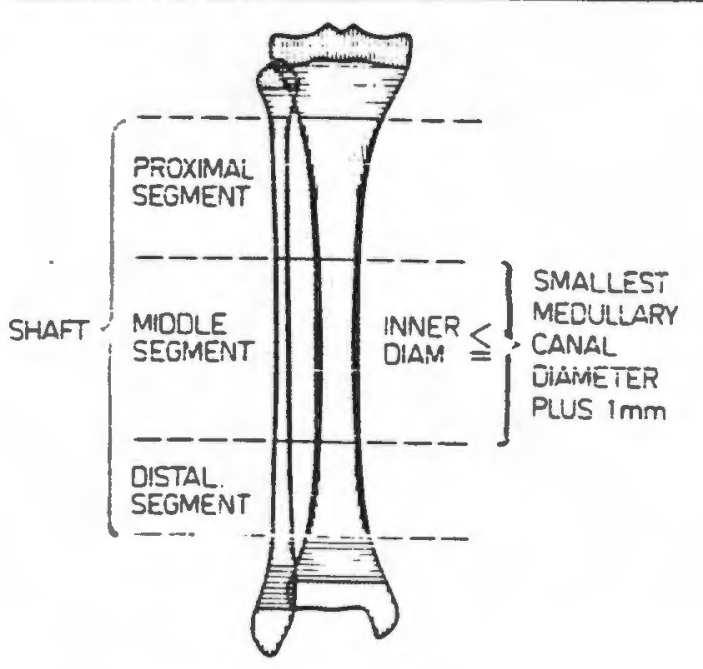

FIG. 1. The tibial shaft segment ends proximally and distally with the intramedullary canal. It is divided into three unequai segments according to the inner diameter. In the middle segment intramedullary nailing with reaming provides rigid fixation. 
- Fresence of \# fibula/or not.

- Mechanism of injury - all.

- Degree of displacement - any.

Within one day ---> 5 days of fracture.

- Age: between 15 and 80 years (stratified).

- Sex/race - all.

- Immobilisation/fixation: PoF/exoskeleton/internal (this is not a method of choice at GSH).

- Presence of multiple fractures.

- Alcohol abuse.

\section{EXCLUSIDN CFITEFIA}

1 > 5 days post fracture.

- Fathological \#s (ie Fagets disease, bone cysts, malignancy, etc).

- Fresence of the following associated medical factors:

- Diabetes mellitus

$-\quad T B$

- Segmental \# tibia.

* Fractures of the tibial metaphysis.

" Fatients not resident in the Cape Town area attrition.

- More than two manipulations in first 2 - 3 weeks to achieve acceptable reduction.

- Grade III B : $\mathrm{C}$.

\section{SAMFLE SIZE}

200 - 300. The present orthopaedic records indicate an average of 280 patients per annum treated for fractures of the tibia, excluding polytrauma cases.

\section{ALLDCATION TO TFEATMENT/CONTFOL BFOUF}

By block randomisation. 


\section{TFEATMENT PROCEDURE}

A Eöperimental group

- X-Ray post reduction is examined, lateral and anter-o-posterior view - identification of \# type and level.

- Distances are measured exactly on the film and measurements transferred to the relevant body area. (Eg, exact distance from tip of medial malleolus to distal limit of \# is measured and transferred to the patient's 1 imb and marked on the FoF/skin. The proximal limit for the \# is marked on the Fof/skin in the same way.

- Cut windows in the POF \pm $/ 2 \mathrm{~cm}$ larger all around than electrodes - only when dry, eg 24 hours post application.

- Selection and position of electrodes. 4 electrodes should be used to provide an effective field.

Longitudinally the electrodes should be at least $2 \mathrm{~cm}$ proximal and distal to the span of the \#.

Anterior ly the medial edges of the electrodes should just overlap the anterior borders of the tibia - the lateral edge of the electrode is approximately in line with the 4th toe.

Posteriorly the medial edges of the electrodes should over-lap the medial border of the tibia. See below.
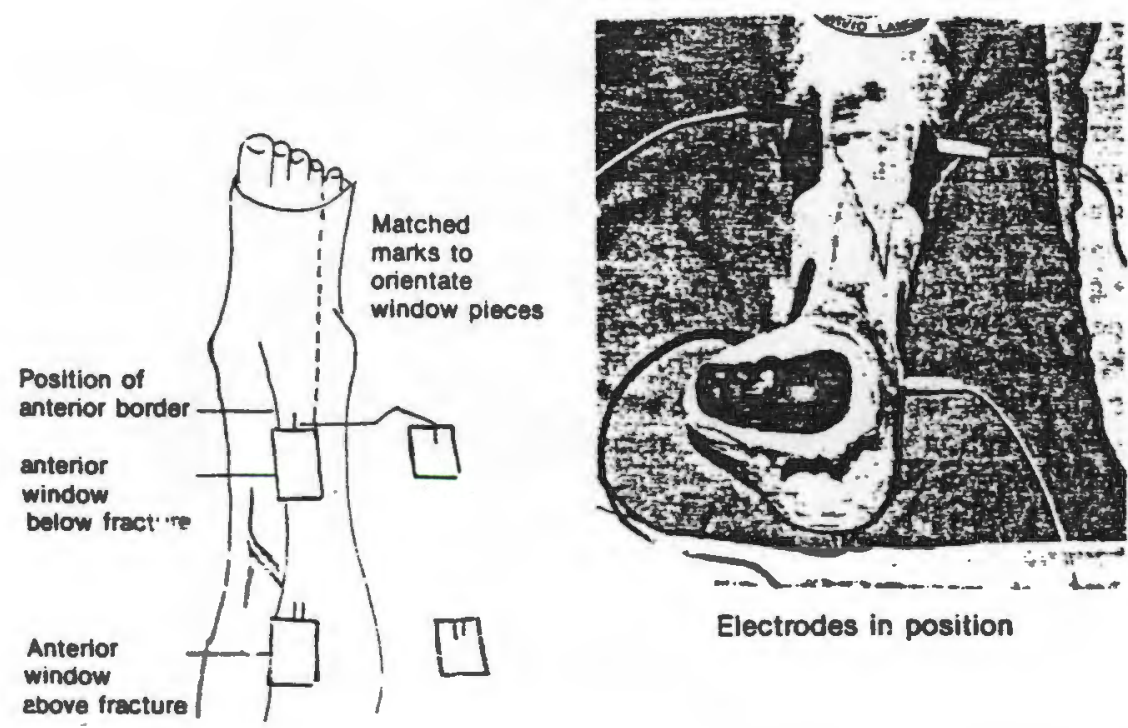

Electrodes in position

Fight leg in plaster.

Fosition of windows to stimulate tibia. 
Electrodes are held on the plaster in this estimated position and a line drawn around them $k_{2}$ cm away. from the edge.

Once cut, the windows are carefully orientated and returned as they will be immediately strapped back into position after treatment. If necessary the plaster is reinforced at this paint.

(Windows to be cut by orthopaedic technician. Note that the windows should not be too big, nor over the fracture as this may weaken the fixation and alter the reduction).

Size of electrodes: $4 \mathrm{~cm}$ diameter - suction electrodes, or $4 \mathrm{~cm}^{2}$ flat electrode.

Beat frequency: $20 \mathrm{~Hz}$ (Ganne 1988) or $10-20 \mathrm{~Hz}$ swing.

Cuprent intensity: should be such as to produce a comfortable contraction of the muscles around the bone, and a definite awareness of vibration across the fracture site.

Duration of treatment: $30 \mathrm{~min}, 5 \mathrm{x} /$ weel: for 15 treatments, not gauged by $m A$ - but by subjective and objective observation.

Administered by: Mrs J A Fourie or research assistant, in her absence, who will be trained in the processs and technique.

As above with the exception that suction electrodes will be applied without the interferential component.

\section{INSTFUMENTATION}

- EMS (Electro-Medical Supplies) interferential therapy unit. Fortable model 52, type BF.

Channel $A-4.0 \mathrm{kHz}$.

Channel B $-4.0-4.25 \mathrm{kHz}$.

4 electrode application $100 \mathrm{~mA}$ r.ms. 60 volt peal: maxi inum.

Swing pattern $1: 1 \quad$ 6:6 $6 \quad 6$ Digital display of time, selected frequency and intensity output.

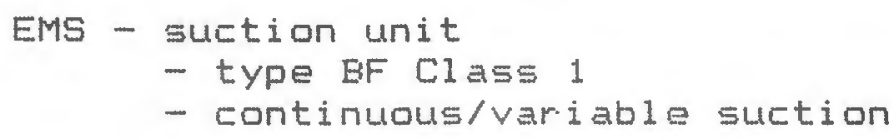


A Exolanatory variables (extraneous)

- Identification: each patient will be assigned a number recorded in a register with hospital no., name, address, etc.

- Age: at time of fracture. Stratification: 15- 24 young adults, 25 - 44 adults, 45 - 64 mature adults, $65+$ elder.ly.

- Sex: [male] [female].

- Race: [black] [coloured] [white].

- Mechanism of injury - MVA

- pedestrian - MVA/other.

- motorbike

- fall

- assault

- sport

- other

- Type and level of \#.

- Displacement - minimal/moderate (k/)/full (width).

- Date of injury.

- Date of referral.

- Date of admission to study.

- Date of crutch walk [NWB]

[FWB]

[FWB]

- Date of discharge.

- Date of clinical union.

- Fadiological follow up -

Dates Comments

Date of radiological union.

" Associated med. factors.

Alcohol abuse:

- Parunkenness as cause of injury.

- DTs in 1st week of stay in hospital.

B Independent variable

Application of IFT to the experimental group. Suction electrodes to the control group.

C Qutcome variable (dependent)

Duration in weeks from fracture to clinical and radiological union. 
Criteria for radiolooical union

Periosteal callus is first identified as an area of faint increase in density in the soft tissue on either side of the fracture line.

In lower extremity fractures, more solid and mature callus, with the outer margins sharp and continuous across the fracture site, is necessary before the extremity can be used. The position of the fracture fragments should have remained constant on serial films before any active use is permitted. The fracture line itself, however, may still be visible.

Finally the trabecular pattern across the fracture line will become continuous. Weissman \& Sledge (1986), Rockwood \& Green (1984).

Criteria for clinical union

Part moves as one

Local pain on stress o Marks 1988

Local tenderness

The criteria for clinical and radiological union should both be satisfied in order to judge a fracture united.

\section{MEASUREMENT ERRORIS}

- Intra and Inter Dbserver Disagreement. Friedman (1978).

- The Reliability of Clinical Methods, Data and Judgement. Koran (1975).

- The Statistical Assessment of the Variability in observer Perception and Description of Roentgenographic Pulmonary Shadows. Radial Clin North AM (1969).

\section{ETHICAL CONSIDEFATIONS}

There is no evidence in the literature to suggest that IFT is detrimental to the patient with fractures, metal implants or skin grafts. The only known contraindications to this modality are:

\section{pacemaker}

deep vein thrombosis

disseminating infection, eg TB.

Consent will be obtained from:

- the Medical Superintendent of GSH

- Ethics Committee

- Department of Orthopaedics GSH.

Since IFT has not yet been established as a proven and effective method of treatment there are insufficient grounds 
for belief that withholding treatment would be detrimental. Each patient will be informed that he/she is the subject of a study which aims to evaluate electrical treatments. If they so wish they may decline or withdraw at any time.

The confidentiality of all personal information will be scrupulously protected.

\section{DATA ANALYSIS}

The experimental design will take the form of categorical analysis for discrete variables, subsets of variables will be characterised by: age, sex, race, mechanism of injury, type of fracture, level of fracture, displacement of fracture, time to weight bearing (non, partial, full), alcohol abuse.

These will be analysed in order to contral confounding variables.

Analytical analyses will be carried out using appropriate statistical analysis for discrete (categorised) variables such as chi squared, Fischer's exact test for smal 1 frequencies and parametric/non parametric statistics will also be applied for continuous variables.

Presentation of descriptive analysis will take the form of frequency distribution tables and graphs.

Healing time (\#- union) in weeks

Age groups

A B C D $\quad$ D $\quad F$

Fracture type 1

\section{PILOT STUDY}

Should the project receive approval from the Ethics

Committee, a pilot study of 5 - 6 patients will be performed in order to practice all the details of refer.ral, randomisation, application or technique etc before the end of November 1988.

\section{BUDGET}

The IFT equipment will be on loan from Medical Distributors.

Cost of administration and stationery should not be over and above the normal, clinical expenditure. 
APPENDIX B 
Start code from right side, eg $2=002$

1 FROJECT REGISTER NO.

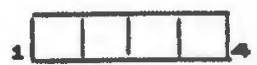

SURNAME:

FIFST NAMES:

HOSPITAL FOLDEF NO.:

2 AGE IN YEARS

3 SEX: MALE $=1$, FEMALE $=2$

4 RACE: $\quad$ BLACK $=1$, COL $=2$, ASIAN $=3$, WHITE $=4$

5 DATE OF ENTRY TO PROJECT:

DATE OF ACCIDENT:

NO. OF DAYS INTEFVAL (within 5 days)

$6 \quad$ FIFM $A=1$, FIRM $B=2$

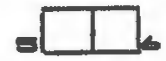

T.

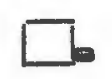

MECHANISM OF INJURY:

MVA Driver $=01$, MVA Passenger $=02$,

MVA Pedestrian = 0.3, Motorbike rider $=04$,

Bicycle rider $=05$, Gunshot $=06$,

Train accident $=0 \overrightarrow{7}$, Sports injury $=08$,

Industrial accident $=09, \mathrm{Fall}=10$,

Assault $=11$,

Dther $=12$ - describe:

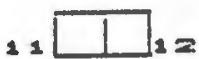

MEASUREMENTS

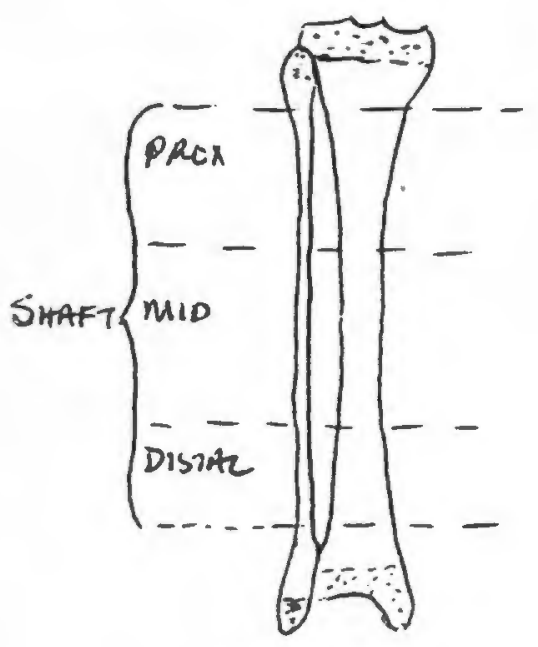

(R) LEG $=1$

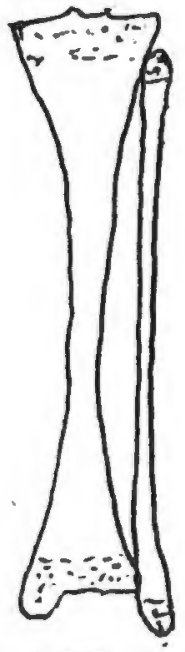

(L) LEG $=2$
BILAT $=3 \quad \square_{13}$ 
9 TYPE OF FRACTURE: TRANSVERSE $=1$, SPIRAL $=2$, OBLIQUE $=3$, COMMIN $=4$

10 COMPOUND \#: CLOSED $=0$, TYPE I $=1$,

$$
\text { TYPE II }=2 \text {, "TYPE IIIA }=3
$$

11 LEVEL OF \#: (DIAPHYSIS ONLY) PROX $1 /==1$,

$$
\operatorname{MID} 1 / 3=2, \operatorname{DISTAL} 1 / 3=3
$$

12 PRESENCE OF \# FIBULA: YES $=1, N O=2$

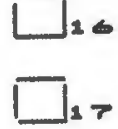

13 DEGREE OF DISPLACEMENT: NONE $=0, M I N=1$, $1 / 2$ DIAM $=2$, FULL DIAM $=3$

14 IMMOBILISATION POP $=1$, EXOSKELETON $=2$, DFIF $=3$

15 ASSOCIATED INJURIES (Brief description next to body part)

NONE $=$ OO

UPPER LIMB $=03$

SFIINE $=$ OS

FOOT $=08$
HEAD $=01 \quad$ CHEST $=02$

SHOULDER GIRDLE $=04$ FEMUR $=07$

PELVIS $=06$

MULTIFLE $=10$

$F A C E=09$

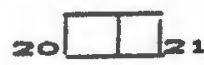

$\square=$

16 ASSOCIATED MED CONDITIONS - YES $=1, N O=2$ EG EPILEPSY

STATE WHAT:

17 ALCOHOL ABUSE - INEBRIATED AT TIME OF ACCIDENT = 1 , DTS IN HOSFITAL $=2$

$\square_{23}$

DATE OF CRUTCH WALK

NO. OF WEEKS FROM INJURY (DECIMAL)

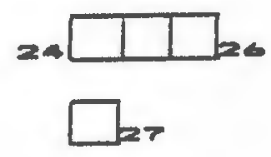

N.W.B. $=1$, P.W.B. $=2$, F.W.B. $=3$

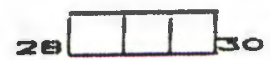

NO. OF WEEKS FROM INJURY (DECIMAL)

20 DATE OF RADIOLOGICAL U* . JN

NO. OF WEEKS FROM INL JRY (DECIMAL)

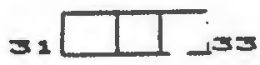

21 DATE OF DISCHARGE

NO. OF WEEKS FROM INJURY (DECIMAL)

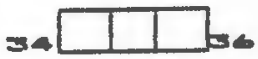

EXFERIMENTAL $=1$, CONTROL $=2$ 
APPENDIX $\mathrm{C}$ 
OOTE SCHUUR HOSPITAL

क $404-3167$

$T$ "GROOTHOSP"

FAX (021) 47-8048

REPLY TO:

SKRYF AAN: MED. SUPERINTENDENT

Mrs J Fourie

Lecturer

Department of Physiotherapy

Groote Schuur Hospital

OBSERVATORY

7925

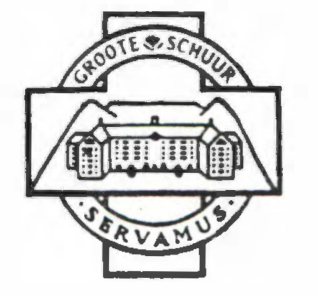

GROOTE SCHUUR-HOSPITAAL

OBSERVATORY,

CAPE/KAAP 7925

REP. SOUTH AFRICA/SUID-AFRIKA

SECTION/ Chief Med Supt

SEKSIE

REF./VERW. $A / 2 / C$

DATE/

DATUM

11 September 1990

Dear Mrs Fourie

RE: PERMISSION TO CONDUCT RESEARCH AT GSH

Thank you for your letter dated 6 September 1990.

You have my permission to conduct research "stimulation of bone healing with interferential therapy in new fractures of the tibial shaft - protocol no: 92/90" at Groote Schuur Hospital.

Yours sincerely

Signature Removed

DR J KANE-BERMAN

CHIEF MEDICAL SUPERINTENDENT

$\mathrm{DAP} / \mathrm{kp}$ 


\section{Faculty of Medicine}

Observatory, 7925

Tel: (021) 47-1250 Fax No: (021) 47-8955

30 August 1990

Mrs J A Fourie

Department of Physiotherapy

Old Doctors' Bungalows

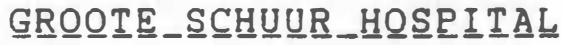

Dear Mrs Fourie

STIMULATION OE BONE HEALING WITH INTEREERENTIAL THERAPY IN NEW FRACTURES OE THE TIBIAL SHAET - PROTOCOL NO: 92/90

Thank you for the protocol of your proposed study.

I have pleasure in informing you that there have been no objections on ethical grounds and it is therefore in order to proceed. It would be appreciated, however, if you could respond to the following comments by a reviewer:

"I am a little concerned that if all the fracture variables are included as subgroups, the sample numbers may not be statistically significant. I am also surprised at the hiatus in the projected time schedule."

Yours sincerely

Signature Removed

PROEESSOR R P MILLAR

ACTING_CHAIRMAN_:ETHICS_\&_RESEARCH_COMMITTEE 
APPENDIX D 


\section{APPENDIX D}

\section{EQUIPMENT TEST}

Both Interferential machines were tested to ensure that the frequency modulation was in accordance with specifications.

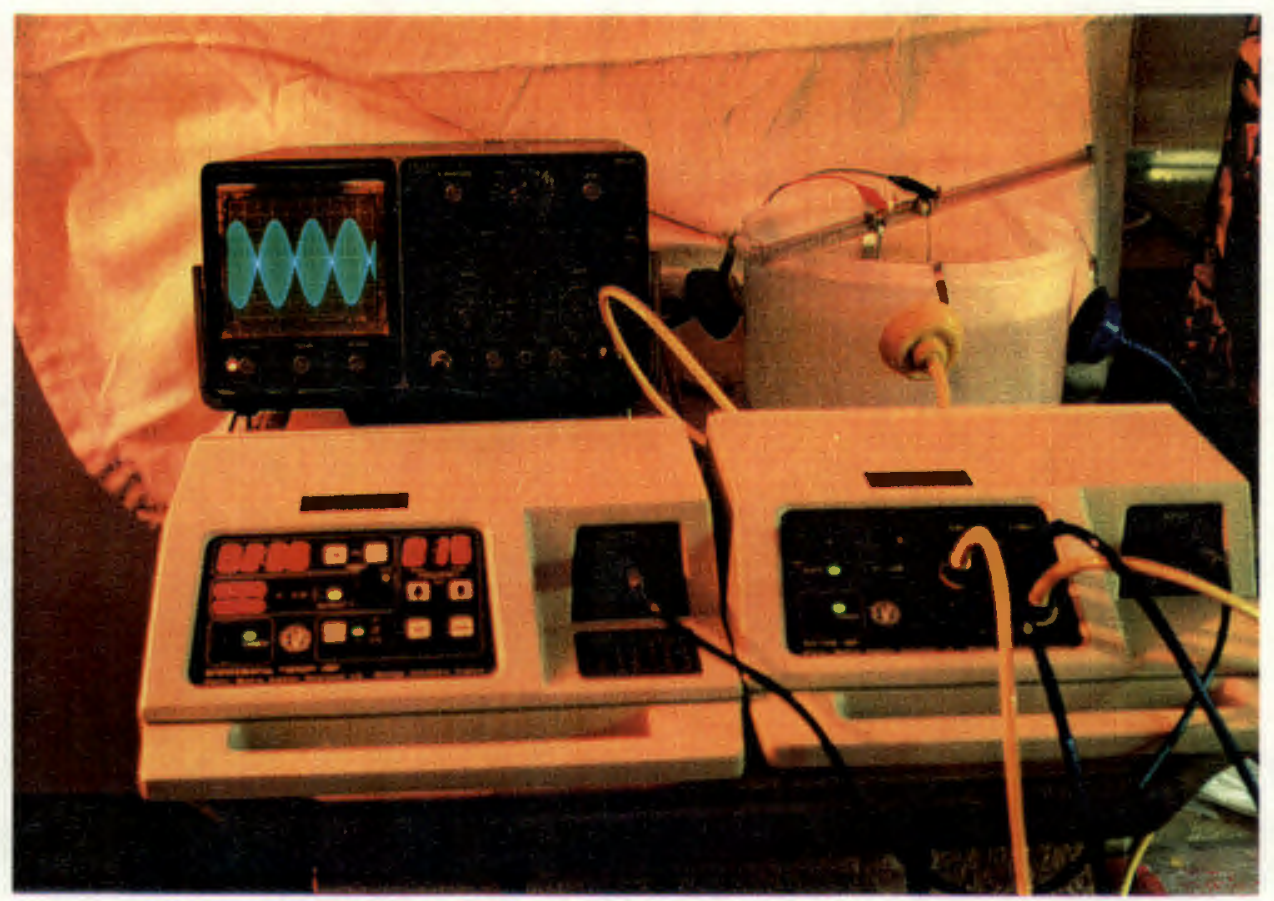


APPENDIX E 
FIG A.2 MOPHA PROBABLITY PLOT

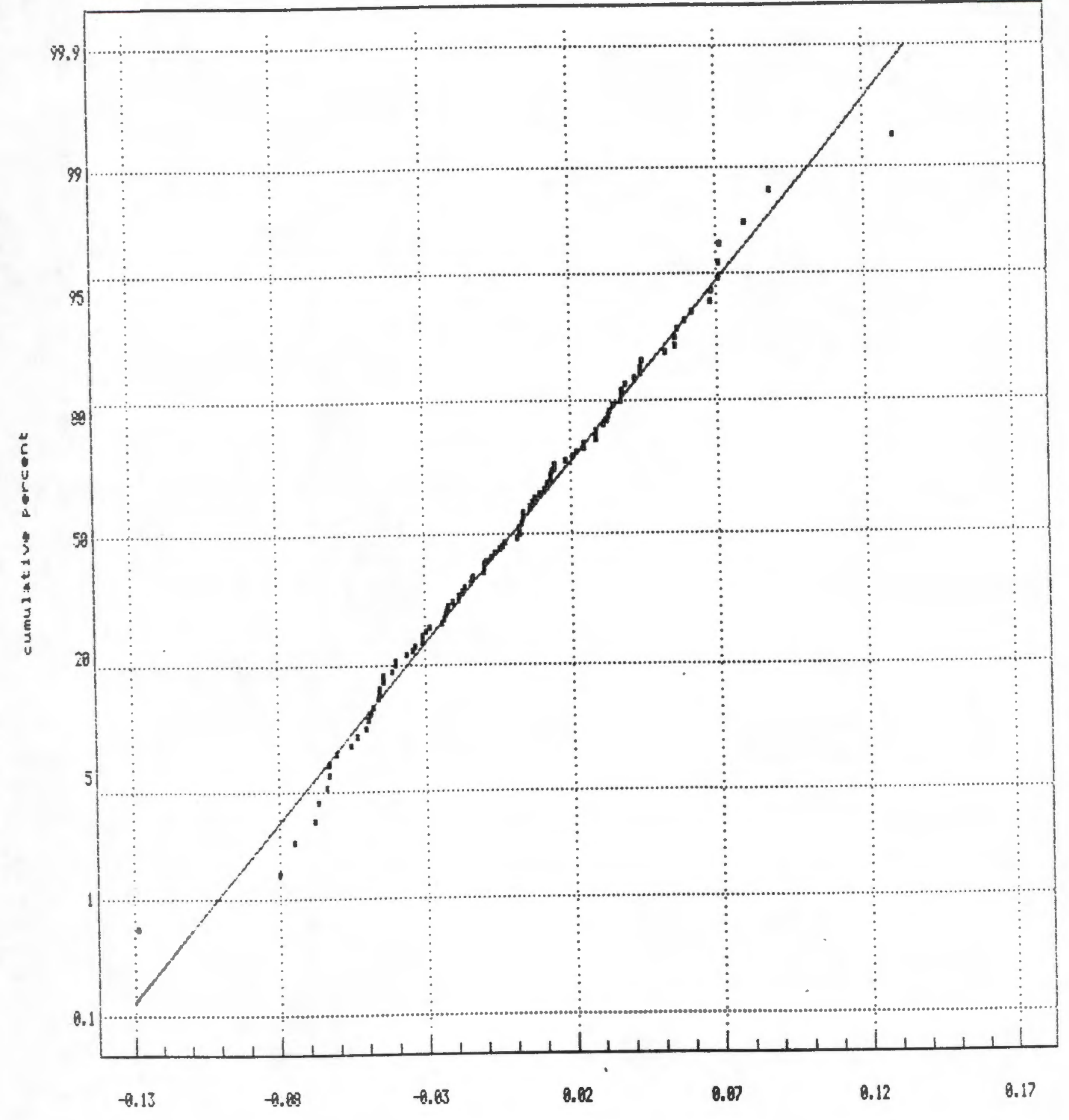

Residuals fro Clinical thion 